
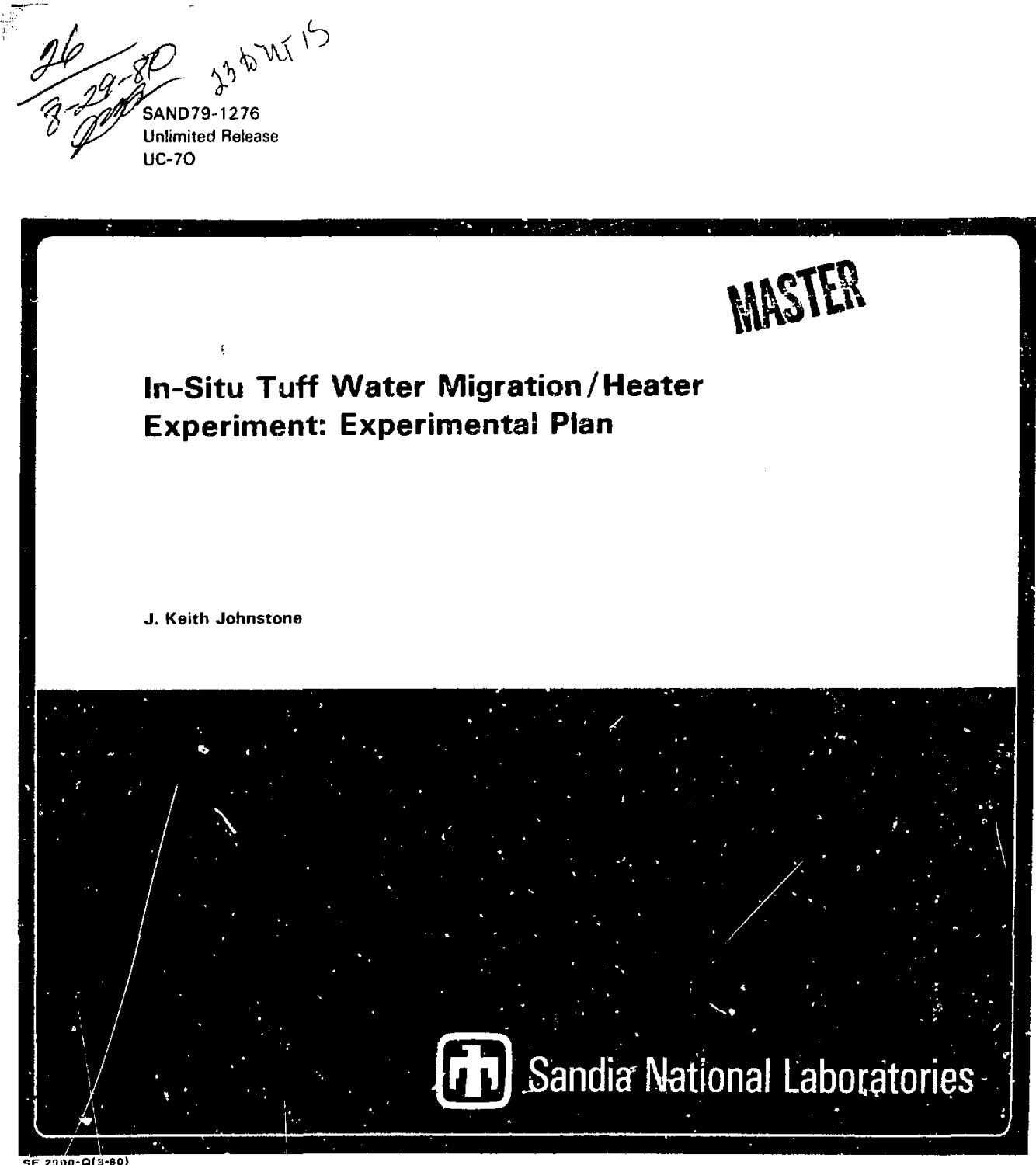
SAND79-1276

Unlimited Release

Printed August 1980
Distribution

Category UC-70

\title{
IN-SITU TUFF WATER MIGRATION/HEATER EXPERIMENT: EXPERIMENTAL PLAN
}

\author{
J. Keith Johnstone \\ Geological Projects Division 4537 \\ Sandia National Laboratories \\ Albuquerque, NM 87185
}

\begin{abstract}
Tuffe on the Nevada Test Site (NTS) are currently under investigation as a potential isolation medium for heat-producing nuclear wastes. The National Academy of Sciences has concurred in our identification of the potentially large water content ( $\leq 40$ vol\%) of $r u f f s$ as one of the important issues affecting their suitability for a repository. This Experimental Plan describes an in-situ experiment intended as an initial assessment of water generation/migration in response to a thermal input. The experiment will be conducted in the Grouse Canyon Welded Tuff in Tunnel U $12 \mathrm{~g}$ (G-Tunne1) located in the north-central region of the NTS. While the Grouse Canyon Welded Tuff is not a potential repository medium, it has physical, thermal, and mechanical properties very similar to those tuf [s curlent $1 y$ under consideration and is accessible at depth $(400 \mathrm{~m}$ below the surface) in an existing facility. Other goals of the experiment are to support computer-code and instrumentation development, and to measure insitu thermal properties.

The experimental array consists of a central electrical heater, $1.2 \mathrm{~m}$ long $x 10.2 \mathrm{~cm}$ diameter, surrounded by three holes $f \mathbf{r}$ measuring waterinigration behavior, two holes for measuring temperature profiles, one hole for measuring thermally induced stress in the rock, and one hole perpendicular to the heater to measure displacement with a laser. This Experimental plan describes the experimental objectives, the rechnica] issues, tha site; the experimental array, thermal and thermomechanical modeling results, the instrumentation, the data-acquisition system, postest characterizacion, and the organizational details.
\end{abstract}

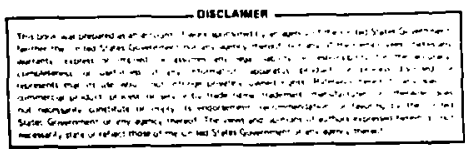




\section{CONTENTS}

\begin{tabular}{|c|c|}
\hline & $\underline{P a g}$ \\
\hline Introduction & 9 \\
\hline Goals & 9 \\
\hline $\begin{array}{l}\text { Assess Water Generation/Migration Behavior } \\
\text { in Welded Tuff }\end{array}$ & 9 \\
\hline Support of Thermal/Thermomechanical Code Development & 11 \\
\hline Support Instrumentation Development & 12 \\
\hline Measurement of In-Situ Thermal Conductivity & 12 \\
\hline The Requirement for an In-Situ Experiment & 13 \\
\hline $\begin{array}{l}\text { Relationship to and Interaction Hith Nevada Nuclear } \\
\text { Water Storage Investigations (NNWSIs) }\end{array}$ & 13 \\
\hline Nature of the Experiment & 14 \\
\hline Expected Duration & 14 \\
\hline Background & 14 \\
\hline The Near-Surface Eleana Argillite Heater Experiment & 15 \\
\hline At-Deptb Climax Granite Heater Experiment & 15 \\
\hline Experiment Description & 16 \\
\hline The Experiment Site & 16 \\
\hline Site Location & 16 \\
\hline Geclogical Properties & 16 \\
\hline Site Mineralogy & 17 \\
\hline $\begin{array}{l}\text { Comparison of the Grouse Canyon Welded Tuff With the } \\
\text { Welded Tuffs From Yucca Mountain: Transferability } \\
\text { of Results }\end{array}$ & 17 \\
\hline The Experimental Design & 20 \\
\hline The Experimental Array & 20 \\
\hline Heater Assembly Description & 24 \\
\hline Experimental Parameters & 26 \\
\hline Instrumentation & 29 \\
\hline Power Supply & 34 \\
\hline Alcove Desigu & 34 \\
\hline Drilling and Survey Technology & 34 \\
\hline
\end{tabular}




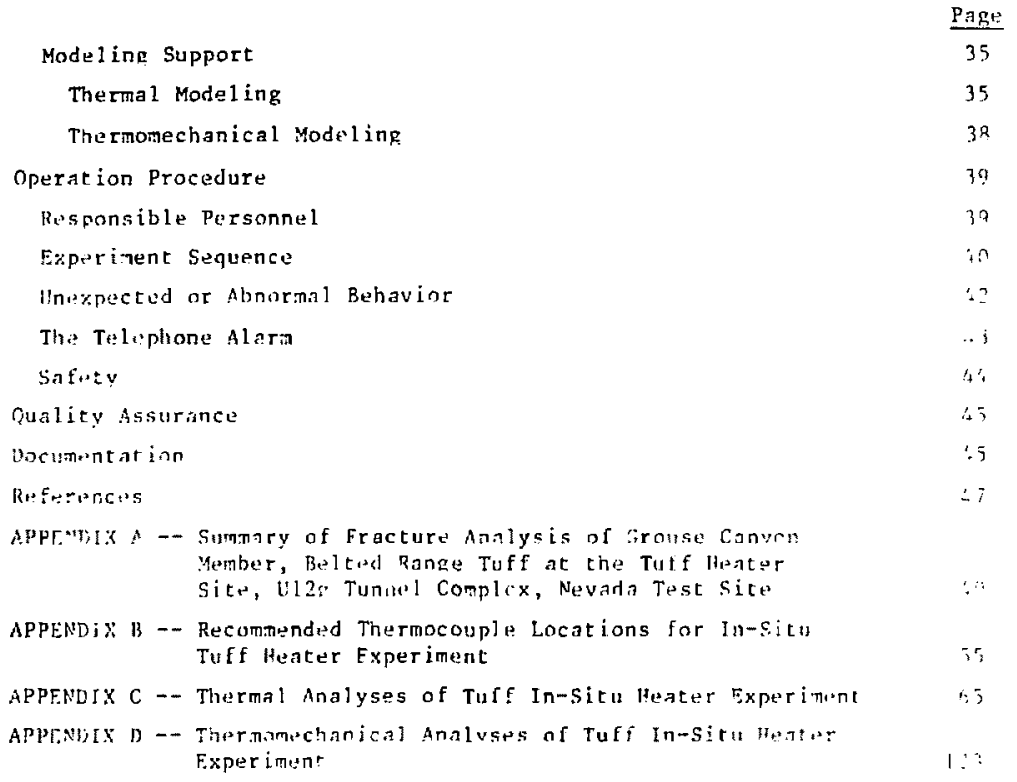

\section{ILLUSTRATIONS}

\section{Figure}

1 Comparison of the Ainbient Pressure Thermal

Expansions of Welded-Tuff Samples From

G-Tunnal (FVk:3) and Yucca Mouncain (Ue25at) is

2 An Example of tha Stress-Strain Beluavior of Welded Tuef

3 Experimental Hole Array

4 Schematic Diagram of Symmetrical orientation of the Experimental Holes Around the lieater Midplane

5 Verrical Orientation of the Experimental lloles in fielation to the alcove and G-Tunnel 


\section{CONTENTS (cont)}

Eigure

Page

6 Plan View of the Experimental Array, the Alcove, and G-Tunnel

7 Drawing of the Heater Assembly

27

8 Block Diagram of the Data-Acquisition Systen

33

9 Fielding Activities Schedule 


\title{
IN-SITU TUFF WATER MIGRATION/UEATER EXPERIMENT: EXPERIMENTAL PLAN
}

\author{
Introduction
}

Goals

The goals of this experiment are to

- Assess water generation/migration behavior in weldad tuff

- Support thermal/thermomechanical code development

- Support instrumentation development

- Measure in-situ thermal conductivity

Each of these goals is discussed in detail below.

Assess Water Generation/Migration Behavior in Welded Tuff -- This experiment begine to address issues steming from the water content of saturated or near-saturated rock. The experiment specifically attempts to assess the in-situ behavior of water in welded tuff as part of the ongoing evaluation of tuff as a potential repository medium.l

Understanding of water behavior near the heat source (e.g., waste canister of experimental heater) will ultimately be essential to repository design and risk assessment for several ressons:

1. Liquid pathways are pustulated as the primary means by which radionuclides might be introduced into the biosphere. The typical reference depth for a repository is $1000 \mathrm{~m}$, well below the water table for most potential sites. Water is well known to attack canioters 
and nuclear waste forms (see below). Such an occurrence is probable at some point in the 1 ife of a repository located below the water table. The solubilized radionuclides would be carried with the flowing groundwater and could eventually discharge into the biosphere.

2. The presence of hot water implies potential hydrothermal conditions of the type that have been shown to accelerate canister and waste-form degradation. 2-4 Both a heat source and a pressure vessel are required to develop hydrothermal conditions, and both are potentially available in a repository. The heat source is the nuclear waste (spent fuel); the pressure could be applied by the lithostatic load of the rock or the water-table head. The decaying heat content of the waste suggesta that such conditions could only exist for the first several hundred years of the repository's lifetime.

3. Water content is known to have a major effect on rock properties such as thermal conductivity, heat capacity, ard mineral alteration. Rocks, such as tuffs, that contain reasonably large quantities of water exhibit large decreases in thermal conductivity and heat capac$i t:$ and increases in compressive strength as the water is driven out (for example, by a nuclear waste heat source). After the thermal period of the waste, the dried-out rock presumably resaturates and the properties approach their initial values. On the other hand, if the water is retained during the thermal period of the waste and a hydrothermal condition develops, then the potential for silicate mineral alteration exists along with potential subsequent changes in thermal and mechanical properties. 
4. The means by which the water is released-if it is released-could seriously affect the mechanical integrity of the rock. For example, microcracking (crumbling) may develop as a consequence of rupture of the rock surrounding water-filled pores caused by fluid expansion of vapor overpressurization. Dehydration of the pores because of water migration down the thermal gradient may be followed by rock collapse into the voids because of in-situ stresses and the weakened condition of the rock. The long-range effects of such behavior are unknown.

5. Collection of water in the canister holes could seriousIy alter the transfer of heat from the canister to the rock mass. Pooling of water in the near-surface fullscale Eleans heater experiment ${ }^{5}$ and the at-depth $\mathrm{Cl}$ imax granite heater experiment ${ }^{6}$ caused significant deviations from predicted thermal behavior. In both cases, the water may have come from outside sources rather than from the rock mass.

The tuff water migration/heater experiment is located in a highly jointed, near-saturated rock mass. Since the rock mass lies well above the water table, ${ }^{7}$ the occluded water is perched. In addition, because the joints for the most part are highly water-transmisgive, it appears likely that drilling water will drain away from the experiment site. In view of the foregoing, the experiment should specifically measure the water behavior in rock mass.

Support of Therma1/Thermomechanical Code Developwent -- Currently, thermal and thermonechanical calculations include relatively simplistic assumptions such as considering the rock msss as homogeneous medium (joints not considered) and using laboratory-determined properties. Comparison of model prediction obtained by using laboratorymeasured properties with the in-gitu experiment result gerves to validate or improve laboratory methods; e.g., by using confining pressures while making thermal 
property measurements. This, combined with careful physical characterization of the rock mass and the deviation from "homogeneity," gradually permits development of more comprehensive codes for describing the medium response, One ultimately hopes to develop a complete constitutive model that includes time-dependent behavior (e.g., dehydration/rehydration, crack generation, crack or joint opening/closing, etc) and that can predict rock behavior based on laboratory-measured properties with a minimum of field tests.

Support Instrumentation Development -- The techniques required to measure in-situ response of a rock mass to various stimuli are not well established. Considerable effort goes into defining what measurements to make and what instruments to use or attempt to improve as well as how to field them. In addition, we must find ways to field the instruments for remote operation, evaluate their long-term durability and stability, and develop methods for in-situ calibration or recalibration--all of which occur in a hostile environment. In this experiment, we actempt to monitor water behavior by ubing developmental depth and relative humidity gages. In addition, in-situ thermomechanical measurements will be made with a modified stress gage and a laser interferometer.

Measurement of In-Situ Thermal Conductivity -- The thermal field near the heat source depends on the thermal conductivity of the rock mass, which in turn strongly depends on the water content. Drying out the rock in laboratory tests has been shown to decrease the thermal conductivity by as much as a factor of 2. Opening of joints or development of microcracks would decrease the conductivity further, resulting in significantly higher temperatures next to the heat source. The ease with which water is released from the rock depends on the fluid pressure, the in-situ stress field, and the tensile strength of the rock. Inability of the dry rock to support the in-aitu loads could result in collapse of the matrix into the newly vacated voids, thereby causing an increase in thermal conductivity. It seems unlikely, however, that the conductivity would assume its original saturated rock value because of the increase in crack frequency. 


\section{The Requirement for an In-Situ Experiment}

Although the results of laboracory measurement of rock properties are seldom ambiguous, extrapolation of these properties to field conditions is usually difficult. Extraction of test specimens for laboratory tests results in release of the in-situ stress followed by reapplication of a uzually isostatic confining pressure in the laboratory. In-situ stresses in a rock mass are seldom isotropic; in some cases, the principal stresses have varied by factors of 3 or more from each other. 8 In addition, arbitrary, Ejnite boundaries are introduced by extracting the samples from the rock mass, and the potential water behavior is probably severely altered.

Except for the stresa-field changes near boreholes or excavations, in-situ experiments measure the natural state response of the rock mass. They include the effects of naturally occurring joints and groundwater. In addition, the sample boundary limitation imposed in laboratory testing is eliminated. Spatial relationships between joints and cracks are undisturbed; i.e., there is no alteration of the joint aperture or translation of opposing joint faces. There is little concern about sample dehydration or chrical changes in the water because of exposure to the air. Even though in-aitu experiments are costly and the data often difficult to interpret, they are the only means of validating behavior models and laboratory test methods and results.

Relat ronship to and Interaction With Nevada Nuclear Waste Storage Investigations (NNWSIg)

This experiment is an integral part of the continuing effort to evaluate yarious media for nuclear waste storage within the boundaries of the Nevada Test Site (NTS). The experiment specifically addresses the water issue in welded tuff that was originally identified by project participants and later reemphesized by the National Research Council's Committee on Radioactive Waste Management, ${ }^{9}$ The experiment is fundamental in providing an initial evaluation of the thermal response of welded tuff and as a basis for future, more elaborate experiments ultimately leading to largescale, site-specific tests. 


\section{Nature of the Experiment}

This experiment, which includes a small heater that is not intentionally scaled in any sense, is primerily generic in a saturated, welded tuff. The experiment is an initial evaluation of the water behavior in a thermal field in which heater power levels are designed to produce a measurable response rather than to simulate a hypothetical waste-canister power sutput. Certain aspects of the experiment are specific for welded tuffs, as described later in the section on Transferability of Results. The experiment is exploratory, in part, in an attempt to field and evaluate some new or improved instrumentation.

\section{Expected Duration}

The heater will be in operation for at least 30 days. This period was selected by noting the near leveling of the predicted thermal profiles and thereby the establishment of a steady-state temperature gradient. However, the actual thermal behavior and the mass-transport kinetics are unknown. The data-acquisition system permits online, real-time analysis of data; consequently, the actual operating time will depend on the response of the tuff. It seems unlikely that operation would continue beyond 4 months.

Background

The in-situ tuff water migration/heater experiment is the latest in a series of in-situ experiments at the NTS designed to address projectrelated media evaluation. It is the first in-situ experiment to be fielded in welded tuff.

Previous experiments were the Eleana argillite 1011 and the Climax granite ${ }^{12}$ heater tests. Both of these were designed to test the thermal response of the medium, and both experienced unexpected difficulty because of water intrusion into the heater hole despite the fact that one was a near-surface and the other an at-depth experiment. Neither test was designed to measure water behavior. 
The Near-Surface Eleana Argillite Heater Experiment 1011

This experiment at 24 m underground was composed of a series of three tests th:t were designed to determine the therual and mechanical responses of argillite to a thermal input representative of a high-level (3.5 to $3.8 \mathrm{kw}$ ) waste. Two of the tests used small, scaled heaters and one used a full-scale heater $0.3 \mathrm{~m}$ in diameter and $3 \mathrm{~m}$ long. The two scaled tests were in support of the full-scale experiment.

Early in the full-scale heater experiment, an unaccountable influx (possibly from the surface) of a small quantity of water collected in the heater hole and caused severe deviations fron the expected thermal behavior. This required shutting down the experiment, removing the heater, and providing the heater hole with water drainage. After restart, the experiment ran 250 days without further incident.

In apite of its near-surface nature, the experiment appears to have answered several important questions about argillice stability in a thermal field. In particular, the effects of expandable clay on the thermal response of the argillite were noted.

At-Depth Climax Granite Heater Experiment ${ }^{6} 12$

These experiments were composec of three scaled heater tests carried out at $425 \mathrm{~m}$ below the ground surface. The experiments were des 1 gned to test the thermal stability and measure the in-situ thermal conductivity, diffusivity, and permeability at temperature. Test periods ranged from 62 to 83 days.

During the first test, water (possibly drilling water forced into the joint system) migrated into the heater hole and shorted the heater power leads. The short was repaired and the connections isolated from the wet region.

The experiments successfully demonstrated the thermal stability of the Clinax granite at high temperature. Good agreement was noted between 
the in-gitu and laboratory therwal conductivity and diffueivity values. The in-situ permeability was very low, $<1$ nanodarcy, and decreased with increasing temperature.

Experiment Description

The Experiment Site

Site Location -- The experiment will be placed in the welded portion of the Grouse Canyon Member of the Belted Range tuff. The site is in the U12g tunne1 (G-tunnel) complex at a depth of $400 \mathrm{~m}$ below Rainier Mesa in the north-central region of the NTS.

Geological Properties -- The welded tuff lies above G-tunnel with only the basal portion partly exposed in the ceiling. Near the experiment, the tuff strikes approximately $\mathrm{N} 3 \mathrm{OE}$ and dips $7^{\circ} \mathrm{NH}$. An alcove $3 \mathrm{~m}$ deep $\times 6 \mathrm{~m}$ long was mined in the tunnel wall to house the experiment. The joints intersecting the tunnel and alcove walls were mapped in detail.

Two fully cored, exploratory holes (U12gHEH $1 \mathrm{~A}$ and $\mathrm{HB}$ ) wera drilled in the welded tuff at respective depths of 6.7 and $20.7 \mathrm{~m}$. The purpose of these holeg was to characterize formations near the experiment and to test drilling capability in order to meet the criteria of hole straightness and wall smoothness for placement of the heater assembly. The exploratory holes also provide pre-experiment test and practice holes for transmissivity testing, practice heater emplacement, and practice packer emplacement and sealing.

Characterization atudies inclused determination of formation thickness $(12.5 \mathrm{~m})$, mineralogy, and joint properties for comparison with the wall-rapping result. Joint properties such as frequency, orientation, width, morphology, nineralogy, and predictability were studied. Downhole TV acans were correlated with the core observations; core indices were also determined. The results are sumarized briefly here and in more detail in Appencix A. 
Four major joint sets were identified. In general, the formation was highly fractured. The joint frequency depended upon the measurement method that increased in the following order: tunnel wall mapping, downhole TV scan, and core determination. Core indices ranged from 30 to 100 . Numerous rubblized zones that varied from 5 to $60 \mathrm{~cm}$ long were found in the cores. Many of the joint surfaces were mineralized, and intense argillization was observed in several of the rubblized regions. These zones are apparently water-transmissive.

Site Mineralogy -- The tuff is composed almost entirely of feldspars and silica polymorphs (quartz + cristobalite). Vitric material is noted only occasionally in the basal vitrophyre. Phenocryst phases reported from within the Grouse Canyon include sodic sanidine, anorthoclase, and quartz, with the sanidine dominant. Widespread accessories include fayalite, apatite, zircon, and sodic Fe-pyroxene. ${ }^{13}$ The tuft is rarely zeolitized. Devitrification textures are common, but not masked by growth of authigenic phases. The welded tuff, which lies at least $200 \mathrm{~m}$ above the water table, ${ }^{7}$ contains $13 \%$ to $17 \%$ porosity and is $>85 \%$ saturated with perched water.

Comparison of the Grouse Canyon Welded Tuff With the Welded Tuffs From Yucca Mountain: Transferability of Results -- Properties of welded tuff 8 from the two locations are compared in an attempt to address transferability of results of the G-tungel test to other welded tuffs--in this case, Yucca Mountain.

Perhaps because of its greater depth, the Bullfrog Member of the Crater Flat tuff (a potential unit in which to locate a repository) appears more varied in general mineralogy than does the Grouse Canyon. In Well J-13 the tuff is fairly biotite-rich (see thermal expansion data, Figure 1), with growth of guthigenic silica, K-feldspar, erionite, and anslcime at least partially making primary and devitrified features through overgrowth and coarsening. ${ }^{14}$ In the Yucca Mountain hole (Ue25A 1), while growth of authigenic feldepars and silica is appareni, 
zectitization is almost totally absent. The expected effects of relevant mineralogical differencer (cristoballite, mica) are discusged below.

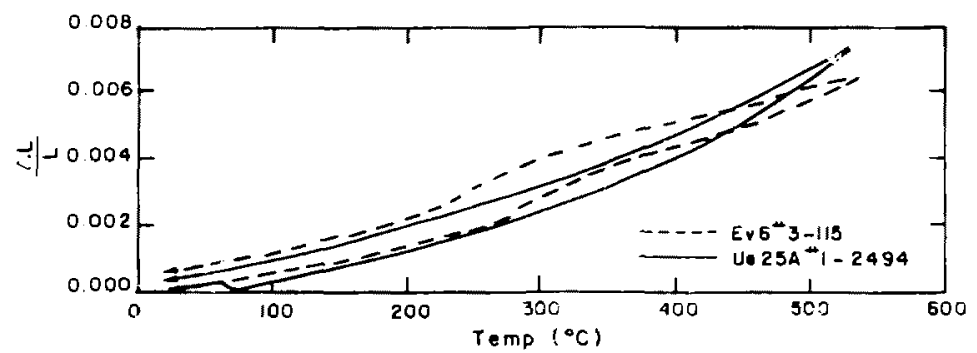

Figure 1. Cumparieon of the Ambient Pressure Thermal Expansions of WeldedTuff Samples From G-Tunnel (Ev6\$3) and Yucca Mountain (Ue25A:)

Table I compares the available physical, thermal, and mechanical properties of the two tuffs. Ranges in porosity and grain density are very similar, though the grain density of the G-tunnel welded tuff is apparently more varied. Measured conductivities at $100^{\circ} \mathrm{C}$ agree to within $6 \%$ of the mean value $(1.23 \mathrm{~W} / \mathrm{m} \cdot \mathrm{K})$. Values obtained by extrapolation to $100 \%$ saturation agree almost perfectly.

The interval values for the ambient pressure tharmal expansion of the two tuffs are quite similar. Samples from both locations exhibit nearly continuous expansion to at least $500^{\circ} \mathrm{C}$. However, differences do exist (Figure 1). The Yucca Mountain welded tuff shows a slight contraction near $75^{\circ} \mathrm{C}$ not seen in the G-tunnel welded tuff. This is probebly because of the presence of a small amount of altered mica in the Yucca Mountain welded tuff. At $250^{\circ} \mathrm{C}$ and above, the G-tunnel welded tuff exhibits a slight but consistent inflection caused by the $a-\beta$ transformation of eristobalite, which is not present in the Yucca Mountain welded tuff.

The comparison between strength and moduli of samples from G-Tunnel and Yucca Mountain is less straightforward. Some, but not all, of the differences between the various values may be caused by different test methods used, other reasons for the differences in values are variationg 
in the degree of sample saturation and the inherent variability of tuffs in general over distances a awell as the length of a test specimen. Variations in minerology may also be a factor, but correlation has not yet been established. Preliminary otudiea have tentatively established an inverse correlation between strength and porosity, which may provide the transferability link from one locrtion to another. In spite of the differences in values, the tuffs exhibit oimilar stress-strain behavior in that they show an approximately linear central region and a sudden loss of strength at the peak stregs (Figure 2).

Table I

Physical, Thermal, and Mechanical Properties of Welded Tuffs From G-Tunnel and Yucca Mountain

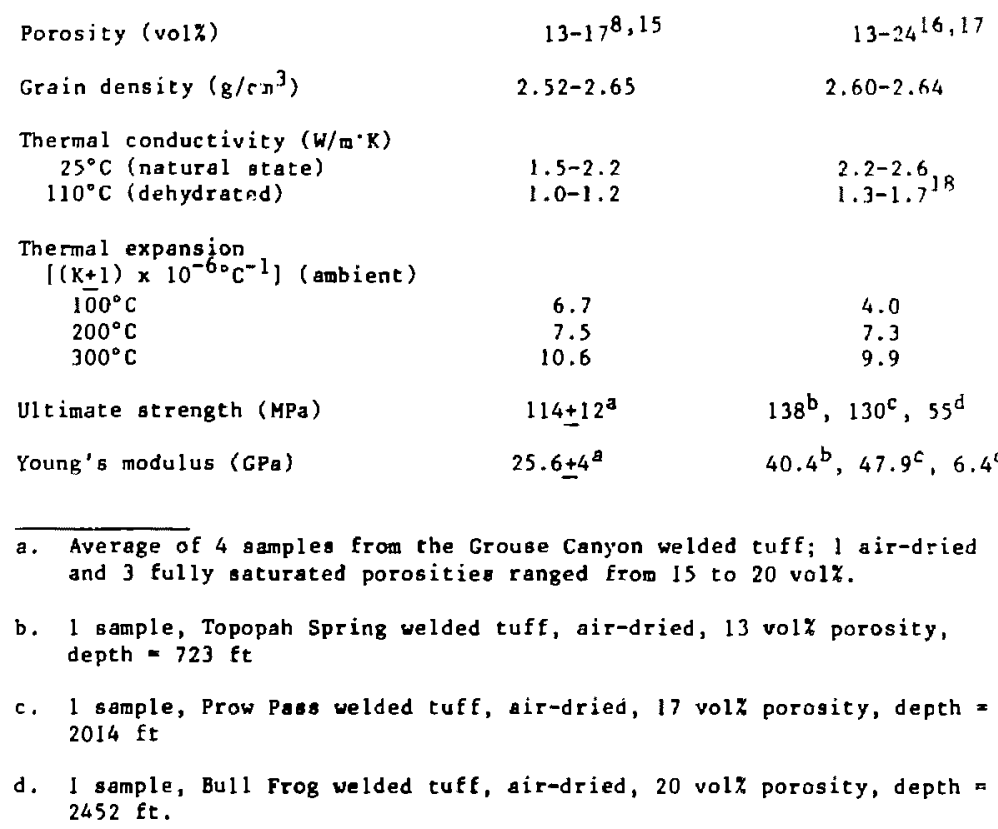

a. Average of 4 samples from the Grouse Canyon welded tuff; 1 air-dried and 3 fully saturated porosities ranged from is to 20 vol\%.

b. I sample, Topopah Spring welded tuff, air-dried, 13 vol\% porosity, depth $=723 \mathrm{ft}$

c. I sample, Prow Pass welded tuff, air-dried, 17 volz porogity, depth = $2014 \mathrm{ft}$

d. I sample, Bull frog welded tuff, air-dried, 20 volk porosity, depth = $2452 \mathrm{ft}$. 


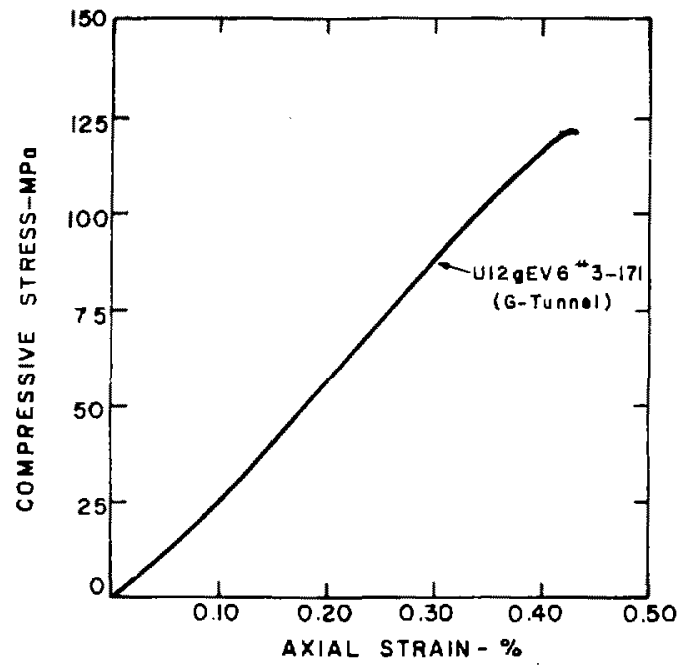

Figure 2. An Example of the Stress-Strain Behavior of Welded Tuff

tased on the laboratory-measured properties, the welded tufts from the two localities are very similar. Virtually all of the properties of one welded tuff lie within the experimental range of the other. Potential differences in the response of a field experiment must be due to the insitu rock mass properties such as in-situ stresses, joint properties (frequency, width, mineralization, etc), and our ability to characterize them. In view of the limited scale (compared to joint spacing) of this experiment, we expect that the response is representative of other sinilar welded tuff units. However, since this is a pilot experiment, its real value lies in bounding the various phenomena for larger scale, more sophisticated experimcots.

\section{The Experimental Design}

The Experimental Array -- The experiment is composed of six satellite holes arranged at three radii concentrically about a central heacer hole 
as shown schematically in Figure 3. Three holes are designed to measure water behavior, two are for measuring in detail the thermal profiles, and one hole is for measuring thermaly induced stress. In addition, a hole aligned as nearly perpendicular to the heater axis and along the midplane as possible is included for a laser interferometer for measuring displacement. The radial diacance of the holes from the heuter was selected after evaluation of the thermal and thermomechanical modeling and current drilling capabilities. Each hole is located so that it is not siradowed from the heater by another hole. All the holes will be 1007 cored during drilling ane where possible, visually scanned with a borehole TV camera.

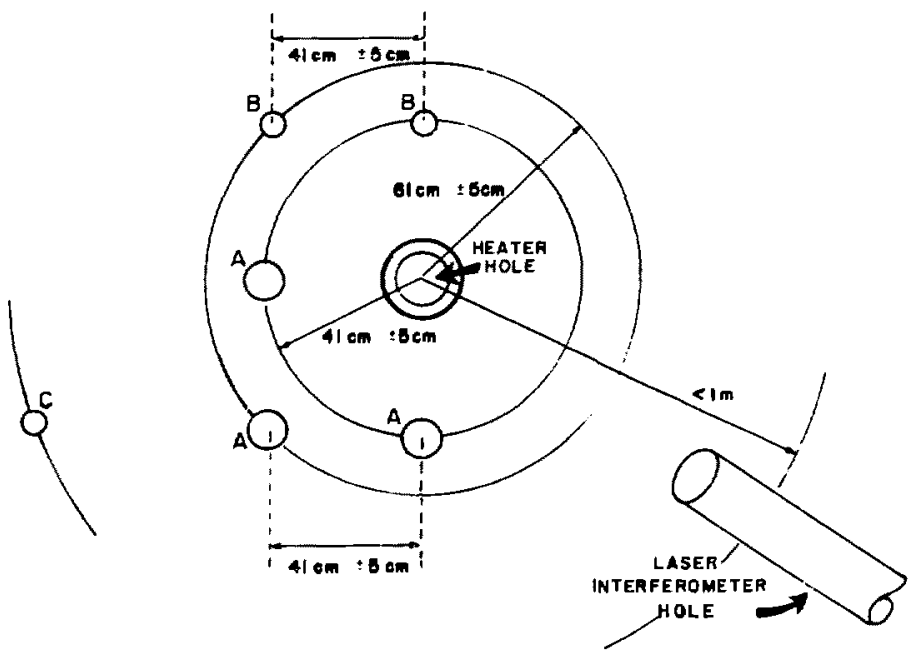

Figure 3. Experimental Hole Array

The nominal diameter of the holea is as follows (in cm):

Heater hole, 12.7

Water migration holes (A), 9.5

Thermocouple holes (B), 7.6 
Stress hole (C), 4,8

Laser interferometer hole, 20.3

The hole depth will depend on the local stratigraphy as determined from the core. Preferably, the holes will be $>9$ m deep to minimize alteration of the in-situstress at the heater depth by the proximity of the tunnel/ alcove. The experimental region in each hole will be located so that the relationship with fractures is known.

The instrument "cavity" in each of the experiment holes is arranged as symmetrically as possible at the midplane of the heater, as shown schematically in Figure 4. One of the water migration holes will be located such that a well-defined joint intersects the water collection cavity, and the other two holes such that joints do nat intersect the water collection cavitirs (if possible). Consequently, the water migration holes may vary from the ideal midplane position shown in Figure 4.

The thermocouple holes will be instrumented with 11 thermocouples arranged as symmetrically as possible about the midplane of the heater. Stratigraphy permitting, the thermocouples will extend to a depth of $2 \mathrm{~m}$ beyond each end of the heater. The inner thermocouples in each hole will align with a similar array on the heater and heater hole surface. Every attempt will be made to minimize the free space in the holes, thereby limiting convection currents. Toward this end, care must be taken not to interfere with the water migration behavior or alter the local chemistry. Further details are given in Appendix B.

Since the welded tuff es in the ceiling over G-tunnel, all of the drill holes except the laser interferometer hole will be oriented at an angle of $20^{\circ}$ above horizontal (Figure 5). As a result, the water will drain away from the heater and prevent the refluxing observed in the Eleana and $\mathrm{Cl}$ imax heater tests. Owing to the tunnel arrangement, the laser interferometer hole will be inclined at an angle greater than $20^{\circ}$. The tunnel plan showing the relation between the experimental alcove, the heater array, and the laser interferameter hole is given in Figure 6. 

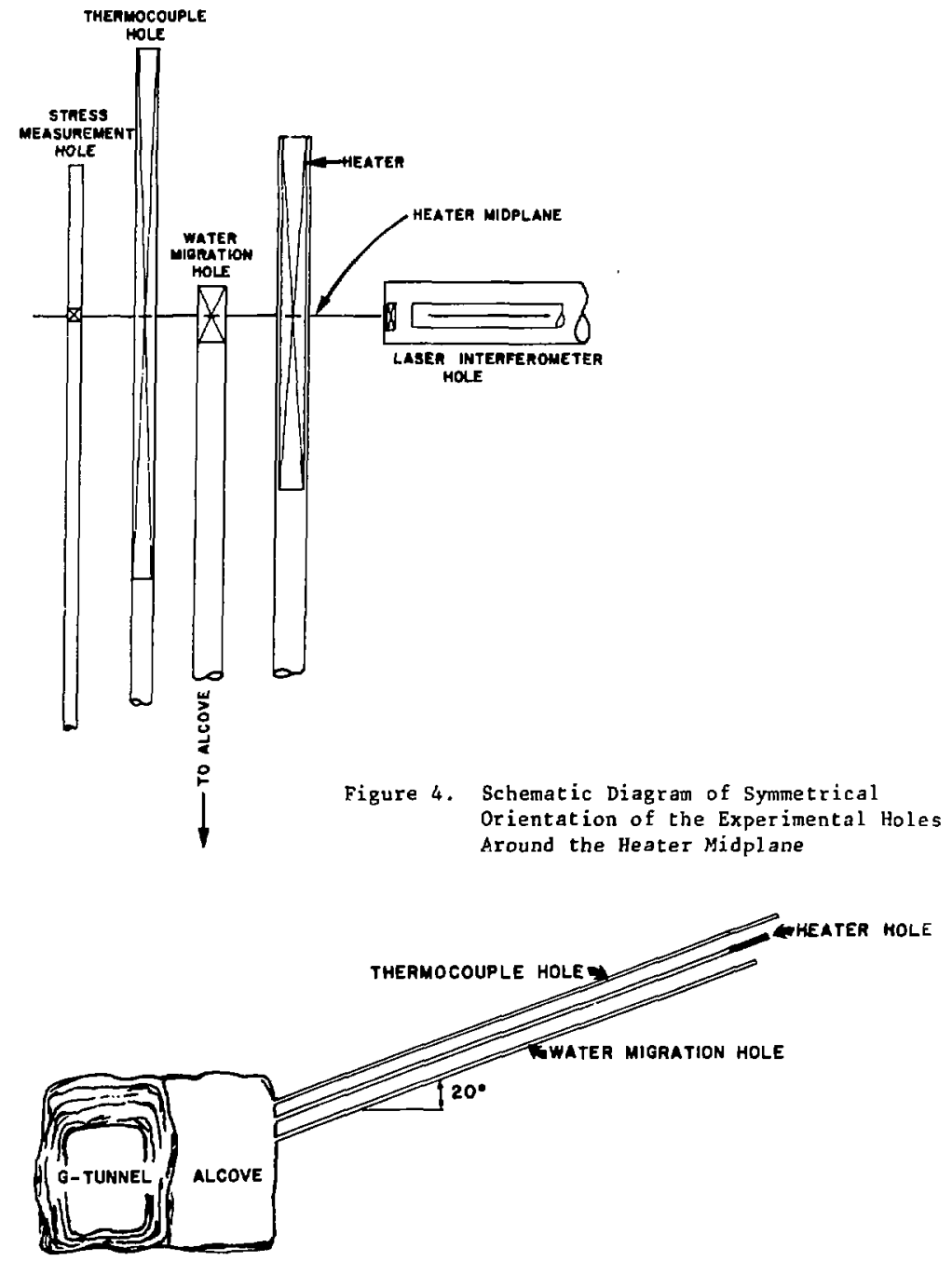

Figure 5. Vertical Orientation of the Experimental Holes in Relation to the Alcove and G-Tunuel 


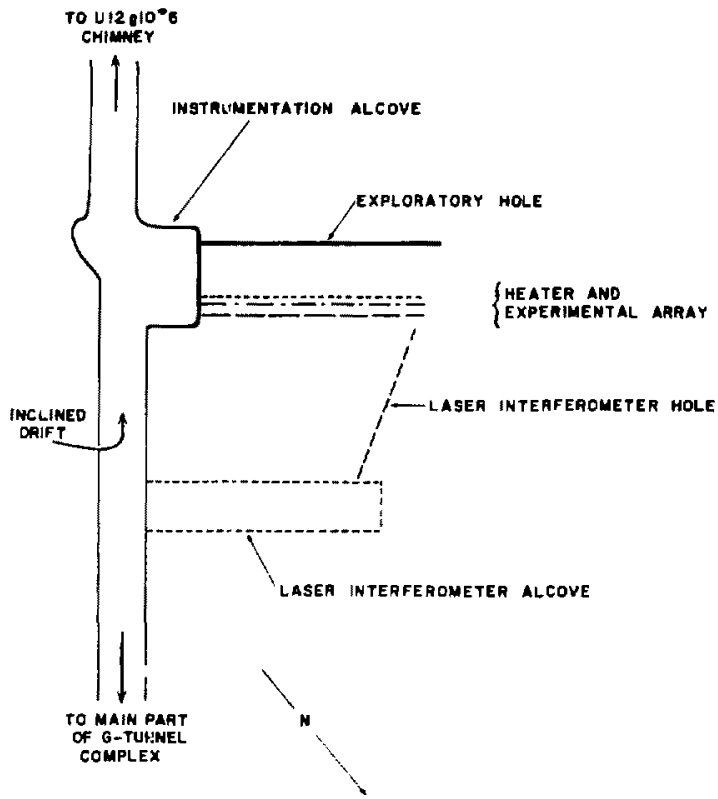

Figure 6. Plan View of the Experimental Array, the Alcove, and G-Tunnel

Heater Assembly Description -- The heater assembly is composed of a heater, insulator, power-leads junction box, instrument bay, packer, and insertion tube coupling. The assembly (Figure 7) is a single unit $\sim 3 \mathrm{~m}$ long and is designed for insertion into a hole that is $12.7 \mathrm{~cm}$ in diameter.

The heater is composed of two $6 \mathrm{~kW}$ haipin heating element $\mathrm{g}$ thst are oriented at $90^{\circ}$ to each other and enclosed in a 304 stainless-steel, closed-end housing $1.2 \mathrm{~m}$ long $\times 10.2 \mathrm{~cm}$ OD. Six equally spaced longitudinal fing are attached to the heater gurface to engure that the heater is centered in the hole and to minimize convection-induced circumferential thermal gradienta. Three thermocouples are embedded in the heater surface circumferentially in alternating sections at the midplane and 6 in. from 
each end of the heater (for a total of 9 heater thetmocouples). Springout thermocouples for measuring the rock wall temperature are located at the same spacing in the remaining sections (also a total of 9 ). This is shown scheratically in Figure 7, section E-E. Even though one heating element is sufficient to operate the experiment, both will be operated to minimize circumferential thermal gradients. In the unlikely event that one burned out, the power to the other can be increased to compensate for the loss.

The insulator section, shown schematically in Figure 7 , Section $D-D$, is designed to minimize convective heat transfer down the hole toward the power lead junction box and instrument package. The insulating material must be selected such that it will have a minimum effect on the water chemistry or migration behavior. The insulator material should be chemically inert in an aqueous enviroment or chemically similar to the tuff. The insulator material should also contain as small a surface area as possible to minimize the amount of surface sorbed water. Typically, insulators exhibit large surface areas that can sorb large quantities of water. Ideally, a single block of closed-cell, inert foam would be inserted into the insulator section. Unfortunately, such an approach is impractical because of the large number of therrocouples and the power leads that must pass through the insulator section. The material chosen for the insulator is plus 10 mesh ( $>2 \mathrm{~mm} \mathrm{dia}$ ) bubbled alumina, ${ }^{*}$ The particles are primarily hollow, closed spheres composed of $99.6 \%$ pure olumina. In addition to meeting the above criteria, the spherical particles simplify filling the insulator section. A thermocouple will be located at both the insulator/heater and insulator/junction box interfaces.

The connection between the power leads and the heating elements will be made in the junction box. The box will be filled with high-temperature RTV silicone to prevent water from attacking (shorting) the connections. A thermocouple will also be included in the junction box. The iunction box is shown schematically in Figure 7, Section C-C.

\footnotetext{
*Manufactured by the Norton Company, Worcester, MA.
} 
The instrument bay provides room for mounting the various instruments that monitor the behavior of the water. It also provides an open volume for collecting water. Individual instruments are described in the next section. The instrument bay is shown scheratically in figure ?, Sections $A-A$ and $B-B$.

The packer is a development device for sealing the heater cavity. It provides for two independent, motor-driven seals. The forward (toward the heater) plate of the packer serves as the platform for mounting the watermonitoring ingtrumentation.

Attached to the aft plate of the packer is the transition section for coupling the insertion tube to the heater assembly. The transition section contains a leveling device to ensure that the entire asgembly is oriented properly during placement. In addition, the transition section containa pressure transducers that could not be mounted in the instrument bay. The transition section is shown schematically in Figure 7, Sections $\mathrm{G}-\mathrm{G}$ and $\mathrm{H}-\mathrm{H}$.

Experimental Parameters -- Water behavior will be monitored in the three water migration holes and the heater hole (Figure 3). Parameters related to the water behavior include temperature, pressure, watergeneration rate, relative humidity, and $\mathrm{pH}$. Water and gas sampling capabilities are also included in the design. In the event that water does not collect in the experimental cavities, the best indicator of the water response may be the changes in the relative humidity of the cavity atmosphere. The sampling tubes allow samples to be withdrawn periodicaily for laboratory analysis. A second water tube allowa the cavity to be drained in case the amount of water collected threatens the operation of the other instruments.

The welded tuff thermomechanical behavior will be monitored in the gtress and laser interferometer holes. Thermally induced otress and displacements will be messured in these holes, respectively, and temperature will be measured in both holes. 
Only two holes are designed specifically to measure the thermal profiles in the rock. However, as noted above, temperature will also be measured in conjunction with the other parameters. Temperature is the fundamental parameter to be measured since all other phenomena depend on it. Temprature measurement ia particularly important for determining the thermal conductivity and boiling behavior since neither can be directly measured in-situ in this experiment. The thermal behavicr of the heater assembly will also be extensively monitored.

liven though the power input is designed to be constant, it is an importan: parameter that will also be monitored.

The operating experimental variables can be summarized according to the following classifications:

- Independent Variable日 - Controlled

Experiment configuration Thermal source degign

- Independent Variables - Uncontrolled (Ambient Rock Properties)

Hineralogy

Water content

Thermal conductivity

Heat capacity

In-situ stresses

Joint characteristica

Characteristic water boiling point

- Dependent Variables

Temperature

Pressure

Thermal conductivity

Thermal-induced stresses

Thermal-induced displacements

Water migration rate

Instrumentation -- The instrunents required to measure the experimental parameters are described below. A commercially available device was selected whenever possible. Nevertheless, there were several 
instances where commercial instruments could not survive the test conditions, could not be fielded remotely, or were unavailable.

1. Theimocouples. Standard chromel-constantan (Type E) thermocouples supplied by Gordon Co, will be used. They meet standard limita of error according to ANSI MC $96.1-1975$ of $\pm 1.7^{\circ} \mathrm{C}$ from $0^{\circ}$ to $340^{\circ} \mathrm{C}$ and $\pm 0.5 \%$ from $340^{\circ}$ to $870^{\circ} \mathrm{C}$ (the upper temperature limit). Those on the heater hole rock wall are $1 / 16$ in. in diameter with Inconel 600 sheaths. All other are 1/8 in, in diameter with 304 stainless-8teel sheaths.

As discussed below, accurate measurement of the rock wall temperature in the heater hole is critical. This measurement will be made with thermocouples that spring out from the heater to make contact with the rock wall. The spring force and radiation shield size and material will be determined in a laboratory simulation of the conditions. The correlation between spring thermocouple measured wall temperature and true temperature will also be determined in the laboratory simulation.

2. Pressure Transducers. Two GS series pressure transducers ( 0 to $15 \mathrm{psi}$ and 0 to $100 \mathrm{psi}$ ) supplied by Gulton Industries will be used. The accuracy for both is $\pm 2 \%$ of full scale up to $80^{\circ} \mathrm{C}$. They incorporate LVDT technology with high-level electrical output and stability. They can be operated in an absolute, gage, or differential mode.

3. pH Measurement. Model SIO0C pH electrodes supplied by Sensorex will be used. They are sealed reference combination electrodes containing a gel electrolyte. The electrodes operate in the temperature range of 0 to $100^{\circ} \mathrm{C}$ and up to pressures of $100 \mathrm{psig}$. The probe will 
be connected to a Model NX pH meter supplied by SargentWelch. The relative accuracy and repeatability are $\pm 0.01 \mathrm{pH}$ unit. The $\mathrm{pH}$ measurement range is 0 to 14 . The temperature compenation accuracy is $\pm 1^{\circ} \mathrm{C}$. The meter has both analog and binary coded decimal (BCD) output for recording.

4. Relative Humidity Gage (Developmental). A developmental humidity probe, Model BR-101B, supplied by Thunder Scientific will be fielded. The sensor accuracy is $\pm 4 \% \mathrm{RH}( \pm 2 \%$ typical). The upper reliable operating range is $80^{\circ} \mathrm{C}$, to which it will be calibrated. The sensor is a solid-state, thin film, semiconductor. It does not contain any aluminum or other unstable metals that exhibit hysteresis, drift, aging, or instability. The sensor contains a platinum resistance thermometer for temperature measurement. The output is a linearized buffered dc voltage directly profortional to relative humidity.

5. Water Depth Gage (Developmental). The depth gage will measure the rate at which water is collected in the experimental cavities. A market survey was unable to locate a autable commercial device. Several different approachea are under evaluation and development.

6. Laser Interferometer (Developmenta1). Laser interferometry is well established but, to the best of our knowledge, it has not been used in an application like this. We are fielding such a device to determine if it can provide a stable, high-resolution displacement measurement in an in-situ environment. A Trapel Model 100 single wavelength continuous wave He-Ne laser will be used. The resolution under ideal conditions is $\lambda / 8$ or $80 \mathrm{~nm}$. The output power is $\sim 1 \mathrm{nW}$. 
7. Borehole-Inclusion Stress Gage (Developmental). A new strain-gaged stressmeter has been designed by Sandia National Laboratories that should be an improvement sver current vibrating-wire types. The extended platen design of the new gage prevents the platen from becoming embedded in the rock during preloading. The straingaged transducer peraits the use of conventional datalogging techniques rather than the special equipment required by the IRA-supplied vibrating wire atressmeters. The developmental stressmeter has a sensitivily comparable to that of the IRAD type. It can read to about 200 microstrains. The dynamic range is potentially greater than for the vibrating wire stressmeter, which is limited by excitation harmonics in the wire.

8. Data-Acquisition Systen (DAS). The DAS is based on a Hewlett-Packard (HP) $9845 \mathrm{~S}$ fully programmable controller. It will control all instrumentation in addition to collecting and storing data. The DAS is powered by an uninterruptible power supply to protect critical instruments from transient voltage variations and power outages. A block diagram of the system is shown in Figure 8 . The bagic features of the DAS are

Enhanced basic language

- 62650 bytes of read/write memory

- Dual tape cartridge drives, $217 k$ byte capacity/ cartridge

- Dual flexible diak drives, 500R byte capacity/disk

- IEEE standard 488-1975 interface bus; programmable control of all bus instruments

- 160 (expandable) analog input channels

- Build-in CRT, $310 \mathrm{~mm}$ diagonal display; graphics capability

- Interrupt capability

- Rea1-time clock

- Internal line printer

- Interface for RS-232 and BCD

- ROMB for graphics, mass storage, and I/O. 


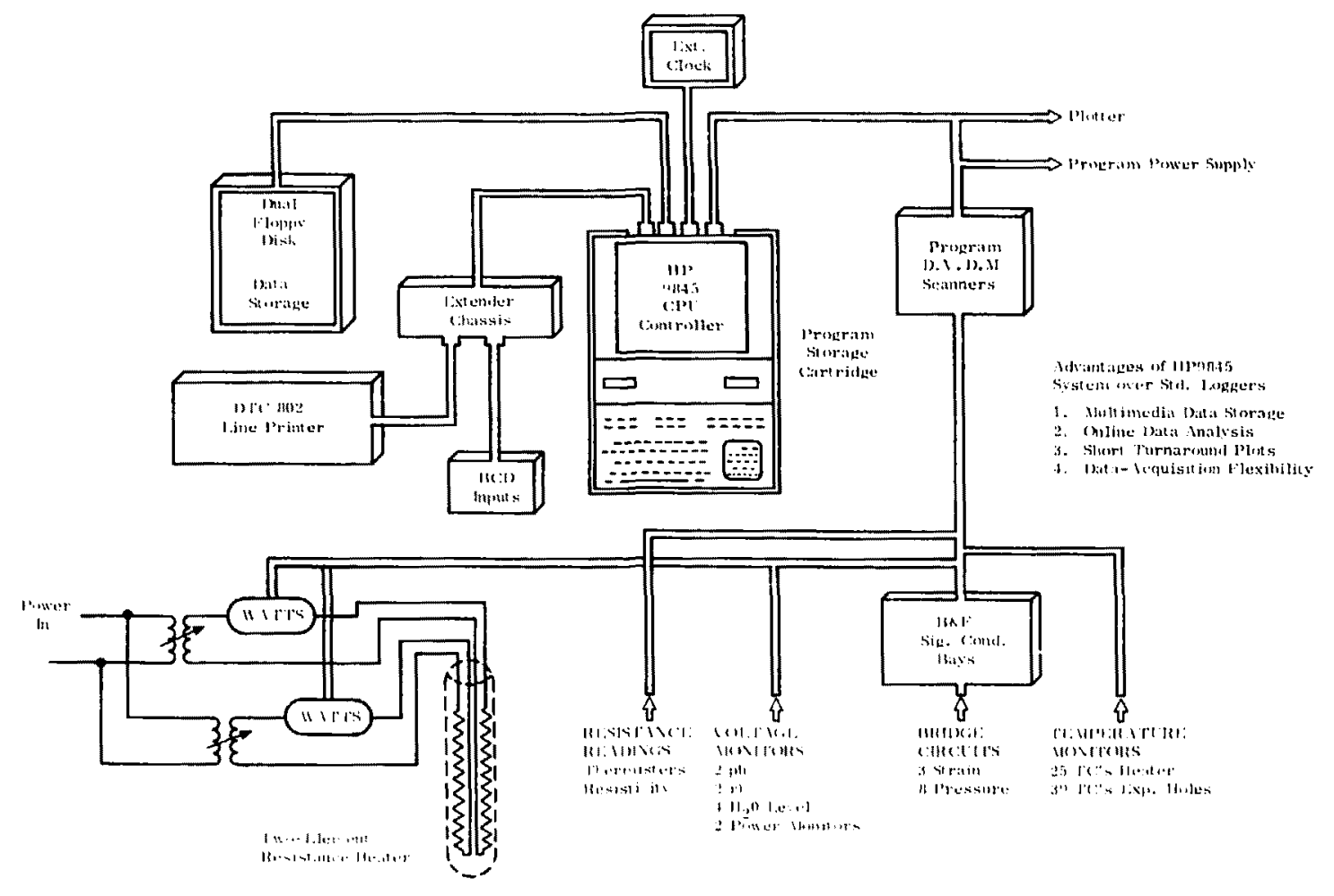


Data will be collected and stored on paper printout, magnetic tape, and flexible magnetic diskg.

Power Supply -- Power will be oupplied by a geparate cunnel circuit for heating elements and all instrumentation required for the experiment. A demand-start diesel generator will be placed outaide the tunnel to provide backup power in case of a comercial power failure.

Alcove Design -- An instrumentation alcove $3 \times 6.1 \mathrm{~m}$ has been mined at the experiment location shown in Figure 6. A floor ard walls will be added to enclose the alcove for use in data acquisition and experimenc control after the necesary drilling has been completed.

Electric power will be provided for heater, instrumentation, and miscellaneous use. An air conditioner will provide climate control including temperature, humidity, and air filtration. Space will be available for instrumentation racks, workbench, power control, and experiment access and operation.

Drilling and Survey Technology -- The requirements for heater hole straightness $(<6.4 \mathrm{~mm}$ deviation in $3 \mathrm{~m})$ and satellite hole placement ( $+5 \mathrm{~cm}$ and $20 \mathrm{~m}$ ) are beyond the capabilities of standard drilling practices. In addition, these difficulties are compounded by the fact that the holes are in a near-horizontal position, which leads to a natural tendency for the hole to drift down and to the right during drilling. State-of-the-art techniques are required to meet the experimental requirements.

Similar comments apply to the survey techniques. Each hole will be surveyed upon completion. The results of the aurvey will be the primary basis for acceptance or rejection of the hole, although other criteria such as stratigraphy, presence of fractures, voids, etc, and insertion of plug gages will also be important. An as-built survey of the heater hole will be partizularly important in locating the laser hole. Upon completion of the drilling activity, an as-built auvey of the entire hole array is required. 
Model ing Support

Thermal Modeling -- Extensive thermal analyois of the experiment was curried out to

- Determine the approp=iste heater power level and locate the experimental effects holes, but remain within the limitations of the heater components and drilling capabilities

- Model the thermal behavior of the heater and the rock for different responses of the rock to the power input

- Determine the sensitivity of the rock response to variations in power input and rock thermal conductivity

Fourtecn possible casea were anslyzed by assuming tuo-dimensional, axisymetric geometry. Temperature solutions for the heater/rock system were obtained numerically through uge of the coyote computer program for heat conduction. The resulta of these analyses are presented in decail in Appendix $C$ and sumerized here.

Except for the effects of water, the rock was assumed homogeneous. The effects of joints on the thermal behavior were not considered. Heater operation was at constant power for 30 days. Cooldown behavior was also calculated for an additional 30 days.

The variables considered in the analysis were heater power input, boiling temperature of the water in the rock, and thermal conductivity and emissivity of the rock. The power levels considered were $1.25,1.9$, and $2.5 \mathrm{~kW}$. Boiling cemperatures of $100^{\circ}$ and $235^{\circ} \mathrm{C}$ were vaed. Atmospheric boiling $\left(100^{\circ} \mathrm{C}\right)$ served as lower bound. Boiling at $235^{\circ} \mathrm{C}$ reflects a vapor pressure of 450 psi, the appraximate minimum in-situ stress in the G-tunnel welded tuff, ${ }^{8}$ and serves as an upper bound. A hydrostatic boiling point was not considered ance such a state does not exist in an unsaturated system.

Thermal conductivity was either helt conotant or allowed to vary during the experiment. An opparent constant thermal conductivity could 
correspond to (1) no water release during the experiment, or (2) pore collapse as the water leaves. The variable case models the change in thermal conductivity that occurs at dryout after boiling. For these analyses, the change was assumed discontinuous. Conductivity for the dried-out rock was $1.2 \mathrm{~W} / \mathrm{m}^{\circ} \mathrm{C}$. Owing to the uncertainties of the conductivicy for fully saturated rock, values of $1.7,2.2$, and $2.7 \mathrm{H} / \mathrm{m}^{\circ}{ }^{\circ} \mathrm{C}$ were used. In all cases, the latent heat of vaporization of water was included in the rock heat capacity.

The results of these analyses are summarized below:

1. The heater power level strongly affects the surface temperature of the heater, the rock wall (heater hole) temperature, and the penetration distance into the rock of the assumed boiling isotherm.

2. The assumed decrease in rock thermal conductivity near the boiling isotherm strongly incluences the near (that portion within the boiling isotherm) thermal field. Significant temperature increases at the heater and rock wall surfaces occur for a decrease in thermal conductivity. The location of the boiling isotherm is sensitive to the power level and the initial value of conductivity for saturated rock $(1.7,2.2$, or 2.7 $\mathrm{W} / \mathrm{m}^{\circ} \mathrm{C}$ ), but it is relatively insensitive to the assumed variation in conductivity at dryout. Calculated differences in penetration distances for conductivity variations at dryout were less than $5 \mathrm{~cm}$, which is probably well beyond the resolution capability of the experimental satellite holes. This suggests that (a) measurements of the rock wall temperature in the heater hole during the experiment should provide the most sensitive definition of in-depth boiling in terms of its effect on rock thermal properties, and (b) the rock thermal conductivity has a major effect on the heater operating power. 
3. The boiling temperature has a negligible effect on the therwal profiles when the conductivity is constant for a given power level. However, for a variable conductivity, the higher boiling point causes lower nearfield cemperatures because of the smaller volume of dried-out rock.

4. Variations in the rock emissivity from 0.6 to 0.8 result in negligible differences $(\sim 1 \zeta)$ in the maximum surface temperature of the heater.

The final power level to be used during the experiment has not been determined. This decision will be based on materials, instrumentation, and rack mechanical property limitations. In addition, the final calculations will be made by using thermal properties obtained on the core removed from the heater hole at the heater location. Present calculations suggest that there are no material (e.g., heater, packers, RTV) limitations, even at the highest anticipated power level of $2.5 \mathrm{kH}$.

The instruments that may be affected are the pressure transducers, oH electrodes, relative humidity gages, and water depth gages. The lowest temperature at which problews with any of these instruments might occur is about $B 0^{\circ} \mathrm{C}$. The only holes likely to experience such temperatures in the vicinity of the instruments are the two water migration holes located $41 \mathrm{~cm}$ from the heater hole (see figure 3 ). Potential instrument difficulties will be evaluated after the final power level/temperature profile calculations.

The potentially most severe difficulties are associated with the heater hole wall stability. Spallation of the rock surface could occur because of thermal shock caused by rapid heating or by steam pressure in closed pores. Rock wall failure could also occur if the thermomechanical stress exceeds the strength of the rock (see the section on Thermamechanical Modeling). Crumbling of the rock wall around the heater would lead to an incresse in the near-field temperature because of the decrease in thermal conductivity. Such an accurrence would probably eliminate any 
hope of characterizing the water behavior. Consequently, the power level must be selected to maintain the integrity of the rock wall.

The final selection of the power level and the reasons for the selection will be documented aeparately.

Thermomechanical Modeling -- Thermomechanical analyoes of the experiment were carried out to determine the

- Optimur locations for atress meters and laser interferometer displacement gage

- Perturbation of the tunnel opening and the alcove on the in-situ stresses in the experimental region

- Perturbation of in-situ stresaes near the heater due to the presence of the heater holes and instrumentation holes

Resulta of the analyses are given in Appendix $D$ and are briefly summarized here.

The analygis to determine instrument location was carried out consigtent with the thermal modeling discused above. Stresees and displacements were obtained by numerical (finite-element) solution of the MARC computer program. The finite-element meah and the temperature fields used in these calculations were identical to those used in the themal analysis. Several cases repreaenting the extremes of power level and boiling temperature were considered. In addition, che rock wass was assumed a homogeneous elastic medium; therefore, the only deviations from in-situ stresses are due to thermoelastic effects. Note then that the instrumentation measures net changes and is independent of initial in-situ stresses.

Streases and displacements for the two cases at the end of 27 days are given in Appendix D. Calculated result are within a factor of 5 of the measurable ranges at a distance of about $1 \mathrm{~m}$ from the heater center1 ine. The minimum distance from the heater will be deternined by the temperature field asoociated with the input power level selected. 
Calculations to determine the effects of the tunnel opening and alcove on the in-situ stresses were done with a closed-form solution that approximates the actual situation. The presence of the heater and satelIite holes was neglected. Results show that che perturbations are negligible at the location of the heater.

The perturbation of the in-situ otresses due to the presence of the heater and satellite holes was calculated by uaing MARC. The thermal effects discussed above were ignored. No attempt was made to account for the $20^{\circ}$ angle of inclination of the holes in the orthogonal stress space. Restlts show virtually no scress interaction between adjacent holes.

The thermal stresses discussed above can be added only to the stress distribution around the heater hole since the thermal alcriacions are axisymmetric around $i t$. When the stresses are added, they approach the laboratory value for the unconfined compressive strength of the rock. In addition, note that the presence of in-situ fractures would lead to a strength less than that of the laboratory value, while drying out the rock ( $0 \%$ saturation) causes an approximate $30 \%$ increase in the laboratory value. The relative importance of chese competing effects is not known; consequently, we will monicor the experiment closely as it approaches 30 days of operation.

\section{Operation Procedure}

\section{Responsible Personnel}

Responsible personnel for this experiment are

L. D. Tyler, Sandia Technical Project Officer for the Nevada Nuclear Waste Storage Investigations program

J, K. Johnstone, Principal Investigator

D. R. Waymire, Director of Field Activities 
Overall responsibility and authority for the experiment lie with the Principal Investigator, although he may be overruled on any decision by the SLA Technical Project Officer. The Principal Investigator is responsible for the conceptual and experimental design. He will coordinate the experimental design and modeling support with the Director of Field Activities to ensure that the experimental objectives are met. The Principal Investigator is responsible for the analysis, interpretation, and reporting of the results. The Director of Field Activities is responsible for instrumentation and heater design, data-acquisition design, coordination of driling and mining activities, fielding of hardware, and operation of the experiment. Additional staff and staff sosistant personnel will support the program as required.

\section{Experiment Segrience}

Figure 9 shows the experiment sequence and estimated weeks for completion of individual activities (numbers in circles). The heater will be turned on only after satisfactory instrumentation checkout and calibration and background data have been obtained. The current estimate for heater turnon is January $29,1980$.

The heater will operate for a minimum of 30 days. Thermal and mechanical responses will be continuougly compared with the pretest predictions to identify any abnormal behavior. The actual operational time will depend on the experimental response. The data will be continuously evaluated during the experiment, and actual shutdown will occur when the goals of the experiment have been achieved.

Data collection intervals will depend on the phase of the experiment. During initial heatup, every channel could be monitored as often as every 5 min. The channels may be monitored every 15 to 20 min during the transition from heatup to steady-state operation, and every hour during steadystate operation. The actuil data collection intervals will depend on the experiment behavior. 


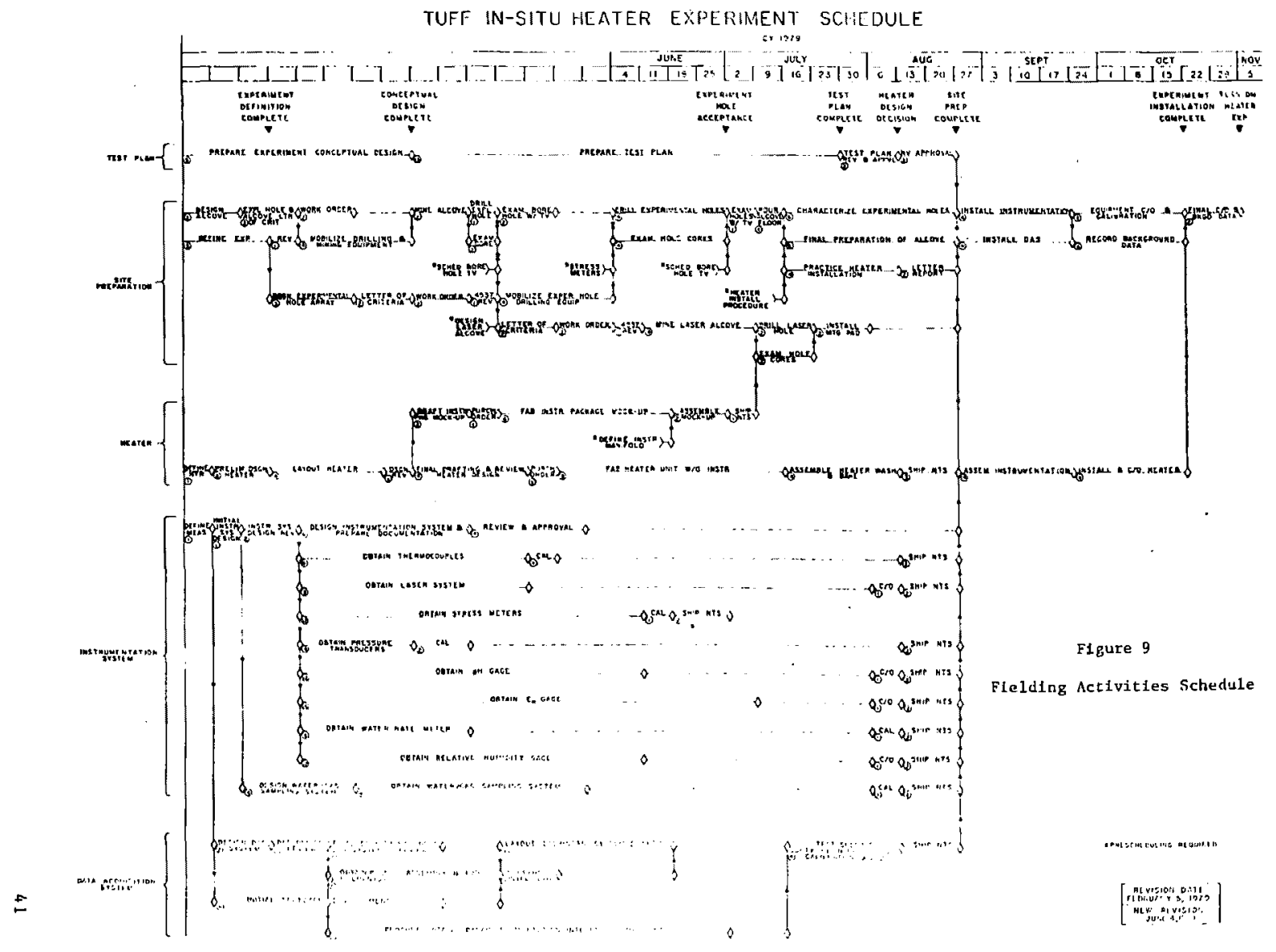


Cooldow behavio. will be monitored for at least 30 daya after the heater has been turned off. Water behavior and expansion and stress subsidence are of particular interest duriy the cooling period.

Poactest characte:ization may include permeability measurements, hole examination with the borehole TV camera, and coring the rock surrounding the heater. The visual examination (TV) will be compared with pretest conditions for gross structural changes, and the postest core will be examined for possible morphological and/or mineralogical alterations. Core samples will also be available for property measurements if desired.

\section{Unexpected or Abnormal Behavior}

One of the purposes of any experiment is to determine unforeseen behavior ot responses. However, unexpected or abnormal behavior could also be detrimental to the success or the experiment or the safety of attendant personnel. A partial 1 ist of unexpected or abnormal behavior follows:

- Thermal runaway Excessive power input Spallation or crumbling of heater hole rock wall

- Loss of heater power

Power outage

Heater burnout

- Rock wall thermocouples in the heater hole fail to spring out

- Overpressurization in an experimental cavity

- Instrumentation (DAS) malfunction

- Losb of packer seal

- RTV burnup in heater lead junction box

- Large displacements in laser or stress holes.

Moat unexpected behavior could be mitigated by altering the heater power; i.e., the power could be decreased, turned off, increesed, or left alone. An overpressurized cavity could be corrected by rt'easing the pressure through a gas or water sampling tube. In general, the impact on the experiment of each of these deviations (or others) must be evaluated at 
the time they occur and a course of action determined. Nevertheless, several of the more serious occurrences have been attached to a telephone alarm described below.

\section{The Telephone Alanm}

Typically, G-tunnel ia open a standard B hr shift, 5 days a week. From time to $t$ ime, it is open longer because of the requirements of various ongoing activities in the tunnel. Except for tire heater turnon and heatup, we do not expect to keep the tunnel open except for emergency situations. A telephone alarm will be included in the system to notify appropriate personnel of conditions judged detriment 31 to the experiment.

Three such conditions have been identified. They are

- Inability of the backup diesel generator to start after a comercial power failure

- Loss of power to the datamacquisition system (DAS)

- Thernal excurgion of the heacer skin of more than $30^{\circ} \mathrm{C}$ above the predicted temperature

The backup diesel generator is programmed to attempt startup three times after a comercial power failure. If the generator has not started after the third attempt, the telephone aiarm will notify the appropriate personnel.

Even if the diesel generator does not start, the DAS is connected to an uninterruptible power supply (battery pack), which can maintain the DAS but not the heaters for at least $5 \mathrm{hr}$. However, should there be a loss of power to the DAS for any reason, the telephone alarm will notify the appropriate personnel.

The heater skin was chosen to monitor the thermal behavior in the heater hole for several reasons. First, because the thermocouples are embedded in the skin and covered with welded plates, they are the best protected of all the thermocouples in the heater hole. Secondly, the heater 
s'in is the most sensitive to both variations in temperature of the heating elements inside the heater or to variations in temperature of the rock wall surrounding the heater. Should the heater skin deviate by about $30^{\circ} \mathrm{C}$ above the predicted temperature, the telephone alarm system will actuate. If the thermal excuraion reaches $100^{\circ} \mathrm{C}$ before the difficulty is corrected, the heater power is automatically shut off. The $30^{\circ}$ and $100^{\circ} \mathrm{C}$ deviations are at present only estimates of the critical temperature intervals; they may be altered once we have some experience in the thermal behavior of the experiment.

Upon actuation, the telephone alarm system automatically calls a preprogramed list of people and plays a prerecorded tape that describes the situation. The syatem is designed to attempt to call each person three $t$ imes before sequencing to the next on the list. At least five people can be notified, and they may be different people depending on the situation that develops. Personnel will be selected for notification according to their ability to deal with the problem. Note in particular that some conditions may require opening G-tunnel. Under these circumatances, certain mine personnel must be on hand in accordance with Federal mine safety regulations.

\section{Safety}

All installation and operational procedures will be consistant with the applicable provisions of the appropriate DOE Manual Chapters and Nevada Test Site Service Organization (NTSSO) Standard Operating Procedures. We have not so far identified any extraordinary hazards associated with this experiment.

One potential hazard is overpressurization of the experiment cavities. Curren data suggest this is highly unlikely; however, certain precautions will be talcen. The rods used to insert the packer/instrumentation packages will be attached to rock bolts to prevent ejection into the alcove. Should the pressure excead 15 paig, the DAS will emit an audible beep and a warning will be printed. If overpressurization in excess of 100 psig occurs, a warning 1 ight will be activated next to the alcove door 
to warn persons entering of the oituation. All of the experimental cavities include gas and water sampling tubes that can be used to relieve the pressure.

\section{Quality Assurance}

A Quality Program Plan (QPP) has been developed for all of Sandia National Laboratories involvement in NNWS activities. The experiment will be carried out in accordance with the QPP. The QPP is written in the 18-chapter format prescribed by 10CFR 50, Appendix B, and its provisions comply with AL Chapter and Appendix 08XA.

The QPP addresaes only those activities internal to Sandia National Laboratories. Any services performed by NTS support contractors fall under their individual quality assurance plans.

\section{Documentation}

A Conceptual Experimental Plan was prepared and submitted to the NNWSI Project Manager for approval. This report, the Experimental Plan, is the second in the series of plan documents prepared subsequatt to approval of the Conceptual Experiment Plan. The final pretest \& amal calculations used to define the heater operating conditions will be documented upon completion (recall that the final calculations will te based on thermal propertieg of core removed from the heater hole; see the section entitled "Thermal Modeling"). Barring unforeseen delays, the final report draft of the results of the experiment will be submitted to the NNWSI Project Manager within 6 montha after cessation of all activity at the experiment site.

Current status reports will be made orally on a weekly bas is to DOE NV NWWS personnel in accordance with current practice. Written status reports will be submitted on a quarterly basis, also in accordance with current practice. All activitiea related to the experiment, such as 
design studies, inspection, calibration, operational procedures, document control, etc, will be carried out in accordance with the Oulity Program Plan described in the previous section. 
1. Nevada Nuclear Wagte Storage Investigationa. FY 1979 Project Plan. NVO-196-9 (Las Vegas, NV: US Department of Energy, Hevada Operations office, March 1979).

2. G. J. McCarty et al, "Interaction Between Nuclear Waste and Surrounding Rock," Nature, 273, 1978, Pp 216-217.

3. G. J. McCarty et al, "Hydrothermal Interactions Among Nuclear Wastes, Containment, and Host Rocks in Geologic Repositories," Scientific Bas is for Nuclear Waste Management, Vol. I. Proceedings of the Symposium on Science Underlying Radioactive Waste Management (Boston, MA: Materials Research Society, November 1978).

4. J.W. Braithwaite and J.K. Johnstone, "Chenical Durability and Characterization of Nuclear Waste Forms in a Hydrothermal Environment." Proceeding of the Symposium on Ceramics in Nuclear Waste Management (Cincinnati, OH: American Ceranics Society, April 1979).

5. A. R. Lappin, R. K. Thomas, and D. F. McVey, "Present Starus of Thermomechanical Yodeling of the Response of Argillaceous Rocks to Digposal of High-Level Nuclear Wastes." Spring Meeting of the Sociecy for Experimental Stresa Analysis TSan Francisco, CA: Society for Experimental Stresa Analysis, May 1979).

6. L. D. Ramspott, ed, Haste Isolation Projects. FY 1978, UCRL-50050-78 (Livermore, CA: Ernest Orlando Lawrence Livermore National Laboratory, January 1979).

7. L. V. Benson, Mass Transport in Vitric Tuffs of Rainier Mesa, Nye County, Nevada, NVo-1253-10 (Reno, NV: Water Resources Center, Desert Research Institute, University of Nevada, Dctober 1979).

8. N. R. Warpinski et al, Hydraulic Fracture Behavior t a Geologic Formacion Interface: Pre-Hineback Report, SAND7B-1578 (Albuquerque, Ny: Sandia National Laboratorieg, August 1978).

9. Letter from E. F. Gloyna, Chairman of the Committee on Radioactive Waste Management, National Research Council, to S. Meyers, Program Director, Office of Nuclear Wate Management, DOE, April 23, 1979.

10. L. D. Tyler et al, Near-Surface Heater Experiments in Argillaceous Rocks, SAND78-140IC. OECD/NEA Neeting on In-Situ Heating Experiments in the Eleana Formation, Nevada Test Site. Division 4537 (Albuquerque, MM: Sandia National Laboratories).

11. Experiment Design for Near-Surface Experiments in the Eleana Formation, Nevada Test Site, Divibion 4537, (Albuquerque: Sandia National Laboratories). 
12. L. D. Ramspott and L. B. Ballou. Experimental Design for the First Heater Test at the Climax Stock, Nevada Test Site, Appendix A in NTS Terminal Wate Storage Program Plan for FY T978 (Las Vegas, NV: US Department of Energy, March 1978).

13. K. A. Sargent, D. C. Nobla, and E. B. Ekren, "Beleed Range Tuff of Nye and Lincoln Counties, Nevada," Changes in Stratigraphic Nomenclature, US Geological Survey, US Geol Survey Bull 1224-A, 1964, pP 32-36.

14. G. H. Heiken and M. L. Bevier, Pecrology of Tuff Units from the J-13 Drill Site, Jackass flats, Nevada, LA-7563-YS (Los Ai amos, NH: Los Al amos National Seientific Laboratory, 1979).

15. N. B. C. Yelamanchili, Thermal Conductivity and Physical Properties of Rock Cores from G-Tunnel, Repore No. 173 (NTS, NV: Hon Macerials Test Laboratory, July 1978 .

16. N. B. C. Yelamanchili, Physical Properties of Rock Cores Samples trom lE2 25A I Drill Hole, Report No. 2458 (NTS, NV: HaN Materials Test Laboracory, April 1979\}.

17. N. B. C. Yelamsnchili, Physical Properties of Rock Cores Drill Mole UE.25A 1, Report No. 2068 (NTS, NV: HSN Macerials Tegt Laboratory, December 1978).

1R. N, E. C. Yelamanchili, HSN Materials Test Laboratory, NTS, INV, personal communication to A. R. Lappin, Sandia National Laboracorories. Albuquerque, NM. 


\section{Sandia Laboratories}

date May 17, 1979

Albuquerque New Menico

to.

J. K. Johnstone -4537

Livermore Califarnis

subject Summary of Fracture Analysis of Grouse Canyon Member, Belted Range Tuff at the Tuff Heater Site, Ul2g Tunnel Complex, Nevada Test Site

Analysis of fracture behavior in the Grouse Canyon Member, Belted Range Tuff was initiated to characterize the near-field geology of the area proximal to the tuff heater experiment planned by Sandia Laboratories. This experiment will be conducted in the Ul2g tunnel complex located approximately 1400 feet below Rainier Mesa on the north-central Nevada Test Site. Fracture analysis $y$ ielded detailed information on the orientation, frequency, morphology, and mineralization of joints in the Grouse Canyon Member.

The Grouse Canyon Member of the Belted Range Tuff is a perallaline, welded ash-flow tuff ext:ruded from the silent Canyon Caldera beneath Pahute Mesa approximately 13 to 15 mybp (Noble and others, 1968). Exploratory drilling at the hoater site has determined that the Grouse Canyon Member is 41 feet thick in this immediate area. Tunnel Bed 5 , an ash-fall tuff, is exposed at the base of the alcove in which the experiment will be run. In sharp contact with Tunnel Bed 5 is the overlying basal vitrophere of the Grouse Canyon Member; the vitrophere is roughly three feet thick. An approximately three feet thick "rubble zone" or zone of large zenoliths occurs above the basal vitrophere. Densely welded ash-flow tuff is exposed above the "rubble zone" at the tunnel back in the alcove area. The strata strike approximately $\mathrm{NJOE}$ and dip $7^{\circ} \mathrm{NW}$ in the alcove area.

Detailed mapping of the tunnel drift in and proximal to the alcove revealed four sets of joints: 1) N-S to N2OE, 77-90 $\mathrm{NW}$ : 2) N50-60W, 75-900NE; 3) N30-75E, 70-9005E; and 4) N30E, 7ONW (compaction foliation or bedaing plane joints). The $\mathrm{N}-\mathrm{S}$ to N2OE joint set is composed of markedly planar joints which vary in width from closed to .5 inch, occur on a spacing of approximately three feet, and are continuous along strike up to twenty feel. The N50-60W joint set is composed of planar and bifurcating joints which occur on a spacing of four feet. vary in width from $1 / 8$ to 2 inches, and are continuous alorig strike up to 25 feet. The $N 30-75$ b joint set is composed of planar, mostly closed joints which occur on a spacing of less 
J. K. Johnstone $-4537 \quad-2-\quad$ May 17, 1979

than ten inches and are continuous along strike up to six feet. Bedding plane joints are not observed in abundance.

Measurement of joint orientations in core from the two heater exploratory holes, U12gHEHIIA, 1B, and three other holes (UEL2glo 5 and 16 , and U12gEVG 3 ) penetrating the Grouse canyon member in the area has determined that the four joint Gets described above are the major sets in the area." The most frequently observed joints in the five cores are orlented roughly perpendicular to the orientations of the particular drill hole.

The welded tuff in the area is, In general, a highly fractured rock mass. Frequency of joints varies from none in two feet of core to nine in $1 / 2$ foot of core. The most systematic feature of joint frequency in the area is its variability. For Instance, hole Ui2gHEH\#1A averages roughly 3.2 joints per foot while hol.e U12gHEH\$1B, located 2.2 feet away, averages only 1.25 joints per foot. In general, the welded tuff in the cores consists of relatively unjointed sections of one to three foot length separated by intensely jointed sections of less than eight inches in length. Numerous rubblized zones of less than one inch lang pieces were found in the cores; these zones vary from two inches to three feet long. In general, there was a substantial increase in the joint frequency in the core above that measured in the alcove and tunnel walls for the existing joint sets.

Mineralization is found along many joint surfaces in the five cores. The most commonly abserved mineralization is reflected by an altered tuff groundmass along many joints. Pancanese and iron oxides, calcite, clay minerals, and guartz coat other joint surfaces. Joints oriented $\mathrm{N} 40-\mathrm{BOW}$ and $\mathrm{N}-\mathrm{S}$ to $\mathrm{N} 2 \mathrm{OE}$ are most affected by mineralization. This meems to indicate that these joints possess the greatest water transmisibility. Intense argillization of several zones of rubblized core suggests that these zones also are water transmissive.

Video scans of the heater exploratory holes show several features: 1) most fractures are nonplanar and bifurcating features; 2) zones of rubblized core result from the intersection of many joints at one locality; 3 ) joints occur in clusters; 4) most joints are open $1 / 16$ to $1 / 8$ inch while several joints are open up to $3 / 4$ inch. Several joints may vary from $1 / 2$ inch wide to cloved within 1 Inch.

Core indices for the two heater exploratory holes and the three other holes tudied are given on Figure 1 . of particular interest are the low core indices from 50 to 70 feet in hole UI2gHEHI1B. Also of interest is the fact that core indices for UEl2glołs and 6 , both vertical holes, are generally lower than the indices for UI2GHEH $1 A, 11 B$ and U12gEV6\$3, all low-angle

No new joint sets were identified. 
holes. Since most joints in this area have near-vertical attitudes, this relationship can probably be ascribed to the greater probability of intersecting a high-angle joint in a low-angle hole.

The strike of joints found in Ul2gHEH\$1A was projected onto the plane of Ui2gHEH $1 \mathrm{~B}$ (and vice versa) to attempt prediction of fracture behavior from core data. Although three rubble zones were predictable, all other rubble zones were not. Most joints do not intersect the other hole at the point projected. These data indicate that either the joints are curvilinear and /or they are not continuous along strike. In conclusion, these results confirm that fracture behavior of the Grouse canyon Member is both complex and generally unpredictable.

GWS : 4537 : dsh

\section{Reference}

Noble, D. C., Sargent, K. A., Mehnert, H. H., Ekren, E. B., and Byers, F. M., Jr., 1968, Silent Canyon volcanic center, Nye County, Nevada, in Nevada Test Site: Geol. Soc. America Mem. 110 , P. 65-75.

copy to:

4530 R. W. Lynch

4537 L. D. Tyler

4537 A. R. Lappin 


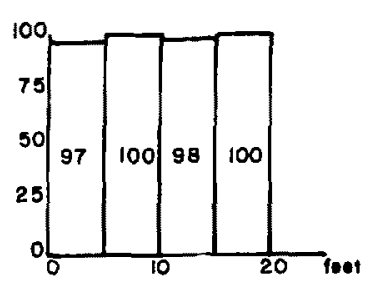

UI2 $\mathrm{HEH}$-IA
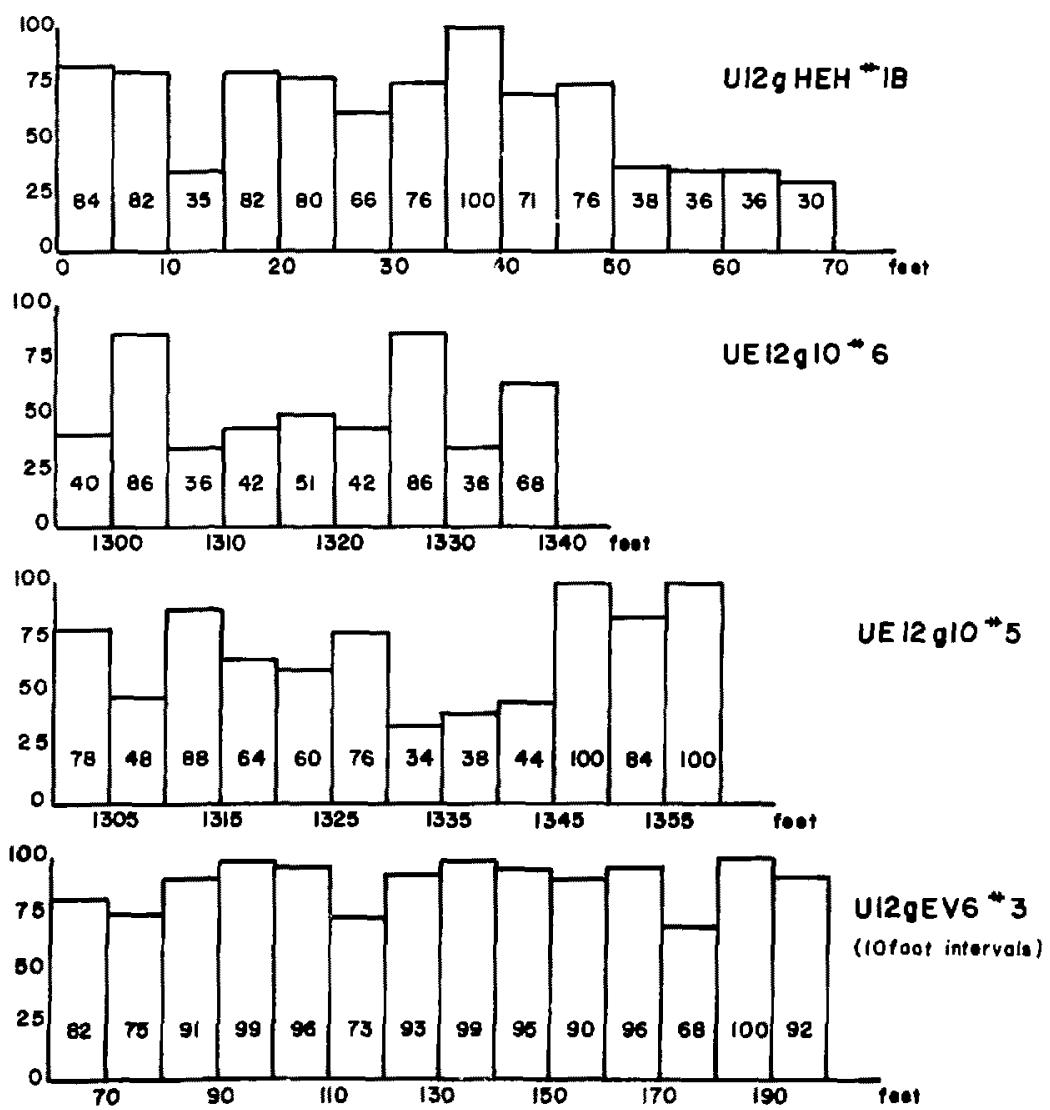

FIgure A-1. Core Indice for Several Holee Proximal to Tuff Heater Experiment Site 


\title{
Sandia Laboratories
}

\author{
date February 15, 1979 \\ 10 A. R. Lappin- 4537

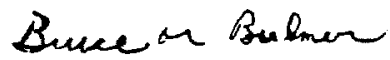 \\ from B. H. Bulmer - 5511 \\ sutinct Reconmenued Thermocouple Locations for In-Situ Tuff \\ lieater Experiment \\ Ref: llemo, B. M. Bulmer, 5511, to A. R. Lappin, 4537, \\ dtd 2/14/79, subject, Thermal Analysis of Tuff \\ In-situ lleater Exporiment
}

Temperature measurements will be made during the tuff heater eyperiment at NTS to determinr the temperature $r$ ise on the heater surface $(R=2 ")$, on the rock surface (bore hole, $R=2.5^{\prime \prime}$ ), and in the rock at two indepth locations ( $R=16$ and $\left.24^{\prime \prime}\right)$. Recommended axial thermocouple locations for this test are symmetric with respect to the heater midplane $(z=0)$ :

\section{Mea surement}

1. Heater surface, $\mathrm{R}=\mathbf{2}^{*}$

2. Bore hole (rock) surface, $R=2.5^{\circ}$

3. Indepth, $\Gamma=16$ and $24^{\prime \prime}$ $\mathrm{z}$, inches

Same as rock surface

0

12-18 (as close to

18 " as possible)

0

6

12-18 (same as selected

for rock surface)

60

96

Recomnended thermocauple locations are superimposed in Figures 1-8 with computed isotherms at 30 days for each of the eight numerical cases considered in the reference.

Rock and heater surface temperatures will be measured at three circumferential positions at the heater midplane and near each end of the heater $(9$ measurements total each surfacel. Computed temperature profiles along the heater 
A. R. Lappin $-4537 \quad-2-$

hole (Figure 9) suggest that there will be a significant axial gradient beyond $212 "$ from the midplane. Thus, a measurement beyond 12" should help to define the axial variation along the hole. However, the measurement should be liept at least 6 " from the ends of the heater so as to avoid ill-defined heater end effects.

Proposed thermocouple locations indepth at $R=16$ and 24 " are positioned axially to provide as much detail as possible within the calculated $50^{\circ} \mathrm{C}$ isotherm for the range of conditions considered thus far. Temperature profiles at 30 days for the $R=16$ and 24 " radii are plotted in Figure 10. The locations of the eleven thermocouples proposed for each radius have been selected to best define the axial temperature variation indepth. Tise location of the second thermocouple from the heater midplane should correspond, if possible, to the axial location sclected for the rock and heater surface measurements. As indicated in Figure 10, a measurement IB" from the midplane will provide the best definition of the indepth temperature profile based on computed results.

BiMB : 5511:1jg

Copy to:

1116 J. D. Pl impton

4530 R. W. Lynch

4537 L. D. Tyler

4537 J. K. Johnstone

4537 D. R. Waymire

5500 O. E. Jones

5510 D. B. Hayes

5511 D. F. McVey

5520 T. B. Lane

5530 w. Herrmann

5531 I. D. Bertholf

5531 W. T. Brown 


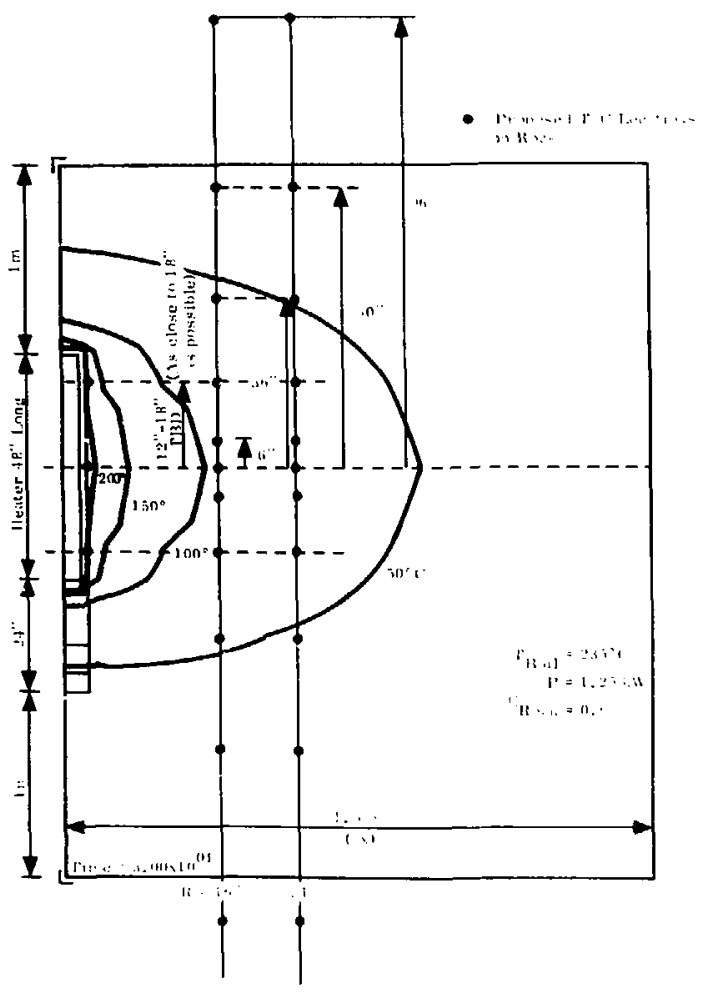

Figure B-1. Case $1 \mathrm{~A}$, Recommended Thermocouple un

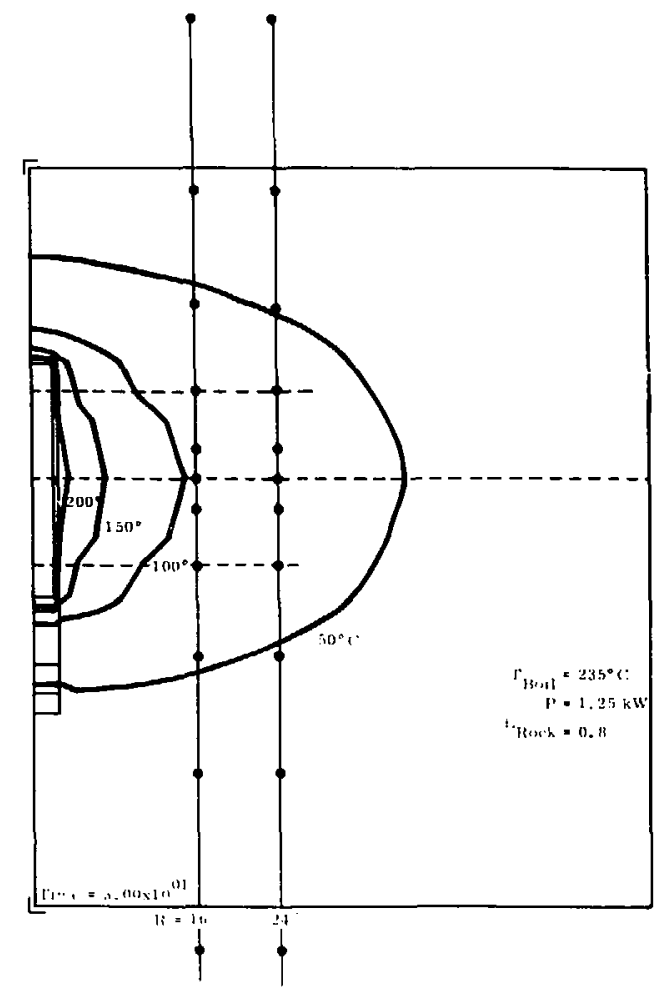

Figure B-2. Case 1B, Recommended Thermocouple locations 


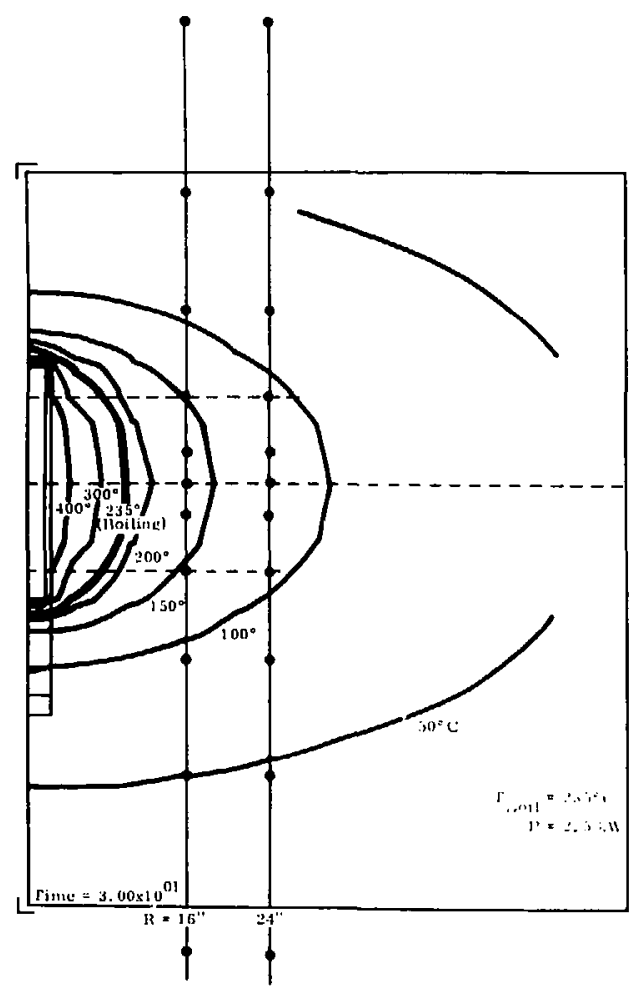

Figure B-3, Case 1C, Recommender Thermocouple Locations

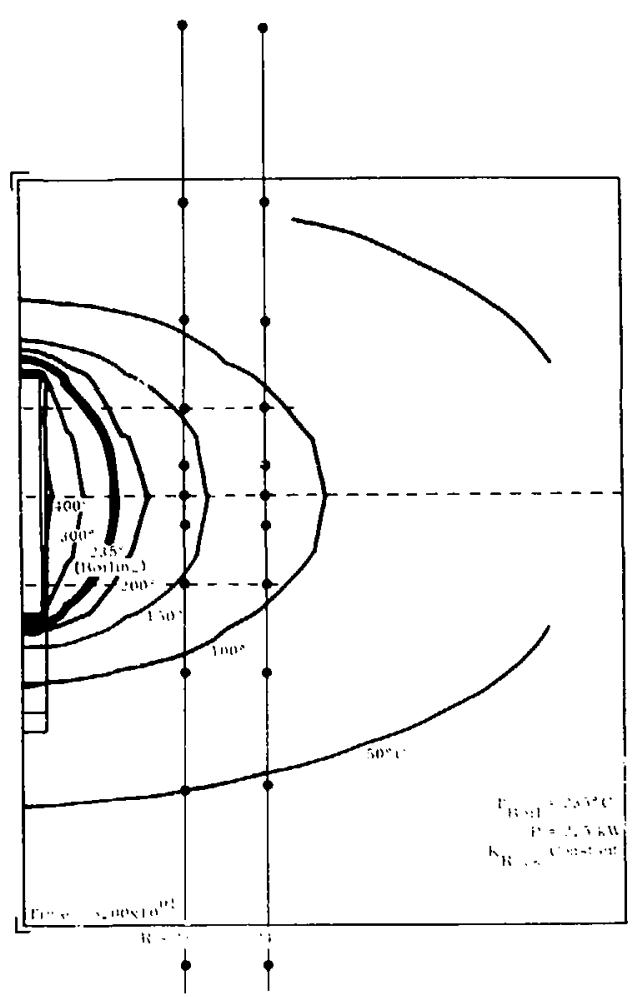
Figure B-4. Case 1l, Recommended Thermocouple
Locations 




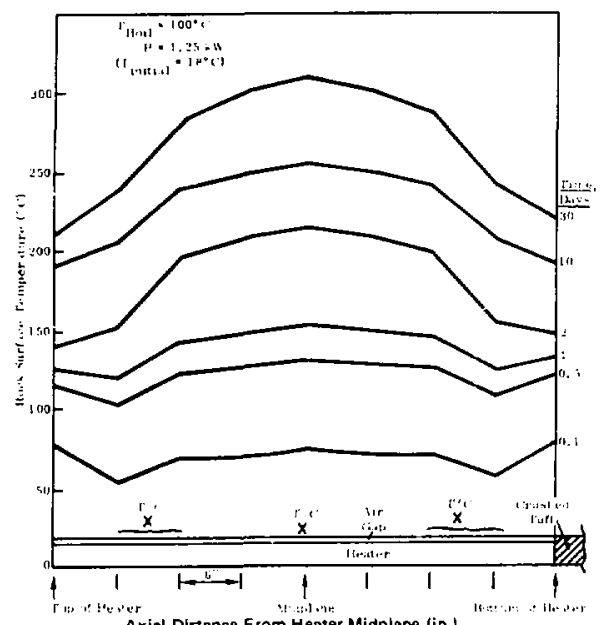

Figurn B-9. Case 2A, Computed Temperature Profiles Along the Heater Bole

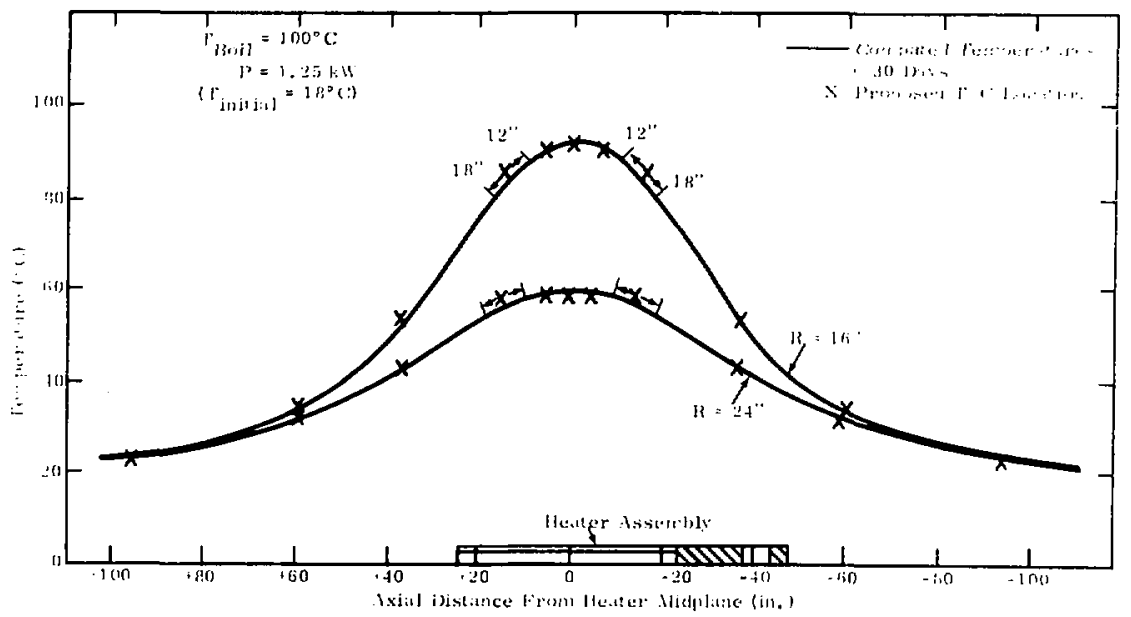

Figure B-10, Case 2A, Temperature Profiles at 30 Days for $R=16$ and 24-In. Rad11 


\section{APPENDIX C}

Thermal Analybes of Tufí In-Situ Heater Experiment

Part I: Thermal Analysis of Tuff In-Situ Heater Experiment

(Memo, B. M. Bulmer, S511, to A. R. Lappin 4537, ded 2/14/79)

(Representative plots were selected for inclusion in the Appendix to Part I; therefore, they are not numbered consecutively)

Part II: Additional Thermal Analyses for Tuff Heater Experiment

(Memo, B. M. Bulmer, 5511, to A. R. Lappin, $4537 \mathrm{dtd} 2 / 23 / 79$ )

(Representative plate were selected for inclusion in the Appendix to Part II; therefore, they are not numbered consecutively)

Part III: Tuff In-Situ Heater Experiment Rock Thermal Conductivity Sensitivity Study

(Memo, B. M. Bulmer, 5511, to A. R. Lappin, 4537 ded $3 / 19 / 79$ )

(Representative plots were selected for inclusion in the Appendix to Part III; therefore, they are not numbered consecut ive1y) 
date February 14, 1979

to

$$
\text { A. R. Lappin }-4537
$$

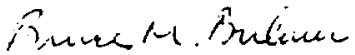

from B. M. Bulmer - 5511

\section{Sandia Laboratories}

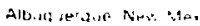

Lathon Cation.

sublect Thermal Analysis of Tuff In-Situ Heater Experiment

A preliminary scoping analysis has been completed for the tuff heater experiment to be conducted at NTS. Problem definition is given in Reference 1. A total of eight numerical cases were considered for a two-dimensional axisymmetric geometry. The various cases are summarized in Table $I$.

A schematic of the conceptual heater assembly (as analyzed) is shown in Figure 1. The end of the heater is assumed to be in direct contact with the rock. At the opposite end of the heater is a layer of crushed tuff followed by an air void (containing an experimental package) and a steel plug bonded in place to provide a seal. Thermal properties for each material are presented in Table II. Grout will be pumped in behind the steel plug and is considered in this analysis to have thermal properties identical to the rock.

Heater operation is a constant power level during the first 30 days with cool down after that time. Two power levels were considered in this preliminary study: $1.25 \mathrm{~kW}$ and $2.5 \mathrm{~kW}$ (see Table I).

Heat transfer between the heater and rock across the 0.5 " ( $1.27 \mathrm{~cm}$ ) gap is assumed to be by one-dimensional (radial) radiation and molecular conduction through the air. The heater surface will be designed so as to minimize free convection effects within the gap; convection was ignored in the present analysis. Thus,

$$
q_{\text {total }}=q_{\text {rad }}+q_{\text {cond }},
$$

or , 
A. P. Lappin $-4537 \quad-2-$

$\frac{2 \pi k_{e f f} l}{\ln \left(r_{0} / r_{i}\right)}\left(T_{i}-T_{0}\right)=2 \pi l r_{i} F_{i-o} \sigma\left(T_{i}^{4}-T_{0}^{4}\right)+\frac{2 \pi k a i r^{l}}{\ln \left(r_{0} / r_{i}\right)}\left(T_{i}-T_{0}\right)$

where,

$$
\begin{aligned}
& k_{\text {eff }}=\text { gap effective conductivity (combined } \\
& \text { radiation and conduction) } \\
& k_{\text {air }}=\text { air conductivity } \\
& \mathbf{F}_{i-0}=\text { radiation shape factor } \\
& \sigma=\text { Stefan-Boltzmann constant, } 4.901 \times 10^{-6} \\
& k J / d a y-m^{2}-k^{4} \\
& l=\text { heater length } \\
& \mathbf{r}_{\mathrm{i}}, \mathbf{r}_{\mathrm{D}}=\text { heater, bore hole radius, respectively } \\
& T_{i}, T_{0}=\text { heater, rock surface temperature, respectivly. }
\end{aligned}
$$

Solving for the effective conductivity,

$$
k_{\text {eff }}=\ln \left(r_{0} / r_{i}\right) r_{i} F_{i-o} \sigma\left(T_{i}^{2}+T_{o}^{2}\right)\left(T_{i}+T_{0}\right)+k_{a i r} .
$$

The radiation shape factor for long, concentric cylinders is assumed, i.e.,

$$
F_{i-0}=\frac{1}{\frac{1-\epsilon_{i}}{\epsilon_{i}}+1+\frac{r_{i}\left(1-\epsilon_{0}\right)}{r_{0} \epsilon_{0}}} \text {, }
$$

where $\epsilon_{f}$ and $\epsilon_{0}$ are the heater and rock surface emissivities, respectively. The heater emissivity is bused on mean values for stainless steel oxidized in air at red heat for $30 \mathrm{~min}, 2$ A curve fit to these data is,

$$
\epsilon_{i}=0.1409 \mathrm{e}^{0.001283 \mathrm{~T}} ; \text { T in }{ }^{\circ} \mathrm{C} \text {, }
$$

and is valid for temperature to approximately $750^{\circ} \mathrm{C}$. 
A. R. Lappin-4537 -3-

The conductivity of air is temperature dependent and is given by the following equation: 3

$$
k_{a j 5}=\frac{0.170 \sqrt{T}}{1+\frac{441.7}{T} 10^{-(21.6 / T)}} ; k \text { in } \frac{k J}{d a y-m-{ }^{\circ} \mathrm{C}}, T \text { in }{ }^{\circ} \mathrm{R} \text {. }
$$

Heat transfer in the air void between the crushed tuff and steel plug is assumed to be by molecular conduction oniy: the preceding expression was used to evaluate this effect.

The boiling of water contained in the tuff may have a significant effect on the rock thermal characteristics as ary-out occurs. A boiling temperature of either $100^{\circ} \mathrm{C}$ or $235^{\circ} \mathrm{C}$ was assumed in the analysis. 1 These values assume fully saturated rock with 6 wt 8 water content. The lower bound, $T_{\text {boil }}=100^{\circ} \mathrm{C}$, represents atmospheric boiling, i.e.. Pfluid $=1 \mathrm{~atm}$. The upper bound value of $235^{\circ} \mathrm{C}$ corresponds to $p_{\text {fluid }}=P_{\text {solid }} \approx 450$ psi (minimum solid stress). During the heater experiment, boiling should occur somewhere between these 1 imits.

The assumed effect of boiling on the thermal conductivity of the rock is:

Variable $k$ cases

$$
\begin{aligned}
& k=\text { constant }=2.2 \mathrm{~W} / \mathrm{m}^{\circ} \mathrm{C}=190.1 \mathrm{~kJ} / \text { day }-\mathrm{m}-{ }^{\circ} \mathrm{C} ; \mathrm{T} \leq \mathrm{T}_{\text {boil }} \\
& k=\text { constant }=1.2 \mathrm{~W} / \mathrm{m}^{\circ} \mathrm{C}=103.7 \mathrm{~kJ} / \text { day }-\mathrm{m}-{ }^{\circ} \mathrm{C} ; \mathrm{T}>\mathrm{T}_{\text {boil }}
\end{aligned}
$$

Constant $k$ cases

$$
k=\text { constant }=2.2 \mathrm{~W} / \mathrm{m}^{\circ} \mathrm{C}=190.1 \mathrm{~kJ} / \mathrm{day}-\mathrm{m}-{ }^{\circ} \mathrm{C} ; \text { all } \mathrm{T}
$$

For heat capacitance, the latent heat of water was included in the rock, $\rho c_{p}$, to account for the energy absorbed during evaporation. This was accomplished by spreaoing the effect over a $50^{\circ} \mathrm{C}$ temperature increment in the vicinity of the assumed boiling temperature:

$$
\begin{aligned}
& \rho \mathrm{C}_{\mathrm{p}}=1975 \mathrm{~kJ} / \mathrm{m}^{3}-{ }^{\circ} \mathrm{C} ; \mathrm{T}<\mathrm{T}_{\text {boil }}-45^{\circ} \mathrm{C} \\
& \rho \mathrm{C}_{\mathrm{p}}=\left\{\begin{array}{l}
8244 \mathrm{~kJ} / \mathrm{m}^{3}-{ }^{\circ} \mathrm{C}\left(\mathrm{T}_{\mathrm{boil}}=100^{\circ} \mathrm{C}\right) \\
6919 \mathrm{~kJ} / \mathrm{m}^{3}-{ }^{\circ} \mathrm{C}\left(\mathrm{T}_{\mathrm{boil}}=235^{\circ} \mathrm{C}\right)
\end{array}\right\} \mathrm{T}=\mathrm{T}_{\mathrm{boil}}+5^{\circ} \mathrm{C} \\
& \rho \mathrm{o}_{\mathrm{p}} \mathrm{C}
\end{aligned}
$$


A. R. Lappin $-4537 \quad-4-$

These results assume fully saturated rock at 6 wt water content; latent heat values were taken from Reference 4 for each assumed boiling temperature.

Rock thermal conductivity and heat capacitance variations with temperature are summarized in Figure 2.

The COYOTE finite element heat conduction code ${ }^{5}$ was used to generate time-dependent, two-dimensional axisymmetric temperature solutions in the heater assem ly and rock. The thermal model is shown In Figure 3 and contains 465 elements. The indicated physical size of the modeled region insures the validity of the assumed adiabatic boundary conditions for the range of hei or powers and problem run times of interest. Thermal mode?. details near the heater are shown in Figure 4; numbered elements for the same region (expanded $5 x$ in the radial dimension) are indicated in figure 5.

Detailed plotted temperatures are presented in the Appendix for each of the eight cases considered (64 plots total). Locations of plotted temperature histories are indicated schematically in Figure 6. Histories are given for three rays (bottom of heater, midplane of heater, top of heater) at the following 10 radii measured from the heater centerline:

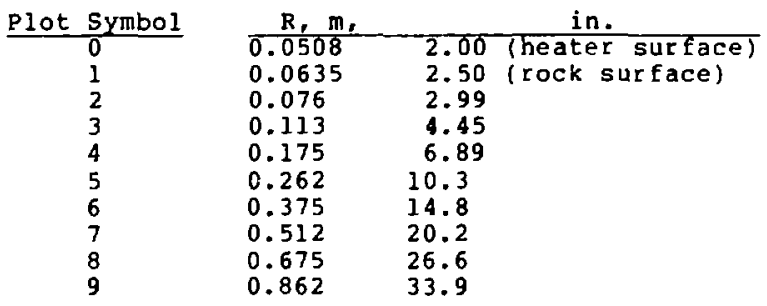

Temperature histories are plotted at eight locations along the centerline (axis) at the following positions measured Erom the top of the heater:

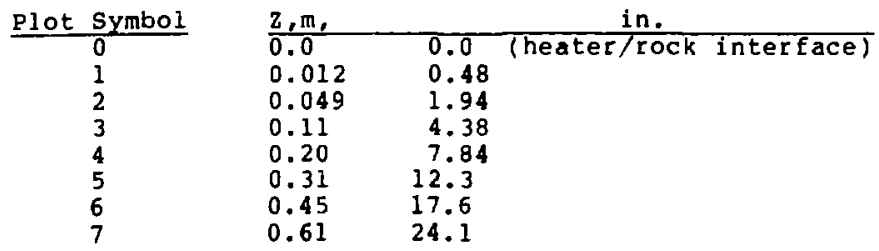


A. R. Lafpin - 4537 -5-

Histories are also provided at the four material interface jocations along the centerline of the heater assembly measured from the bottom of the heater:

\begin{tabular}{clll} 
Plot Symbol & $\frac{2, m}{m}$ & in. \\
\cline { 2 - 3 } & 0.0 & 0.0 (heater/crushed tuff) \\
1 & 0.36 & 14.0 (crushed tuff/air void) \\
2 & 0.51 & 20.0 (air void/steel plug) \\
3 & 0.61 & 24.0 [steel plug/grout (rock)]
\end{tabular}

Maximum temperatures are reached at 30 days as the power is assumed to be shut of at that time.

Three contour plots are presented for each case at the following times: 1 day, 10 days and 30 days. Note that the contour plots encompass only the immediate region near the heat assembly: $1 \mathrm{~m}$ axially from each end of the heater assembly, and $1.5 \mathrm{~m}$ radialiy from the centerline. All contour plots are expanded $2 x$ in the radial dimension.

Some significant thermal results are summarized in Table II . These include maximum computed temperatures on the heater and rock surfaces (at the heater midplane) and in the steel plug, and maximum $r$ adial and axial penetration distances of the assumed boiling isotherm.

Several conclusions may be drawn from this stuly:

(1) Tuff is not as dark as the Eleana argillite and emissivitjes in the range 0.6-0.8 appear to be reasonable for the present analysis. Variations of $\epsilon_{\text {rock }}$ (compare cases $1 A$ and $1 B)$ result in relatively small differences $(\sim 1 Z)$ in the maximum heater surface temperature.

(2) The heater power level has a strong effect on all important variables (compare Case IA with $1 \mathrm{C}$, Case $2 \mathrm{~A}$ with 2B and Case 2C with 2D). All temperatures of interest increase significantly with power, as do the maximum penetration distances of the assumed boiling front into the rock. Thus, it seems reasonable, from the standpoint of test objectives, to operate at the maximum power consistent with the maximum allowable heater operation temperature to achieve the desired extent of boiling in the rock.

(3) The effect of boiling temperature on the thermal field can have an important "near-field" influence depending on how the rock thermal conductivity is assumed to vary as dry-out occurs. An assumed decrease in krock at bolling results in a signiflcant temperature cise within 
A. R. Lappin $-4537 \quad-6-$

the "near-field" region bounded by the boiling isotherm compared to those cases in which $k_{\text {rock }}$ is assumed constant everywhere (compare Cases lC with ID, Casos $2 \mathrm{~A}$ with $2 \mathrm{C}$ and Cases $2 \mathrm{~B}$ with 2D); little temperature change occurs in the region outside of the boiling isotherm. Also, note that the iscation of the voiling isother is relatively insensitive to the assumptions

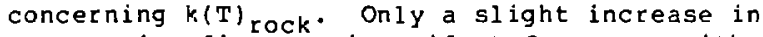
penetration distance is evident for cases with an assumed decrease in krock at boiling compared to the corresponding constant $k_{\text {rock }} r$ uns.

(4) For the cases considered, only power has a significant influence on the maximum temperature of the steel plug. However, even for $2.5 \mathrm{~kW}$ power, the highest temperature computed for the steel is $75^{\circ} \mathrm{C}$, well below the maximum allowable limit of the plug bonding sealant. The $\Delta T$ in the steel plug, both radially and axially, is negligibly small.

$\mathrm{BMB}: 5511 ; 1 \mathrm{jg}$

Copy to:

4530 R. W. Lynch ( $w / 0$ Append $i x$ )

4537 L. D. Tyler (w/o Appendix)

4537 J. K. Johnstone

4537 D. R. Waymire

5500 O. E. Jones ( $w / 0$ Append $i x$ )

5510 D. B. Hayes ( $w / 0$ Append $i x$ )

5511 D. F. McVey (w/o Appendix)

5520 T. B. Lane (w/o Appendix)

5530 w. Herrmann ( $w / 0$ Append $i x$ )

5531 L. D. Bertholf (w/o Appendix)

5531 พ. T. Brown 
A. R. Lappin - $4537 \quad-7-$

\section{References}

1. Memo, A. R, Lappin, 4537, to B. M. Bulmer, 5511, dta 12/1/78, subject: COYOTE Thermal Modeling of Tuff Heater Experiment.

2. Y. S. Touloukian and D. P. DeWitt, Thermophysical Properties of Matter, Volume ?, Thermal Radiative Properties, Metallic Elements and Alloys, IFI/Plenum, New York-Washington, 1970, p. 1217.

3. Handbook of Supersonic Aerodynamics, Vol. 5, Bureau of Ordnance, Department of the Navy, Washington, D.C., 1953.

4. J. H. Keenan and F. G. Keyes, Thermodynamic Properties of Steam, Wiley and Sons, New York, 1936.

5. D. K. Gartling, "COYOTE--A Finite Element Computer Program for Non-Linear Heat Conduction Problems," SAND77-1332, Sandia Laboratories, Albuquerque, NM, June 1978 . 
A. R. Lappin - 4537 -8-

TABLE I

TUFF HEATER THERMAL ANALYSIS

Case

Description

$1 \mathrm{~A}$

$$
\begin{aligned}
T_{\text {boil }} & =235^{\circ} \mathrm{C} \\
\epsilon_{\text {rock }} & =0.6 \\
k_{\text {rock }} & =\text { VARIABLE } \\
P & =1.25 \mathrm{~kW}
\end{aligned}
$$

IB

Same as $1 \mathrm{~A}$ except rock $=0.8$

$1 \mathrm{C}$

Same as $1 \mathrm{~A}$ except $P=2.5 \mathrm{~kW}$

ID

Same as $\mathrm{IC}$ except $k_{\text {rack }}=$ CONSTANT

2A

$\mathbf{T}_{\text {boil }}=100^{\circ} \mathrm{C}$

$\epsilon_{\text {rock }}=0.6$

$\mathrm{k}_{\text {rock }}=$ VARIABLE

$P=1.25 \mathrm{kw}$

$2 \mathrm{~B}$

Sanie as $2 \mathrm{~A}$ except $\mathrm{P}=2.5 \mathrm{~kW}$

$2 \mathrm{C}$

Same as $2 \mathrm{~A}$ except $k_{\text {rock }}=$ CONSTANT

2D

Same as $2 B$ except $k_{\text {rock }}=$ CONSTANT

(All cases assume uniform initial temperature of $18^{\circ} \mathrm{C}$.) 


\section{TABLE IT}

\section{MATERIAL PROPERTIES}

\section{Tuff}

$$
\begin{aligned}
& \rho=2360 \mathrm{~kg} / \mathrm{m}^{3}
\end{aligned}
$$

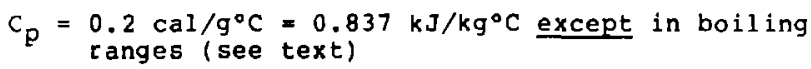

$$
\begin{aligned}
& k=\operatorname{variable}(\text { see text) }
\end{aligned}
$$

\section{Crushed Tuff}

$$
\begin{aligned}
\rho & =0.5 \rho_{\text {tuff }}=1180 / \mathrm{m}^{3} \\
\mathrm{C}_{\mathrm{p}} & =0.5 \mathrm{C}_{\mathrm{P}_{\text {tuff }}}=0.418 \mathrm{~kJ} / \mathrm{kg}^{\circ} \mathrm{C} \\
\mathrm{k} & =1 \mathrm{w} / \mathrm{m}^{\circ} \mathrm{C}=86.40 \mathrm{~kJ} / \mathrm{daY}-\mathrm{m}^{\circ}{ }^{\circ} \mathrm{C}
\end{aligned}
$$

Steel Plug

$$
\begin{aligned}
\rho & =7817 \mathrm{~kg} / \mathrm{m}^{3} \\
\mathrm{C}_{\mathrm{p}} & =0.460 \mathrm{~kJ} / \mathrm{kg}^{\circ} \mathrm{C} \\
\mathrm{k} & =10 \mathrm{Btu} / \mathrm{hrft}+\mathrm{F} \text { (mean value) }=1494.4 \mathrm{~kJ} / \mathrm{day}-\mathrm{m}-{ }^{\circ} \mathrm{C}
\end{aligned}
$$

\section{Heater}

$$
\begin{aligned}
\rho= & 7817 \mathrm{~kg} / \mathrm{m}^{3} \text { (based on estimated mass of } 441 \mathrm{bm} \text { and } \\
\text { total heater volume) } & \\
\mathrm{C}_{\mathrm{p}}= & \mathrm{C}_{\mathrm{p}_{\text {steel }}}=0.460 \mathrm{~kJ} / \mathrm{kg}^{\circ} \mathrm{C} \\
\mathrm{k} & =\mathrm{k}_{\text {steel }}=1494.4 \mathrm{~kJ} / \mathrm{day}-\mathrm{m}-{ }^{\circ} \mathrm{C}
\end{aligned}
$$

Air Gap, Air Void

$$
\begin{aligned}
\rho & =\rho_{\mathrm{air}}=i .20 \mathrm{~kg} / \mathrm{m}^{3} \\
\mathrm{C}_{\mathrm{p}} & =\mathrm{C}_{\mathrm{P}_{\mathrm{air}}}=1.01 \mathrm{~kJ} / \mathrm{kg}^{\circ} \mathrm{C} \\
k & =\text { Variable (see text) }
\end{aligned}
$$


TUFF HEATER THERMAL ANALYSIS SUMMARY

Maximum Heater Surface

Temperature Midplane, ${ }^{\circ} \mathrm{C}$

Maximum Rock Surface

Temperature Midplane, ${ }^{\circ} \mathrm{C}$

Maximum Steel Temperature, ${ }^{\circ} \mathrm{C}$

Maximum Radial Penetration of Boiling Front a Midplane, Inches (Measured from

Centerline)

Maximum Axial Penetration of Boiling Front Along Axis, Inches (Measured from Top of Heater)

\footnotetext{
"No boiling occurs.
}

(All cases assume uniform initial temperature of $18^{\circ} \mathrm{C}$. )

1

144

TABLE III

$7 \quad 15$ 

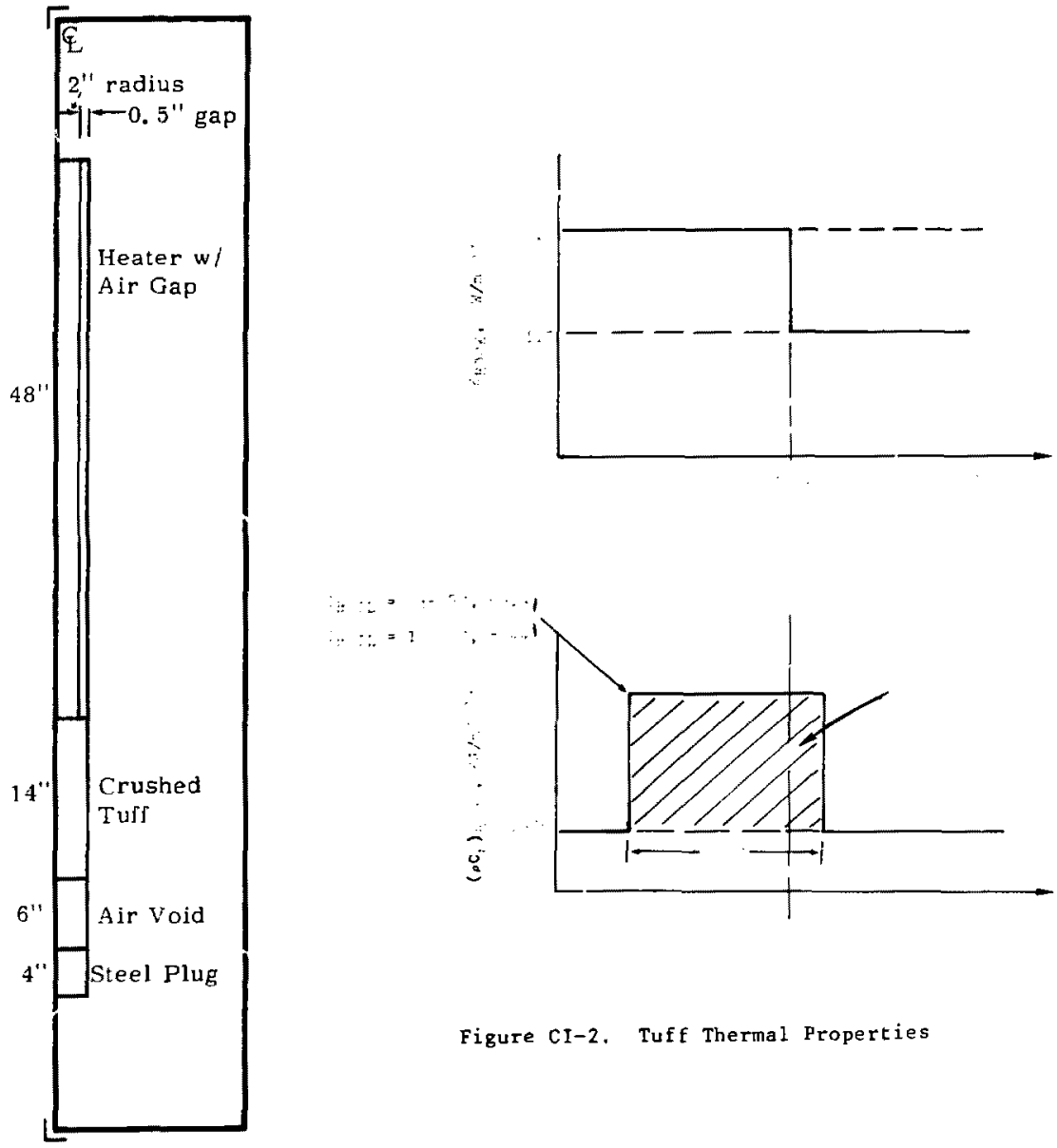

Figure CI-2, Tuff Thermal Properties

Figure CI-1. Heater Assembly (Conceptual) 


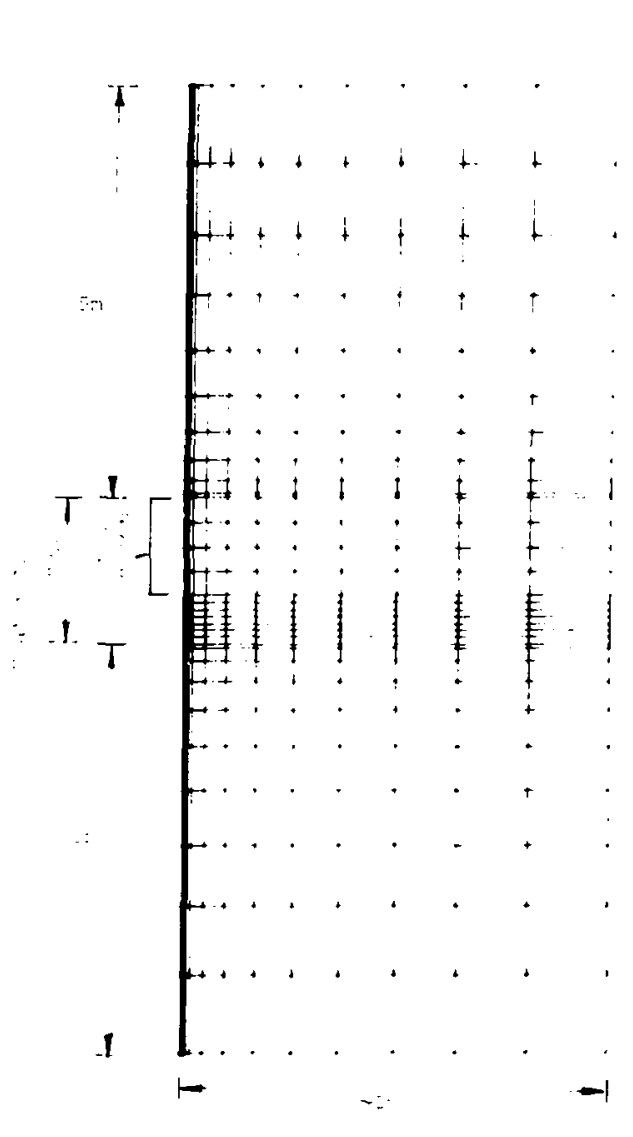

Figure CI-3. Coyote FE Thermal Model

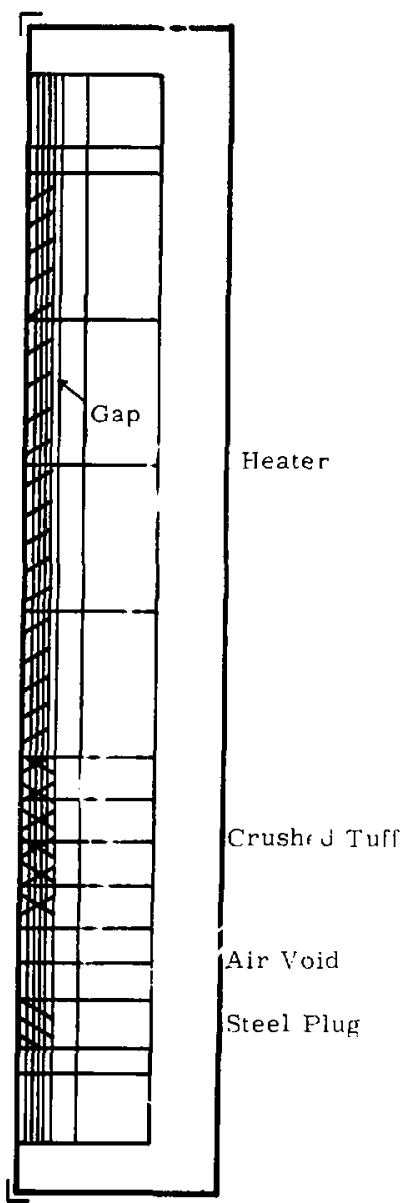

Figure CI-4. Thermal Model Detail 


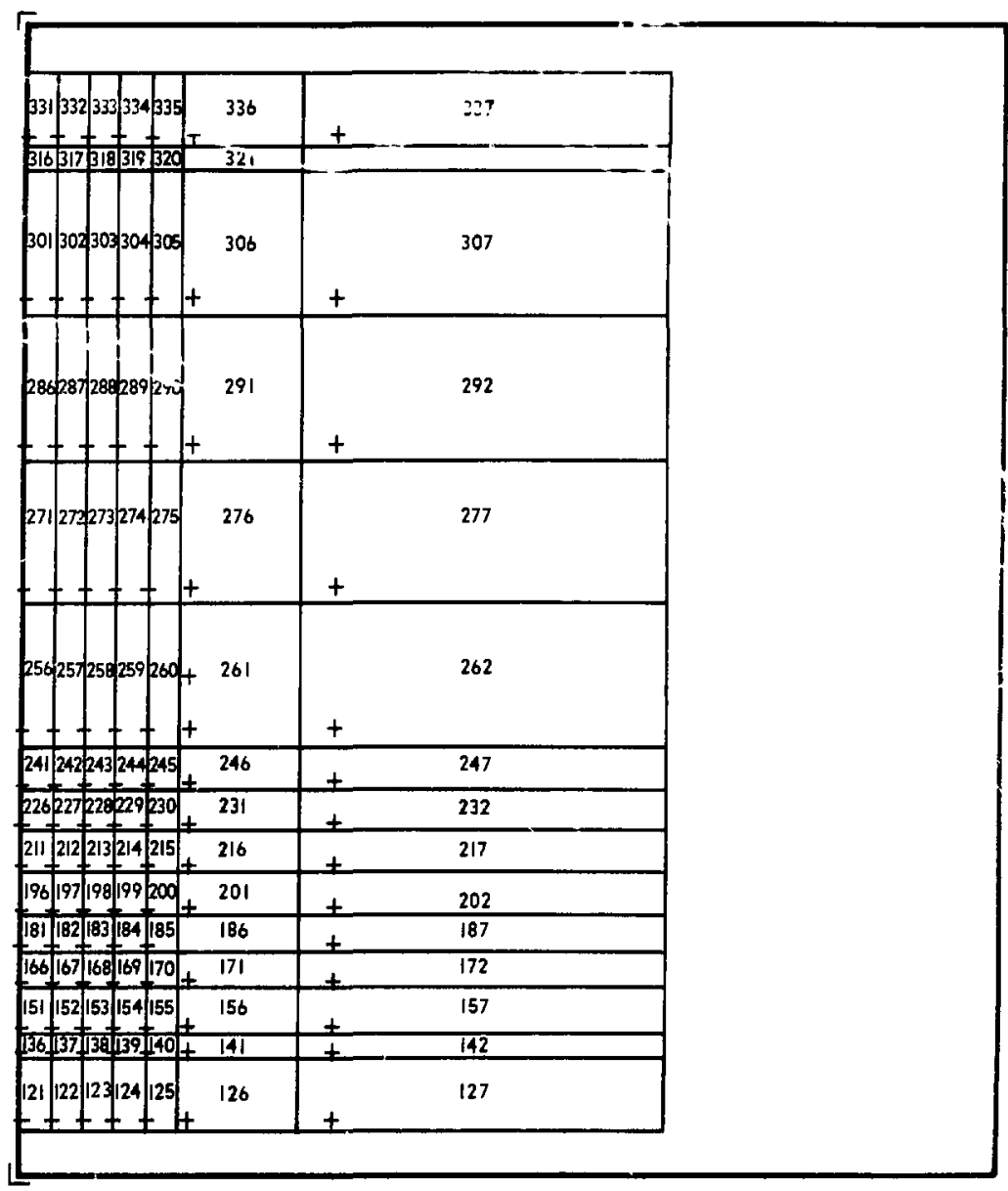

Figure CI-5. Elements ( $5 \times$ kiadial) 


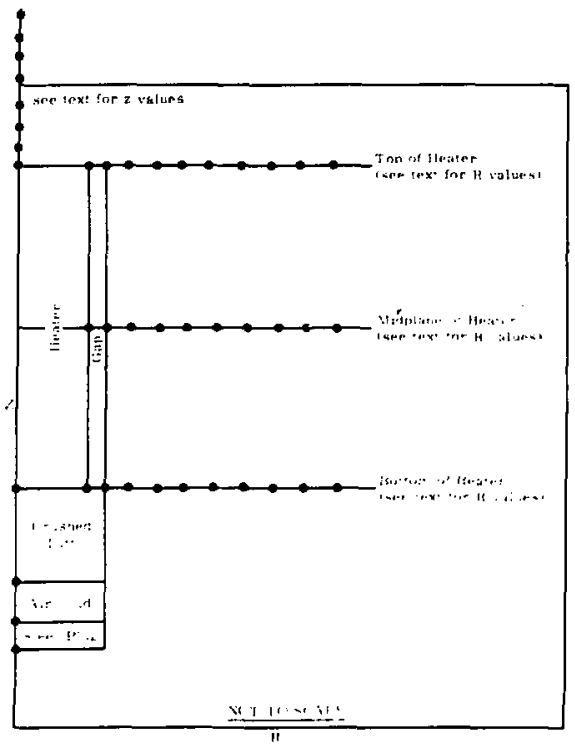

Figure CI-6. Temperature History Plot Locations 

s.
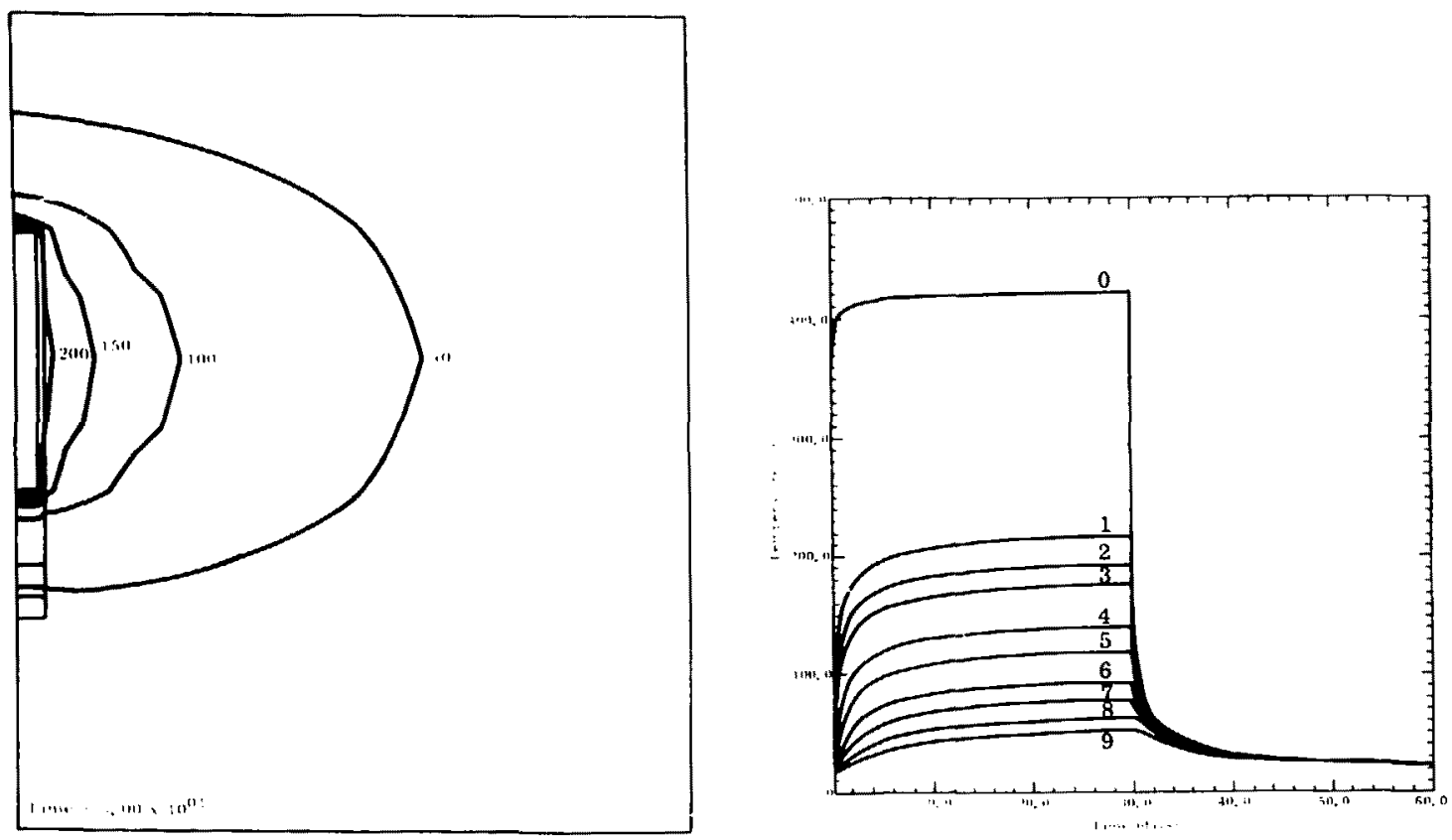

Fipurv (:1A-R. Case 1A, 30 Days

Figure Cla-10. Case IB Radial, Midplane of Heater 


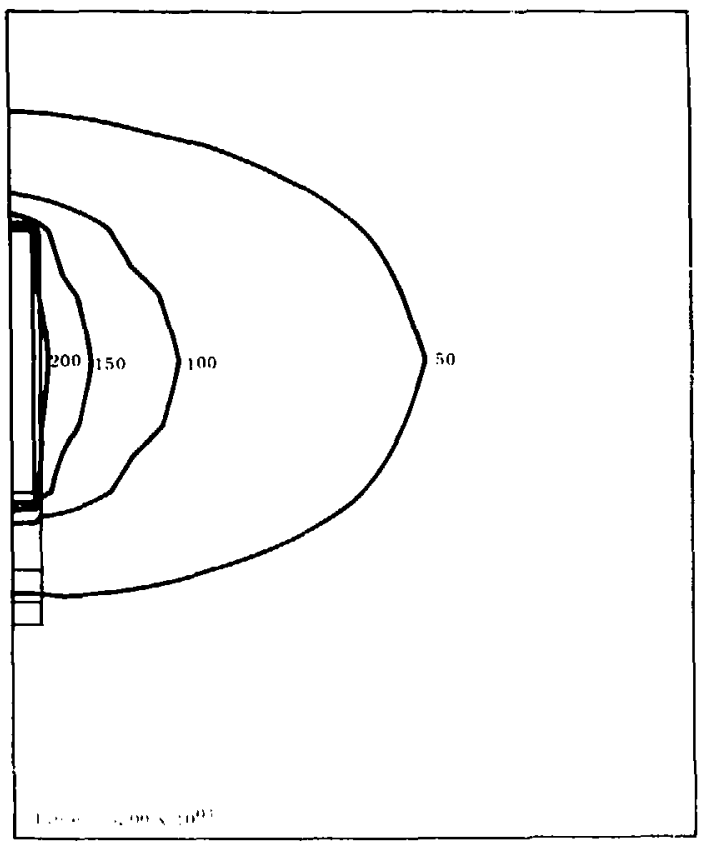

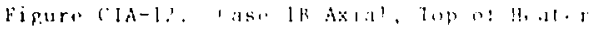

Figure Cin-16. Case lB, 30 Days

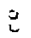




$$
\text { 直国 }
$$





$$
\text { 目D }
$$




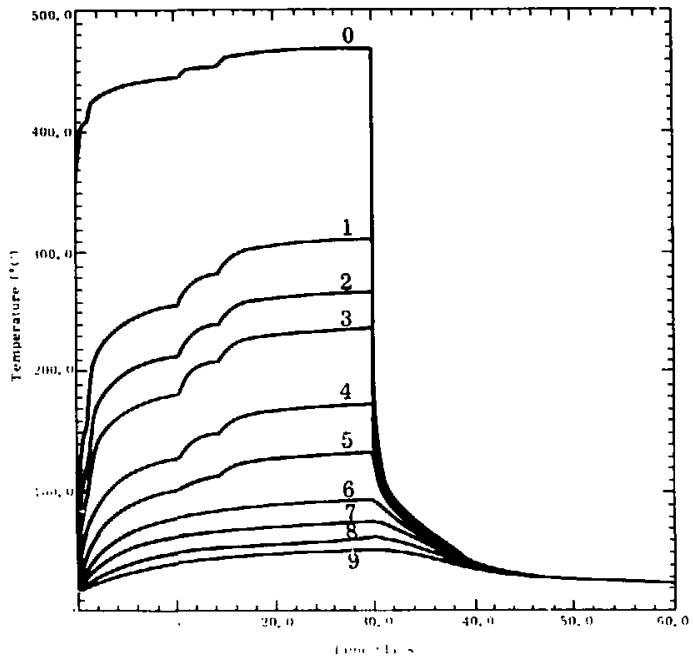

Figure ClA-34. Case $2 \mathrm{~A}$ Radial, Midplane of Heater

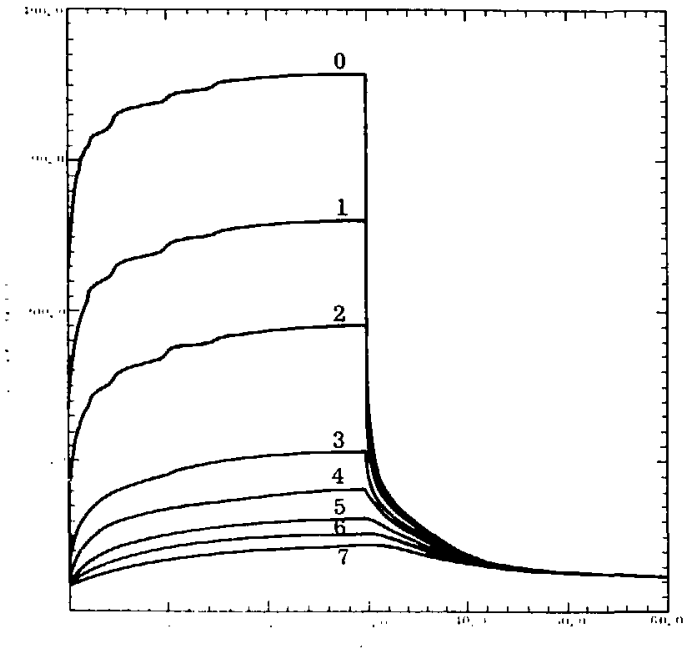

Figure CIA-36. Case 2A Axial, Top of Heater

$\underset{v}{q u}$ 
$\stackrel{0}{0}$

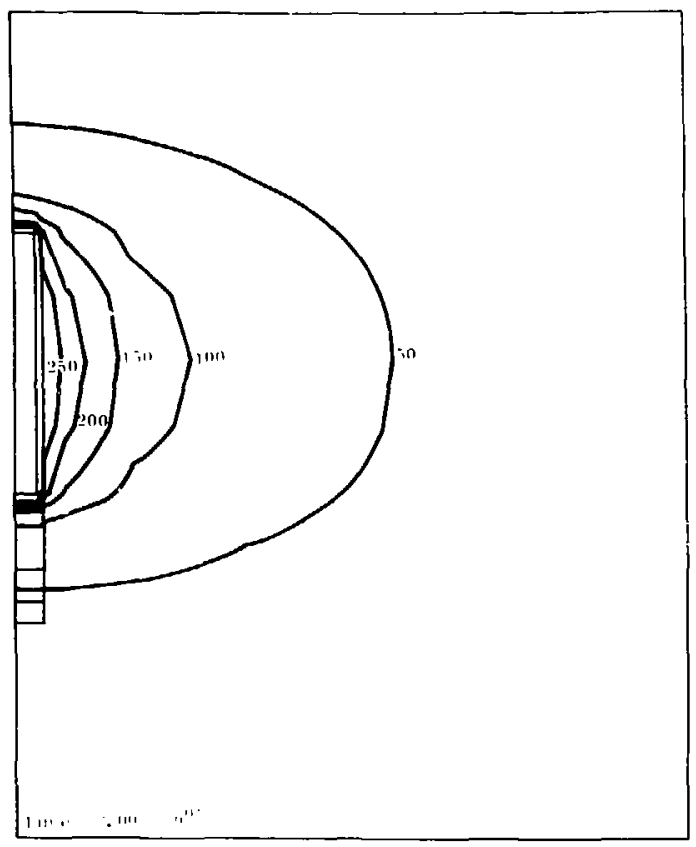

Figure CIA -40. Case $2 A, 30$ Days

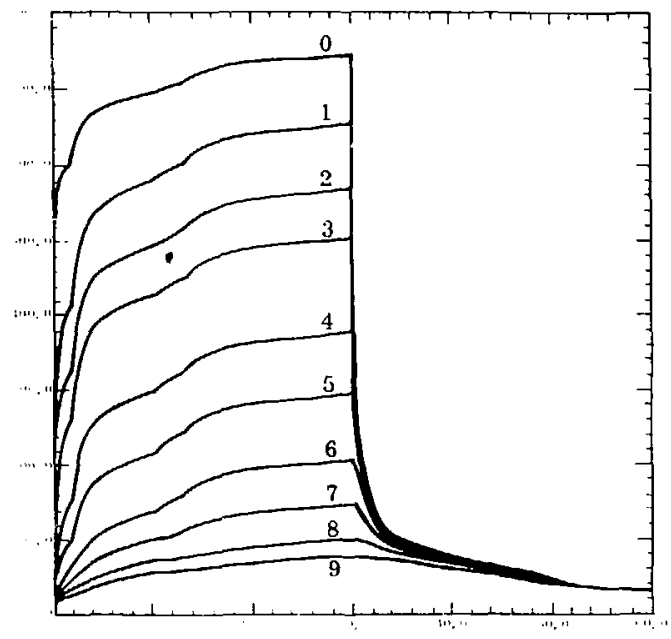

Figure $\mathrm{C}: \mathrm{A}-42$. Case 28 Radial, Midplane of Heater 



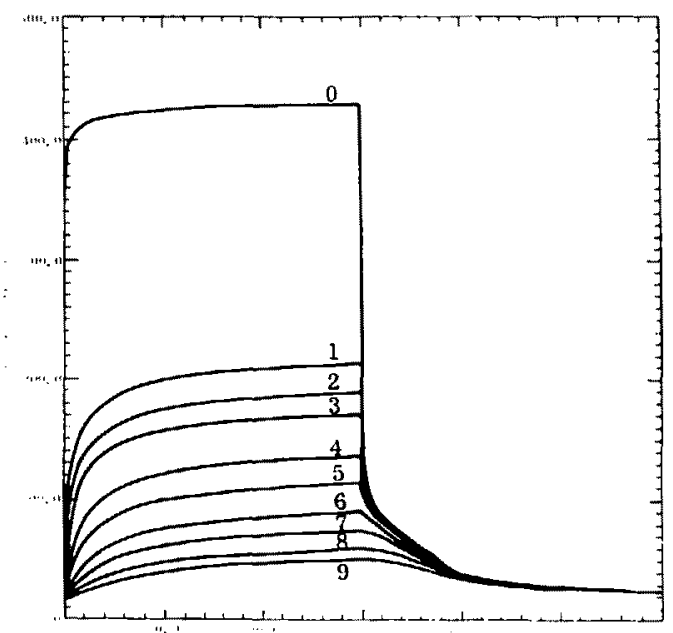

Figure CIA-50. Case 2C Radial, Midplane of Heater

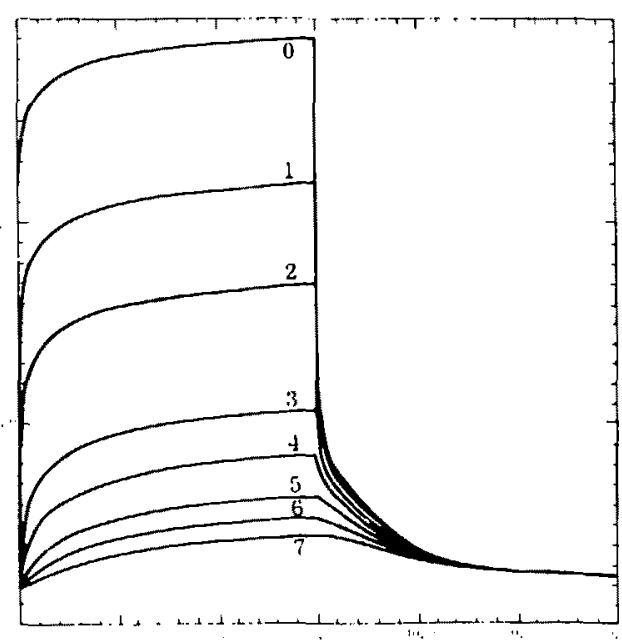

Figure CIA-52. Casp $2 C \mathrm{Axial}$, Top of Heacer 


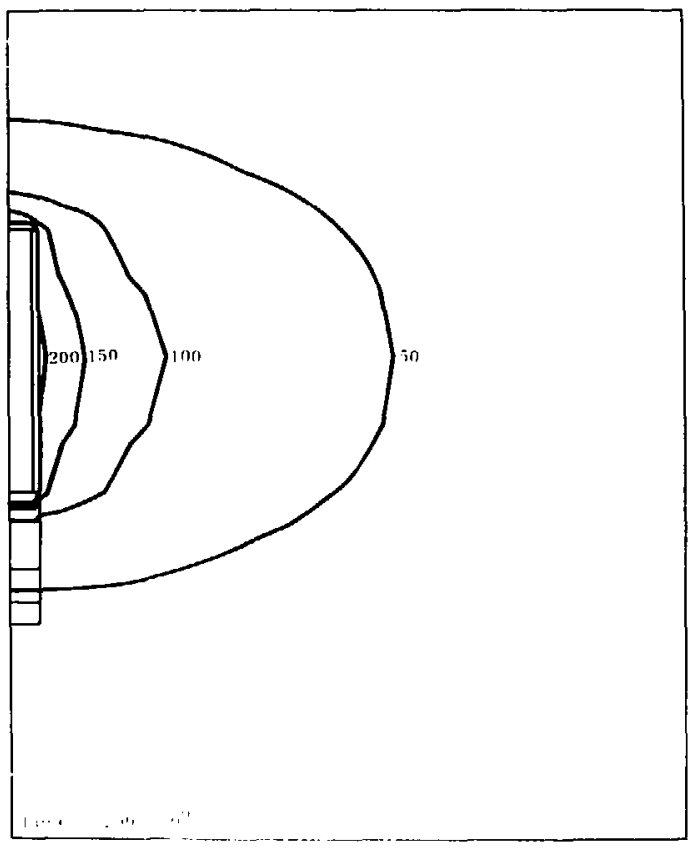

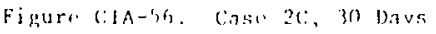

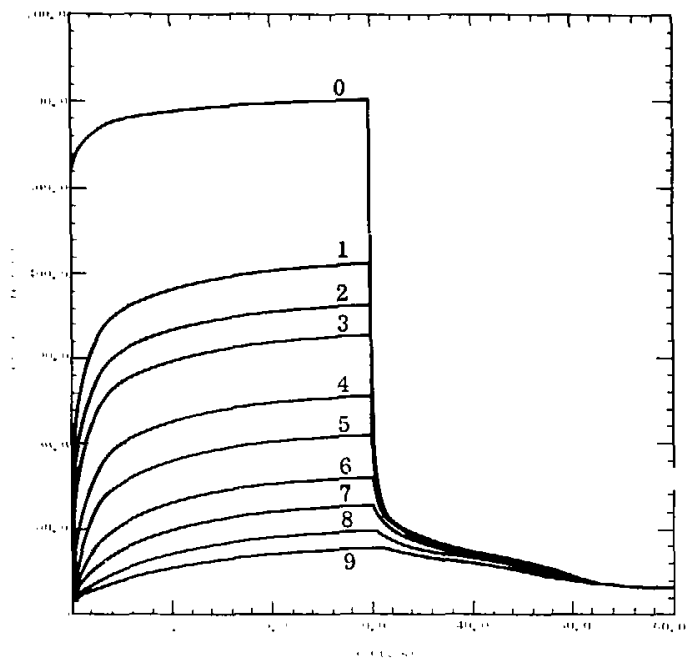

Figure CIA-58. Case 2D Radial, Midplane of Heater

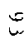



date: February 23, 1979

to A. R. Lappin -4537

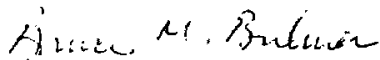

from. B. M. Bulmer - 5511

\section{Sandia Laboratories}

Albuquerque. New Mexico

Livermore. Californa

\section{subfect Additional Thermal Analyses for Tuff Heater Experiment}

Ref: Memo, B. M. Bulmer, 5511, to A. R. Lappin, 4537 dtd 2/14/79, subject: Thermal Analysis of Tuff In-situ Heater Experimen+

Two additional numerical (COYOTE) cases have been Iun for the tuff in-situ heater experiment at NTS. These correspond to an intermediate power level $(1.9 \mathrm{~kW})$ with an assumed boiling temperature in the rock of $100^{\circ} \mathrm{C}$. This memo presents the details of these calculations and compares significant results with those reported previously in the reference.

The heater geometrical configuration, material properties, and all calculational procedures are identical to those discussed in the reference. The two individual cases presently considered are:

\section{Case Description}

$2 E$

$$
\begin{aligned}
\mathbf{T}_{\text {boil }} & =100^{\circ} \mathrm{C} \\
\epsilon_{\text {rock }} & =0.6 \\
k_{\text {rock }} & =\text { VARIABLE } \\
p & =1.9 \mathrm{~kW}
\end{aligned}
$$

$2 \mathrm{~F}$

$$
\text { Same as } 2 \mathrm{E} \text { except } \mathrm{k}_{\text {rock }}=\text { consTANT }
$$

Both cases assume a uniform initial temperature of $18^{\circ} \mathrm{C}$.

"Variable" rock thermal conductivity refers to a discontinuous change at dry-out from 2.2 to $1.2 \mathrm{w} / \mathrm{m}^{\circ} \mathrm{C}$ at the assumed boiling temperature of $100^{\circ} \mathrm{C}$, whereas, "constant" implies krock $=2.2$ $\mathrm{w} / \mathrm{m}^{\circ} \mathrm{C}$ everywhere. The latent heat of water is included in the rock heat capacitance in all cases. The reference contains a mr: complete description of the assumed variations in krock

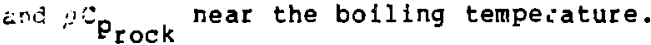



A. R. Lappin -4537
$-2-$

Detailed plotted temperatures for Cases $2 \mathrm{E}$ and $2 \mathrm{~F}$ are contained in the Appendix. Locations of the plotted temperature histories are identical to those presented earlier. As before, all contour plots are expanded $2 x$ in the radial dimension. significant thermal results are summarized in Table $I$ for Cases $2 \mathrm{E}$ and $2 \mathrm{~F}$. These include maximum computed temperatures on the heater and rock (bore hole) surfaces at the heater midplane, maximum temperature in the steel $\mathrm{pl} u \mathrm{~g}$, and maximum radial and axial penetration distances of the assumed boiling isotherm.

The intermediate power of $1.9 \mathrm{kw}$ considered in this memo permits a direct comparison with previous results (Case 2A-2D, 1.25 or $2.5 \mathrm{~kW}$ ) in terms of heater power. In Figure 1, maximum computed temperatures on the heater and rock surfaces are compared for all cases with $\mathrm{T}_{\text {boil }}=100^{\circ} \mathrm{C}$ over the range of heater power considered. Figure 2 shows the variation of maximum temperature in the steel plug with power. These maxima occur at 30 days as the heater is assumed to be shut off at that time.

As evidenced by the rock surface temperatures in Figure 1 , the assumed variation of $k(T)$ rock near boiling strongly influences the near thermal field. Measurements of rock surface $\left(R=2.5^{n}\right.$ ) temperature during the experiment should provide the best and most sensitive definition of indepth boiling in terms of its effect on rock thermal properties. Thus, it is imperative that these measurements be made as carefully and as accurately as possible. Other planned measurements at $R=16$ and $24^{\text {" }}$ will be helpful as well, but the surface measurements are the most useful data from this standpoint.

Radial temperature gradients in the rock at 30 days are compared in Figure 3 for the $\operatorname{six}$ cases with $\mathrm{T}_{\text {boil }}=100^{\circ} \mathrm{C}$. Locations of the boiling isotherm determined by these plots differ slightly ( 1-2") from those interpreted from the temperature contour plots using a variable scale as in the reference (rounded to nearest inch). The boiling isotherm penetration distances derived from the radial gradients are probably more accurate, as the computer-generated contour plots contain inaccuracies owing to code interpolation, plotter distortion, etc., in a $r e g i o n$ of relatively large radial temperature variations.

As reported in the reference, the location of the boiling isotherm is relatively insensitive to the assumptions concerning

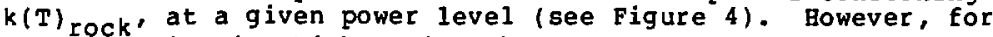
the situation in which maximum heater temperature is the limiting parameter, the assumed thermal conductivity variation at boiling will influence indirectly the penetration distance through its effect on permissible heater operating power. Consider the following: 
A. R. Lappin - $4537-3-$

Suppose, for example, the upper limit for the heater surface is $550^{\circ} \mathrm{C}$. From Figure 1, operating power levels are $1.65 \mathrm{~kW}$ ( $k_{\text {rock }}=$ VARIABLE) and $2.09 \mathrm{~kW}$ ( $k_{\text {rock }}=$ CONSTANT). In Figure 4, these power levels correspond to boiling isotherm locations of 18.3 and $22.3^{n}$, a 20 variation caused by uncertainties in rock conductivity near boiling.

BMB : $5511: 1 j g$

Copy to:

4530 R. W. Lynch

4537 L. D. Tyler

4537 J. K. Johnstone

4537 D. R. Haymire

5500 O. E. Jones

5510 D. B. Hayes

5511 D. F. McVey

5520 T. B. Lane

5530 w. Herrmann

5531 L. D. Bertholf

5531 W. T. Brown 
A. R. Lappin - 4537 -4-

TABLE I

TUFF HEATER THERMAL ANALYSIS SUMMARY

Maximum Heater Surface Temperature

a Midplane, ${ }^{\circ} \mathrm{C}$

$\mathrm{T}_{\text {bail }}=100^{\circ} \mathrm{C}$

Maximum Rock Surface Temperature

Gidplane, ${ }^{\circ} \mathrm{C}$

Maximum Steel Temperature, ${ }^{\circ} \mathrm{C}$

$\underline{2 E} \quad 2 \mathrm{~F}$

$605 \quad 524$

Maximum Radial Penetration of Bolling

Front Along Axis, inches (measured

Erom centerline)

Maximum Axial Penetration of Boiling

Front Along Axis, inches (measured

from top of heater)

$479 \quad 316$

$\begin{array}{ll}57 & 57\end{array}$

$(21) *(21)$

1110

*Determined from radial temperature gradient; all others from computer contour plots (rounded to nearest inch). 


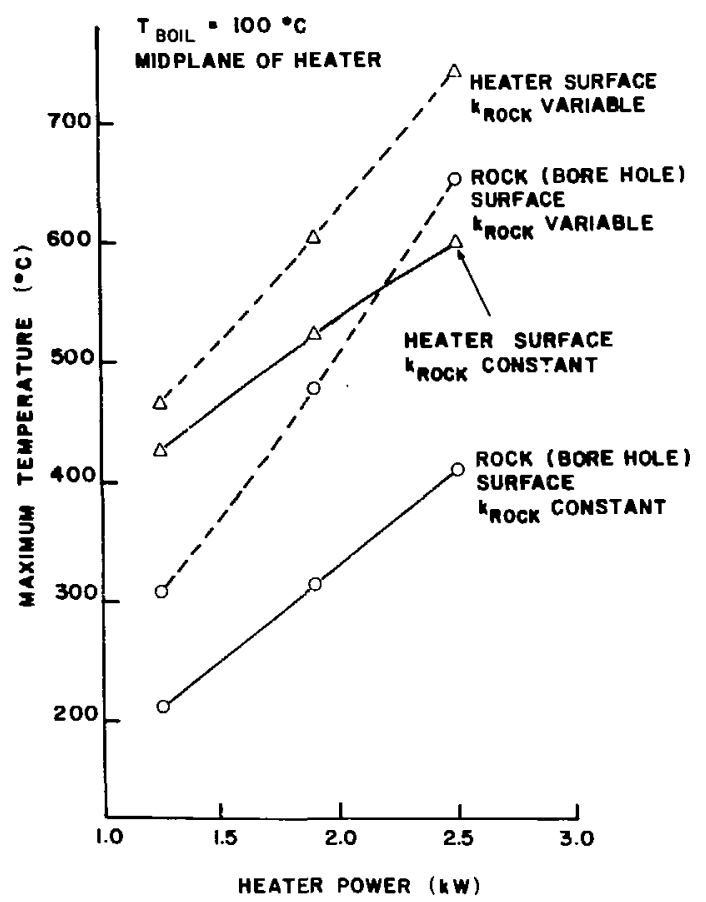

Figure CII-1. Comparison of Maximum Computed Temperature on the Heater and Rock Surfaces for All Cases Over the Range of Heater Power Considerod

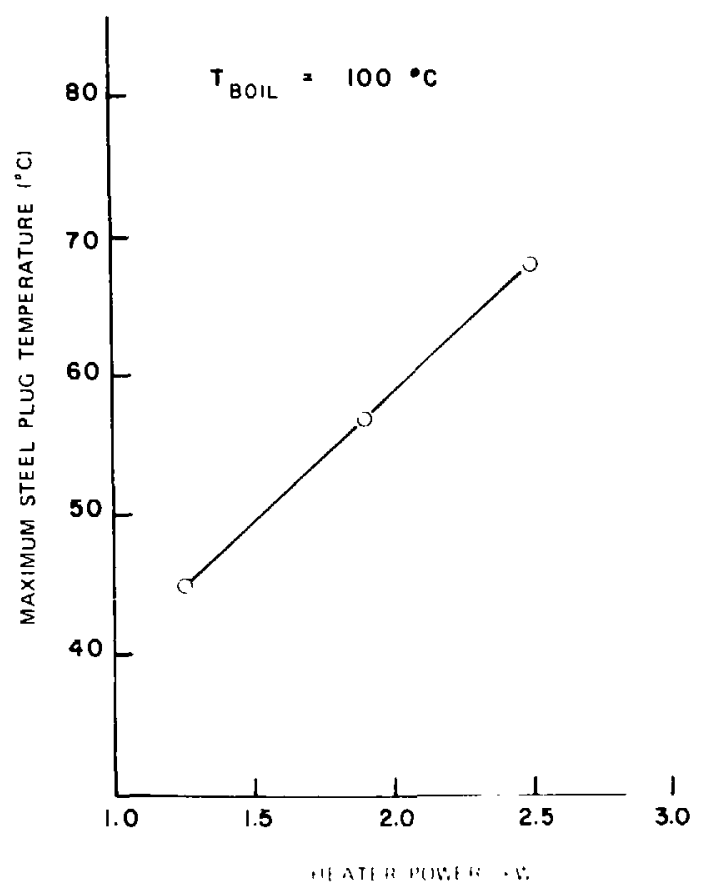

Figure cll-2. Variation of Maximum Temperature in the stal plug with Power 


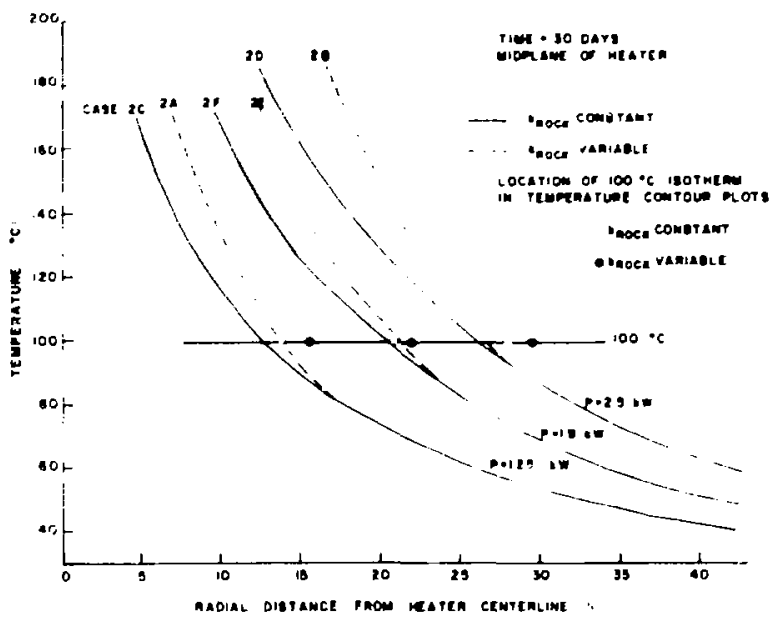

Figurr CJj-3. Comparison of Radial Temperature Gradients for all Cases at 30 Days

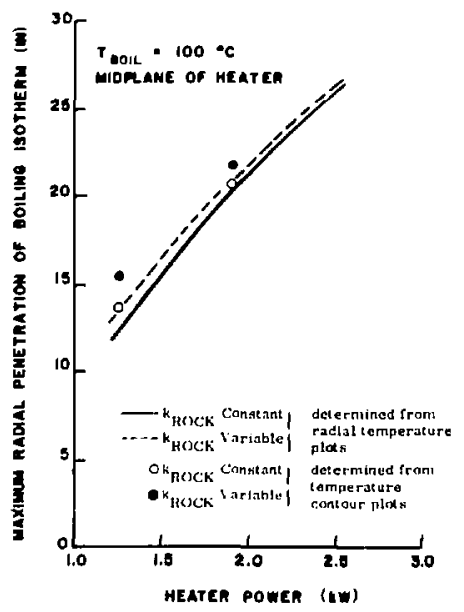

Figure CII-4. Location of the Boiling Isotherm at Given Power Levels 




$$
\text { ED }
$$




\section{Sandia Laboratories}

'sif: March 19, 1979

A. R. Lappin -4537

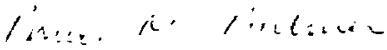

B. M. Bulmer - 5511

Tuff In-situ Heater Experimnnt Rock Thermal Conductivity sensitivity study

Additional heat conduction (COYOTE) analyses have been porformed at your request for several assumed rock thermal condurtivity variations for the tuff hearer experiment. This study stems from the uncertainty in initial 1100 z water saturater) rock thormal condictivity in G-tunnel, wTs, I and its impact on heater design requirements and experimental test objectives.

The present analysis was conducted with an intermediate heater power level of $1.9 \mathrm{~kW}$ ant an assumed boiling tamperature in the rock of $160^{\circ} \mathrm{C}$. The heater geometrical configuration, material properties (with the exception of tuff thermal conductivity), and all calculotional procedures are identical to those discussod in Reference 2. Individual cases considered presently are described below:

Case Description

26

$T_{\text {boil }}=100^{\circ} \mathrm{C}$

$\epsilon_{\text {rock }}=0.6$

$k_{\text {rock }}=$ VARIABLE $= \begin{cases}1.7 & \mathrm{~W} / \mathrm{m}^{\circ} \mathrm{C} ; \mathrm{T} \leq \mathrm{T}_{\text {boil }} \\ 1.2 \mathrm{~W} / \mathrm{m}^{\circ} \mathrm{C} ; \mathrm{T} & \mathrm{T}_{\text {boil }}\end{cases}$

$P=1.25 \mathrm{~kW}$

2H

Same as $2 \mathrm{G}$ except:

$k_{\text {rock }}=$ VARIABLE $= \begin{cases}2.7 \mathrm{~W} / \mathrm{m}^{\circ} \mathrm{C} ; \mathrm{T} \leq \mathrm{T}_{\text {boil }} \\ 1.2 \mathrm{~W} / \mathrm{m}^{\circ} \mathrm{C} ; \mathrm{T}>\mathrm{T}_{\text {boil }}\end{cases}$

$2 I$ Same as $2 G$ except:

$k_{\text {rock }}=$ CONSTANT $=1.7 \mathrm{~W} / \mathrm{m}^{\circ} \mathrm{C}$

$2 J$ Same as $2 \mathrm{H}$ except:

$k_{\text {rock }}=$ CONSTANT $=2.7 \mathrm{w} / \mathrm{m}^{\circ} \mathrm{C}$ 
A. R. Lappin-4537 -2-

All cases assume a uniform inttial temperature of $18^{\circ} \mathrm{C}$. The latent heat of water is included in the rock heat capacitance near boiling (see Reference 2 for a complete description).

Note that in the previous analyses 2,3 "variable" rock thermal conductivity refers to a discontinuous change at dry-out from 2.2 to $1.2 \mathrm{~W} / \mathrm{m}^{\circ} \mathrm{C}$ at the assumed boiling tamperature, whereas "constant" implies $k_{\text {rock }}=2.2 \mathrm{w} / \mathrm{m}^{\circ} \mathrm{C}$ everywhere. The present results thus bound (within a reasonable uncertainty) the anticipated total saturation value and provide a basis for comparison with previous results. Assumed variations in $k(T)$ rock are summarized ín Figure 1; included are Cases $2 \mathrm{E}$ and $2 \mathrm{~F}$ for $1.9 \mathrm{~kW}$ reported in Reference 3 .

Detailed plotted temperatures for Cases $2 \mathrm{G}-2 \mathrm{~J}$ are contained in the Appendix. Locations of the plotted temperature histories are identical to those presented earlier, and, as before, all contour plots are expanded $2 x$ in the radial dimension. Significant thermal results are summarized in Table I for Cases 2G-2.J. These include maximum computed temperatures on the heater and rock (bore hole) surfaces at the heater midplane, maximum temperature in the steel plug, and maximum radial and axial penetration distances of the assumed boiling isotherm.

The rock thermal conductivities assumed herein permit a direct comparison with previous results (Cases $2 \mathrm{E}$ and $2 \mathrm{~F}$ ). In Figures 2 and 3, maximum computed temperatures on the heater and rock surfaces and in the steel plug are compared at 30 days (time of power shutoff) for $\mathrm{T}_{\text {boil }}=100^{\circ} \mathrm{C}$ and $\mathrm{P}=1.9 \mathrm{~kW}$. For the "variable" krock runs, the "reference" thermal conductivity used as the abscissa refers to the 1008 saturated value assumed for $T \leq T_{\text {boil }}$ (see Figure 1 ).

Radial temperature gradients in the rock at 30 days are compared in Figure 4; results for Cases $2 \mathrm{E}$ and $2 \mathrm{~F}$ near $\mathrm{T}_{\text {boil }}$ are included for comparison. As noted in Reference 3, locations of the boiling isotherm determined by these plots differ slightly $\left(\sim 1-2^{n}\right)$ from those interpreted from the temperature contour plots using a variable scale. The boiling penetration distances derived from the radial gradients are considered to be more accurate.

The location of the boiling isotherm (Figure 5) is sensitive to the thermal conductivity chosen for saturated rock. However, the assumed variation at dry-out (i.e., "constant" versus "variable") has little effect for a given power level.

BMB : $5511 ; 1 j g$ 
A. R. Lappin - $4537-3-$

Copy to:

4530 R. W. Lynch ( $w / o$ Append $i x$ )

4537 L. D. Tyler (w/o Appendix)

$4537 \mathrm{~J}$. K. Johnstone

4537 D. R. Waymire

5500 O. E. Jones (w/o Append $i x$ )

5510 D. B. Hayes ( $w / 0$ Appendix)

5511 D. F. McVey (w/o Appendix)

5520 T. B. Lane ( $w / o$ Append $i x$ )

5530 W. Herrmann ( $w / 0$ Append $i x$ )

5531 L. D. Bertholf ( $w / 0$ Appendix)

5531 W. T. Brown 
A. R. Lappin - 4537

\section{References}

1. Memo, A. R. Lappin, 4537, to B. M. Bulmer, 5511, dtd 3/7/79, subject: Additional Thermal Modeling for Tuff Heater Experiment, Part II.

2. Memo, B. M. Bulmer, 5511, to A. R. Lappin, 4537, dta 2/14/79, subject: Thermal Analysis of Tuff In-Situ Heater Experiment.

3. Memo, B. M. Bulmer, 5511, to A. R. Lappin, 4537, dtd 2/23/79, subject: Additional Thermal Analyses for Tuff Heater Experiment. 
A. R. Lappin - 4537 -5-

TABLE I

TUFF HEATER THERMAL ANALYSIS SUMMARY

$\mathrm{T}_{\text {boil }}=100^{\circ} \mathrm{C}$

Maximum Heater surface

Temperature (a) Midplane, ${ }^{\circ} \mathrm{C}$

Maximum Rock Surface

515

Temperature Midplane, ${ }^{\circ} \mathrm{C}$

$2 \mathrm{G}$

627

Maximum steel

Temperature, ${ }^{\circ} \mathrm{C}$

Maximum Radial Penetration of Boiling Front a Midplane, inches (measured from center 1 ine)

Maximum Axial Penetration of Boiling Front Along

Axis, inches (measured from top of reater)

\section{3}

27

(25) *

14

$2 \mathrm{H}$

587

448

53

19

(18)*

8

13

8

ॠ Determined from radial temperature gradient; all others from computer contour plots (rounded to nearest inch). 


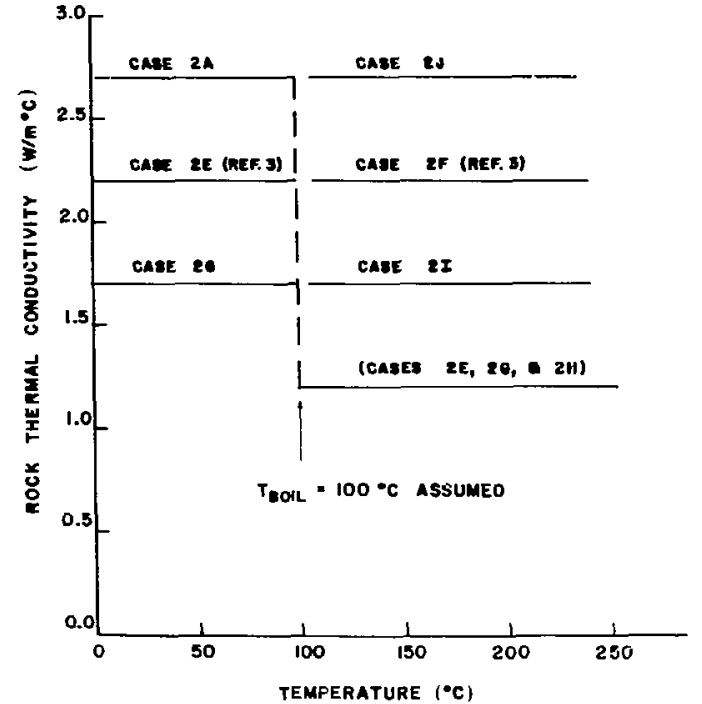

Figure CIII-1. Summary of Variat $1 \ldots$ in $k(T)$ rock

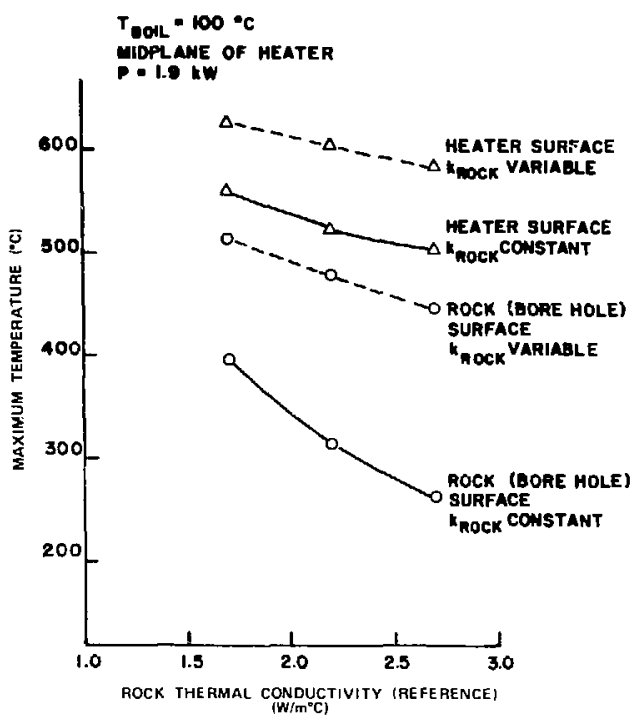

Figure CIII-2. A Comparison of Maximum Computed Temperatures on the Heater and Rock Surfaces ot 30 Days 


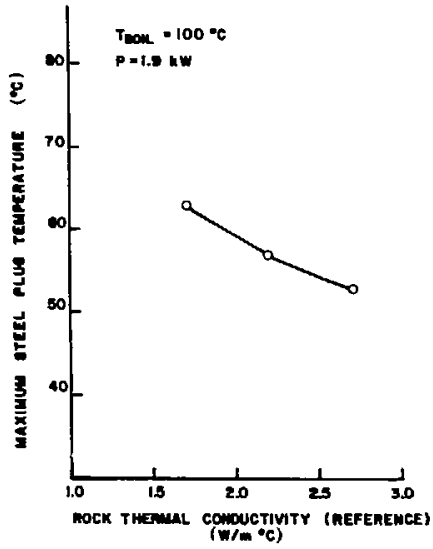

Figure CIII-3. A Comparison of Maximum Computed Temperatures on the Steel Plug and the Rock Surfaces at 30 Days

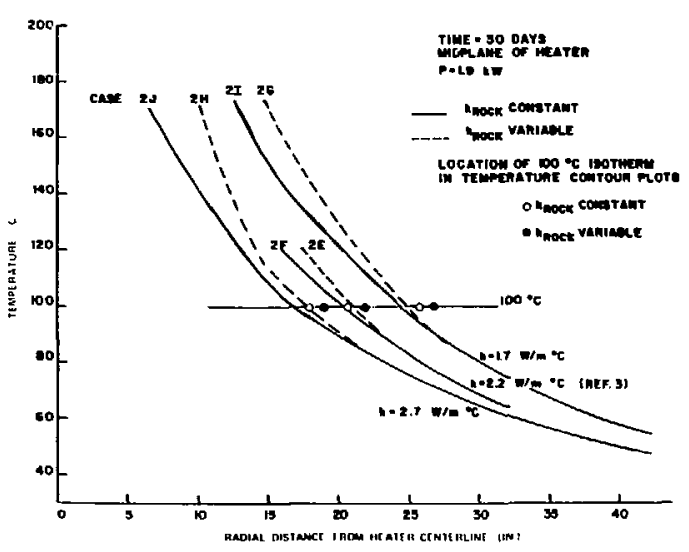

Figure CIII-4. A Comparison of Radial Temperature Gradients for all Rock at 30 Days 
$T_{\text {DOIL }} \cdot 100^{\circ} \mathrm{C}$

morlane of meater

$P=1.0 \mathrm{~kW}$

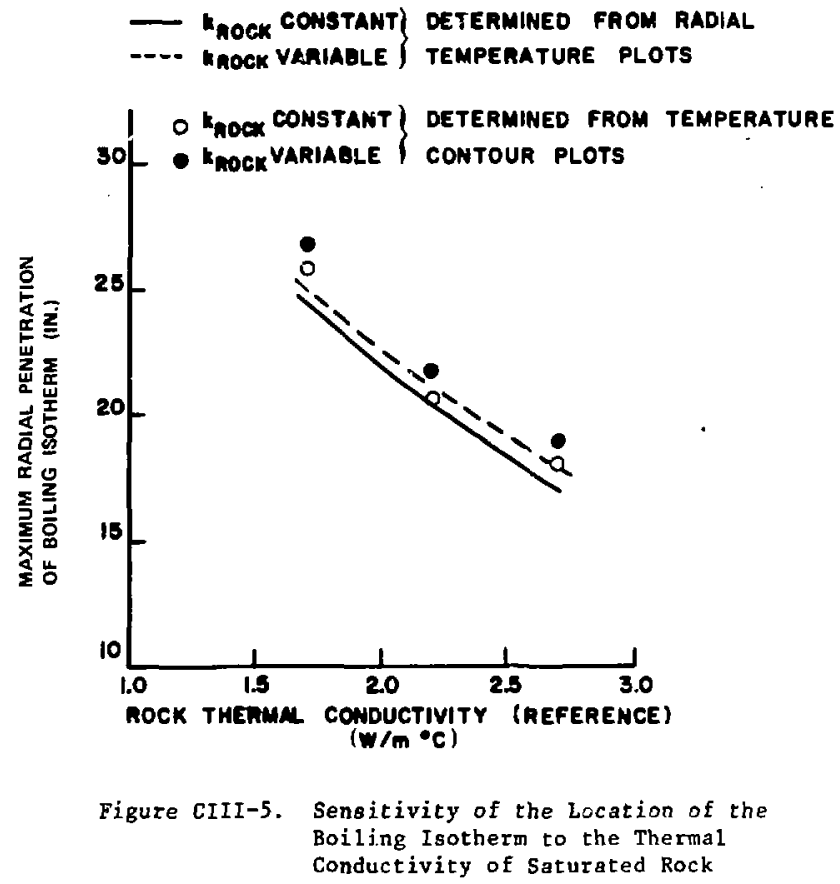




\section{APPENDIX}

Notes:

(1) See Test of CI for plot locations of temperature histories.

(2) Contour plots are expanded $2 \times$ radial; see Reference 2 for details. 


$$
\text { 国 }
$$


$\underset{\infty}{*}$

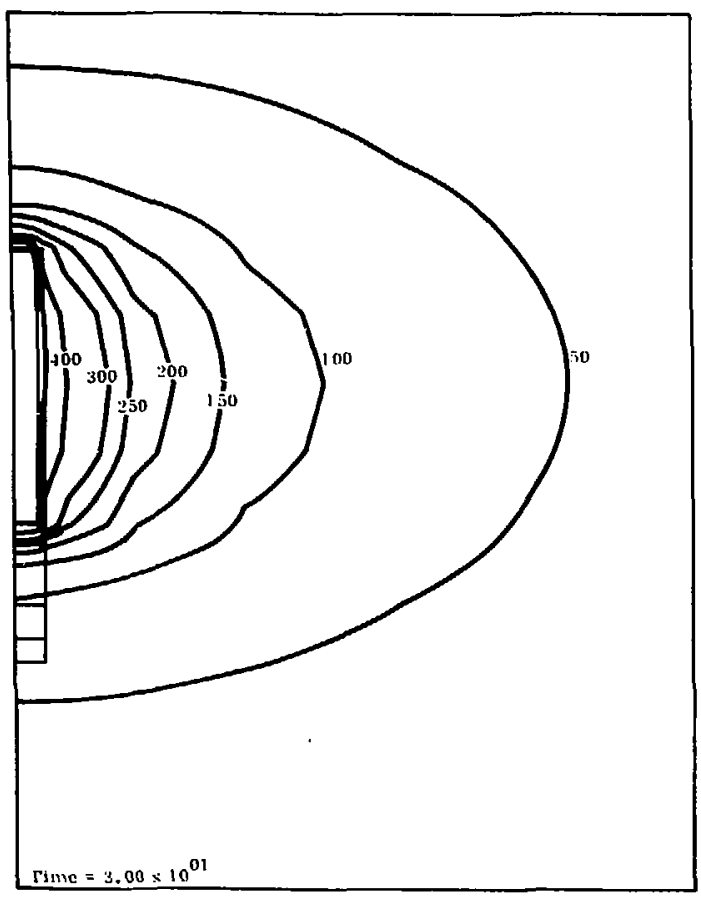

Figure CIIIA-8. Case 2G, 30 Days

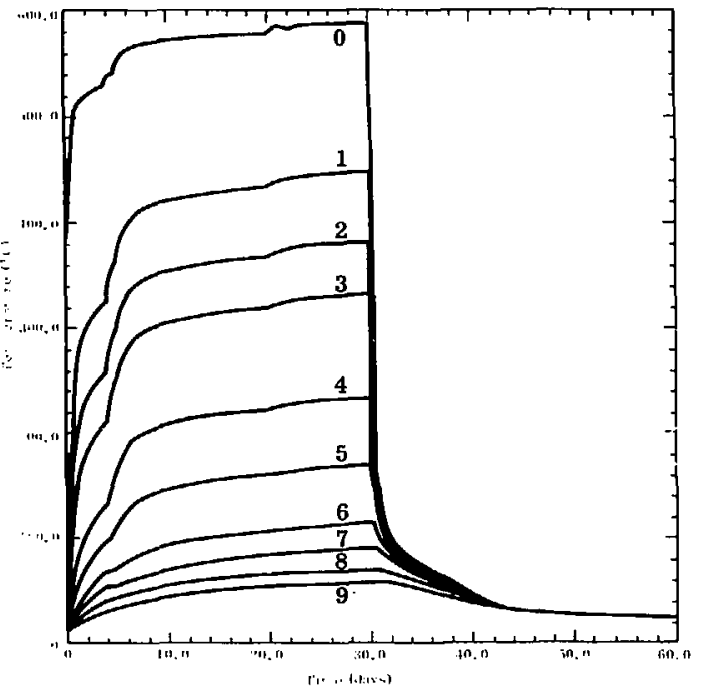

Figure CIIIA-10, Case 2H Radial, Midplane of Heatar 


$$
\text { 目D }
$$




$$
\text { 国 }
$$




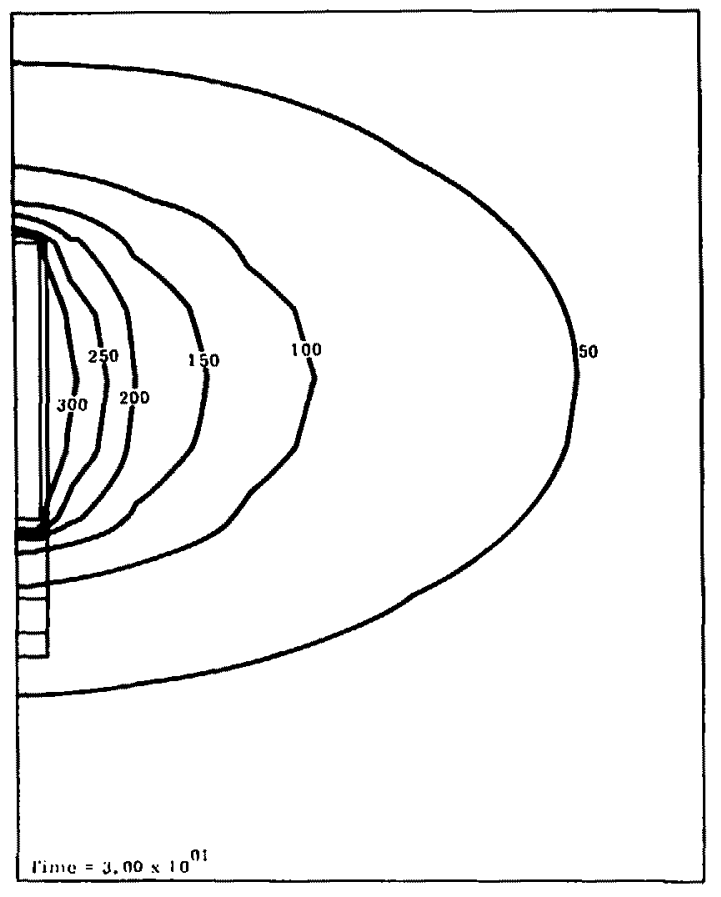

Figure CIIIA-24, Case 21, 30 Days

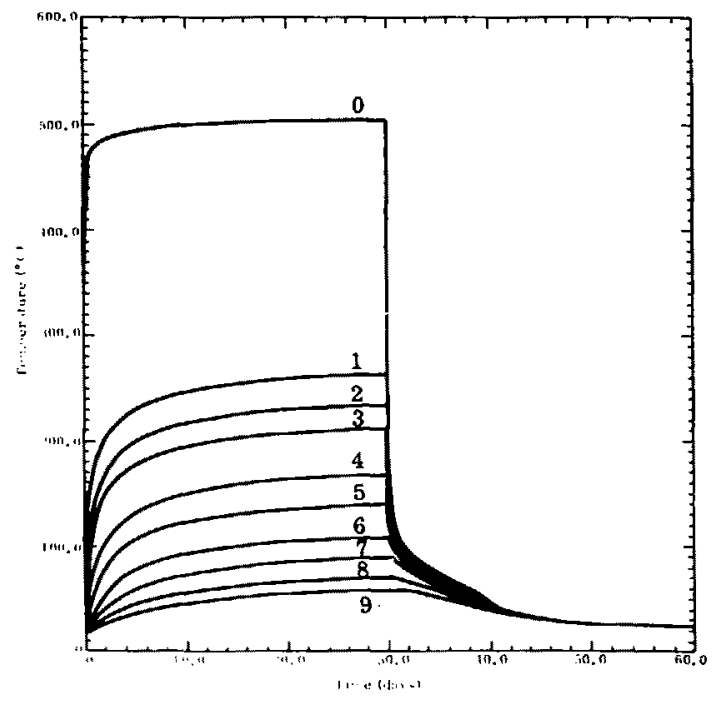

Figure CIIIA-26, Case 2J Radial, Midplane of Heater

$\Xi$ 



\title{
Sandia Laboratories
}

\author{
date: JUN $(1, \%$ \\ 10: J. K. Johnstone -4537
Wili - T. Brawn
from: W. T. Brown - 5531

Albuquerque. New Mexico

Livermore, Californa

subjecl: Thermomechanical Analysis of Tuff In-S1tu Heater Experiment

The flrst phase of the thermamechanteal analysis of the Tuff In-Situ Heater experiment has been completed. The major objectives of this modeling effort were:

1. To determine optimum locations for stress and displacement instrumentation.

2. To determine the extent to which the presence of the access tunnel and alcove perturbs the 1n-situ stresses in the experimental region.

3. To determine the perturbation of in-situ stresses in the vicinity of the heater due to the presence of the heater bole and the instrumentation holes.

Only Item 1 is treated in this memo; the other two items will be covered in a later memo.

Several two-dimenslonal, finite-element calculations were done with MARC to model the reapunse of welded tuff to a heat source. The models represent the best attainable approximations to the situation expected to exist in the planned heater experiment in welded tuff at the Nevada Test Site. The details of the heater configuration are discussed in Reference 1 , and the assembly has been represented schematically in Reference 2. That schematic representation hes been reproduced in Flgure 1 with the basic features of the assembly 1dentlfied. In the modeling of the mechanical response, the a1r gap and air vold were included in the calculation. The regions containing crushed tuff and the steel plug were not treated in any detail. Their properties were assumed to be identical to those of the welded tuff. Th1s 18 adequate because the response in those regions will not be important.

The modeling of the mechanical reaponse was done in a manner that is consistent with the thermal response calculations for the same configuration (Reference 2). Those calculations treated a heater operating at a constant power level for 30 days followed by a cool-down oerlod of 30 days. A total of eleven different cases were considered in modeling the thermal behavior. These different cases allowed for variations in power levels, as aumed bolling temperature for in-situ water, varlations in rock thermal conductivity $(K)$ and verlations in $\in m i s s i v i t y ~(\epsilon)$ of the rock. of these cases, 
only twc were considered in the mechantcal response calculations. The cases, as identifled in Table I of Reference 2, were:

$$
\text { Case 1D } \begin{aligned}
\mathrm{T}_{\text {boll }} & =235^{\circ} \mathrm{C} \\
\epsilon_{\text {rock }} & =0.6 \\
\mathrm{~K}_{\text {rock }} & =\text { coNSTANT } \\
\mathrm{F} & =2.5 \mathrm{~kW} \\
\text { Case 2A } \quad \mathrm{T}_{\text {boll }} & =100^{\circ} \mathrm{C} \\
\epsilon_{\text {rock }} & =0.6 \\
\mathrm{~K}_{\text {rock }} & =\text { VARIABLE } \\
\mathrm{P} & =1.25 \mathrm{~kW}
\end{aligned}
$$

These two calculations considered the two extremes of heater power levels and bolling tenperatures that were treated in the thermal calculations. The temperature flelds calculated frum the thermal modeling were used as Input, as a function of time, for the wechenical reoponse calculations.

The planned heater experiment will include two separate sets of instrumentation for messuring stresses and displacements. A hole will be drilled parellel to the heater centerlene to allow for atreas mesourements. The otress gauge, a currently planned, will be oltuated to obtaln the radial atress component and atresa component normal to this. The gauge will be approxdmately in the heater midplane; the distance of the gauge from the centerilne is a parameter to be determined from these calculations. The displacements will be messured with a laser interferometer by placing a mirror in-situ to obtain redial displacements of the rock in a coordinate oyotem which has cylindrical symistry about the centerline of the heater.

The finite-element mesh used for these celculations is show in Figure 2. It is Identical with the mesh used in the modeling of the themal response. The boundary conditions are all taken as zero displacement. The experiment y1ll take place at a depth of about 400 meters. The zero displacement conditions on the other boundariea simulate the confining effects of the surrounding rock mass. The actual in-situ stresses due to an overburden and a gravity load on the material in the calculation region were not applied as boundary conditions or body forces. The response of the tuff 1s purely elastic, and, thus, the only devlations from in-situ stresses are due to thermolastic effects. The ambient, 1n-situ stresses will be used as a baseline for the stress gauge; thus, it is adequate to ignore the streases due to overburdens and body forces. 
The properties used for the tuff were values that ar: appropriate to the depth of the experiment. They were Benerated at a coufining pressure of about $20 \mathrm{MPa}$. The values used were;

$$
\begin{array}{ll}
\text { Young's Modulus }^{3} & 31.0 \mathrm{GPa} \\
\text { Polsson's Ratio }^{3} & 0.25 \\
\begin{array}{l}
\text { Thermel Expension } \\
\text { Coefficlent }
\end{array} & 1.2 \times 10^{-5} /{ }^{\circ} \mathrm{C} \\
\text { Density } &
\end{array}
$$

Because of the requirements of the experiment, the important results to be obtained from the calculations are radial stresses, circumferential stresses and radial displacements. The results are presented in two forms. Each of the above quantities are plottei et several radial locations, near the heater midplane, as a function of time. In addition, contours of corstant stress have been generated at several selected times durizg the heating 1nterval of 30 days. The historles of the radial stresses are show in Flgures 3 through 11 . for both of the cases considered. Figures 12 through 21 show similar historles for circumferential stresses and the radial displacements are presented in Figures 22 through 29. The jumps that occur in the plots of the varlous hlatories are due to the fact that the time axis is not uniform. In adation, the calculation which uses a variable themal conductivit; (Case 2A) shows findte tempereture jumps (see Reference 2). The cortours are shown at selected times in Figures 30 to 47 . When the stresser and displacements are examined, the calculated results are well wthin Lingurotie ranges within a distance of about 1 meter from the heater centerline. For the cases with the higher power level (Case 10$)$, the atresses and displacements are measurable beyond 1 meter. The other restriction placed upon instrumentation locations is the temperature fleld. The gauges should be far enough from the heater to insure that temperatures do not exceed operating temperatures.

Calculations were considered which treated the boundary conditions of the problew with stresses that are more appropriate to the depth of the experiment. 5 These results are not reported becauge they show net change in atresses and displacements from their initial values that are the same as reported here. But by assuming the inftial values to be zero, it is much easier to determine changes due to thermoelastic effects.

The absolute magnitudes of stresses existing in the medium are important for treating the problem of the balance between pore pressure and in-situ atress. A knowledge of in-situ strese dietributions is required to treat this problem. Some aspects of this wil be treated in a later memo. 
J. K. Johnstone $-4537 \quad-4-\quad \ldots . .199$

References

1. Memo, A. R. Lappin, 4537, to B. M. Bulmer, 5511, dtd 12/1/78, subject: COYOTE Thermal Modeling of Tuff Heater Experiment.

2. Memo, B. M. Bulmer, 5511, to A. R. Lappin, 4537, atd 2/14/79, subfect: Thermal Anaiygis of Tuff In-Situ Heater Experiment.

3. Private Communication, พ. A. Olsson, 5532, to พ. T. Brown, 5531, atd $3 / 7 / 79$.

4. Private Communication, A. R. Lappin, 4537, to W T. Brown, 5531.

5. Memo, A. R. Leppin, 4537, to W. T. Brown, 5531, dtd 3/7/79, subject: Mechanical Modeling of Tuff Heater Experiment.

WTB: 5531:8s

Copy to:

4530 R. W. Lynch (w/o Appendix)

4537 L. D. Tyler (w/o Appendix)

4537 A. R. Lappin

4537 D. R. Waymite

5500 O. E. Jones (w/o Appendix)

5510 D. B. Heyes (w/o Appendix)

5511 D. F. McVey (w/o Appendix)

5511 B. M. Bulmer

5520 T. B. Lane (w/o Appendix)

5530 W. Herrmann (w/o Append1x)

5531 I. D. Bertholf (w/o Append1x) 

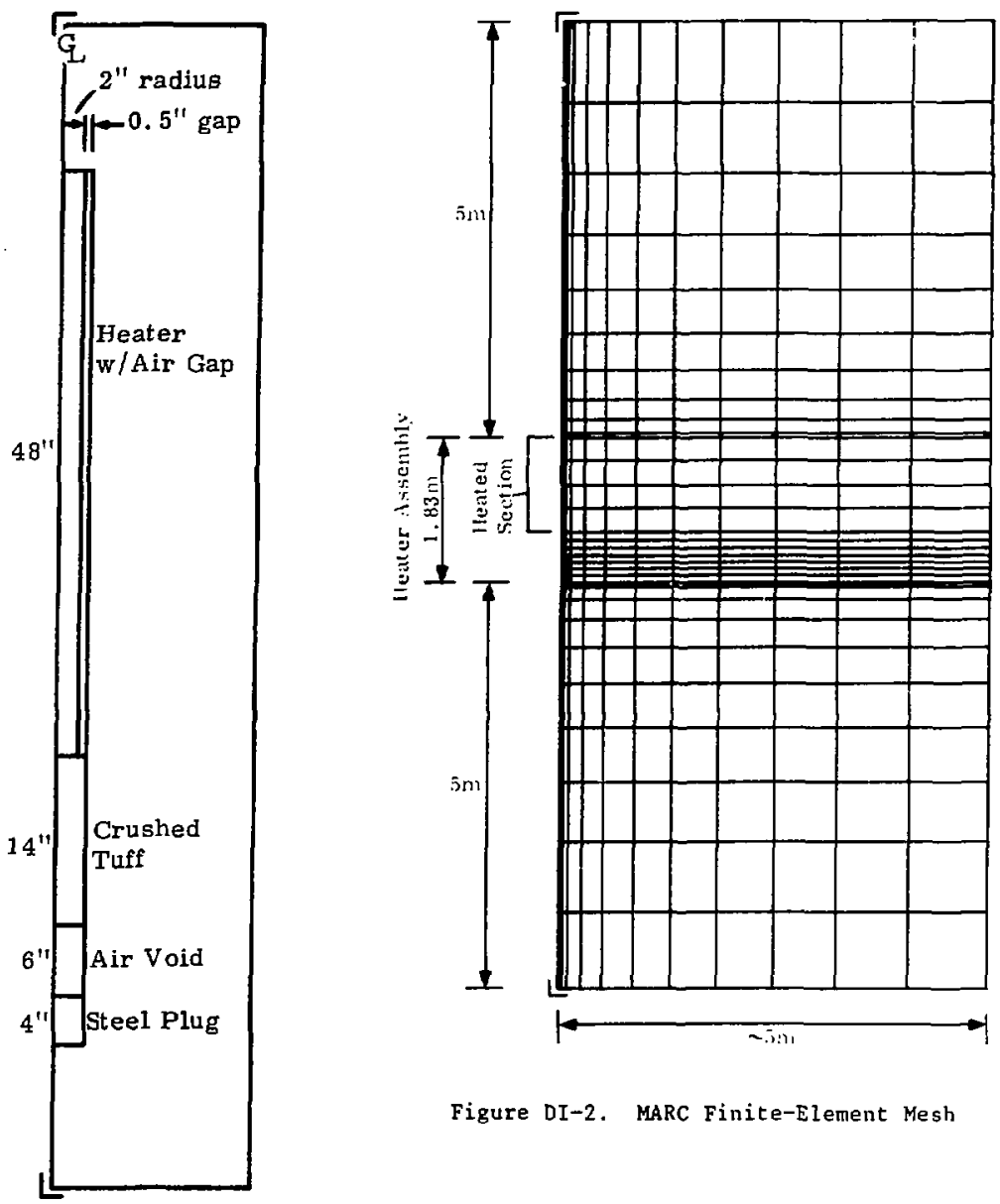

Figure DI-2. MARC Finite-Element Mesh

Figure DI-1, Schematic

Representation of

Heater Assembly 


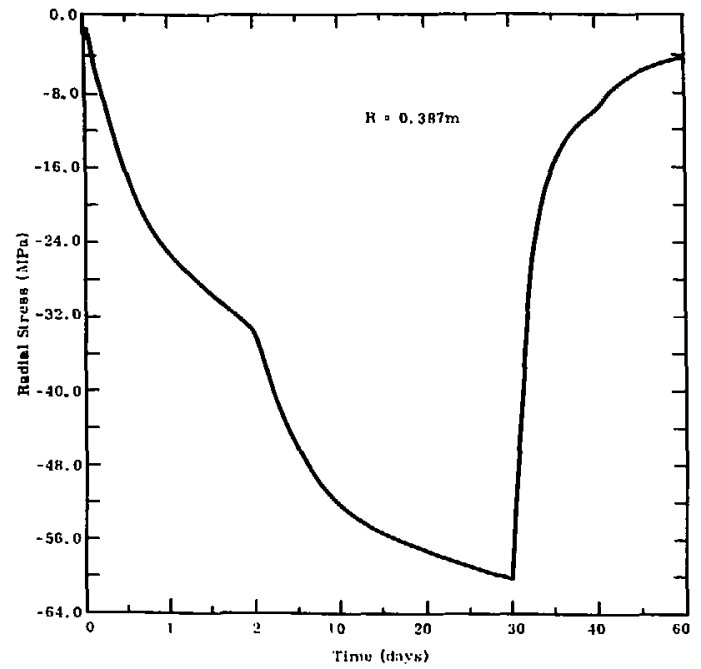

Figure DI-3. NTS Heater Simulation Case 1D

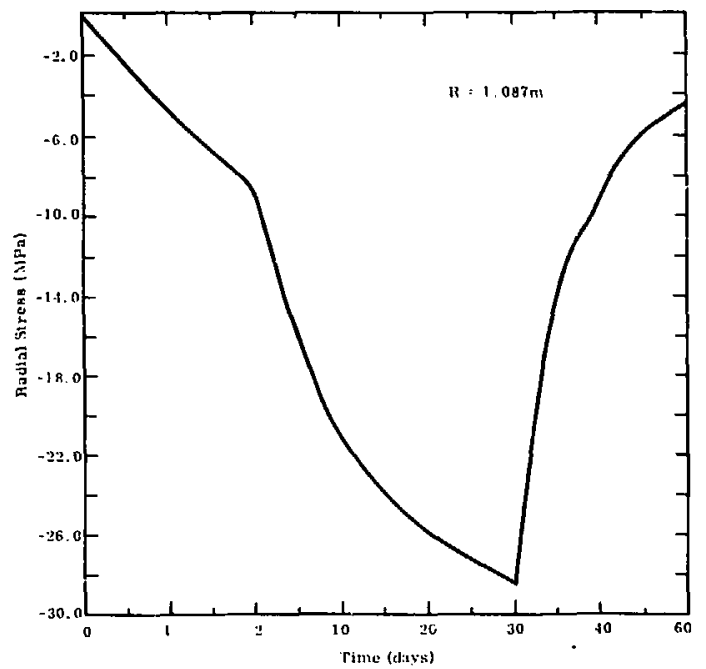

Figure DI-4. NTS Heater Simulation Case ID 


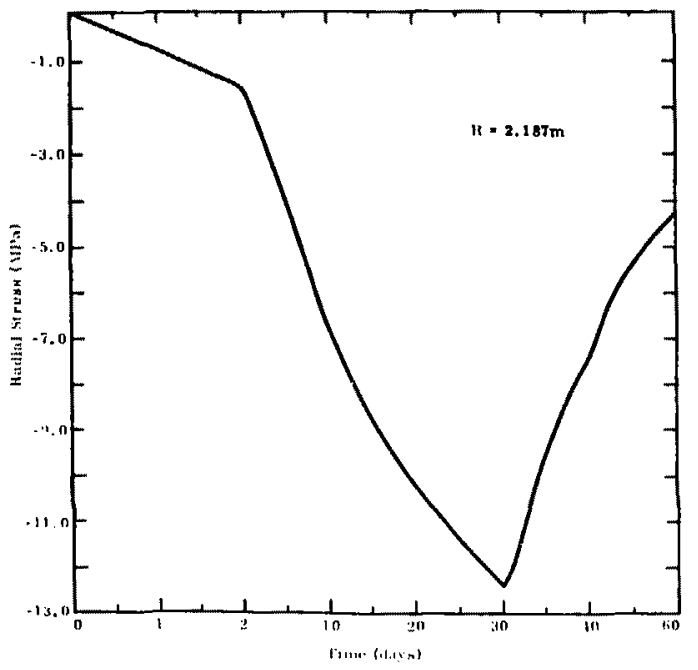

Figure DI -5. NTS Heater Simulation Cage ID

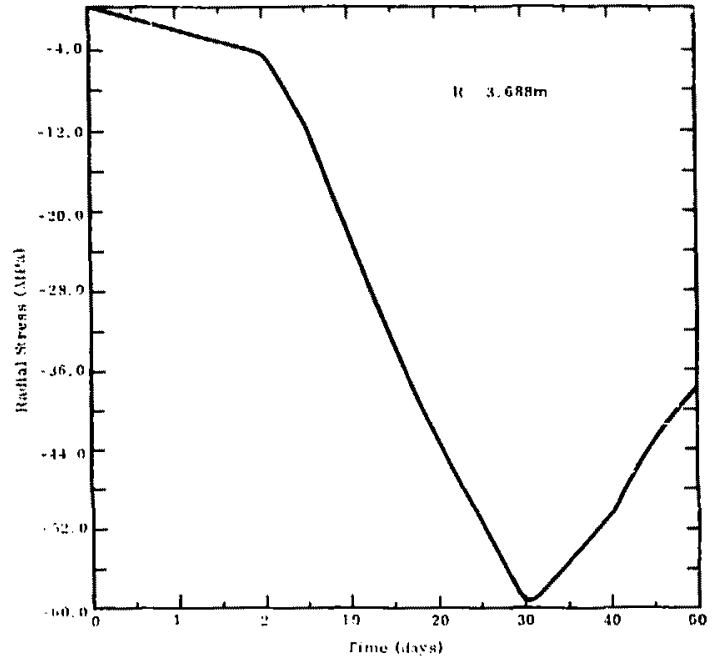

Figure DI-6. NTS Heater Simulation Case 1D

$\omega$ 


$$
\text { 里 }
$$




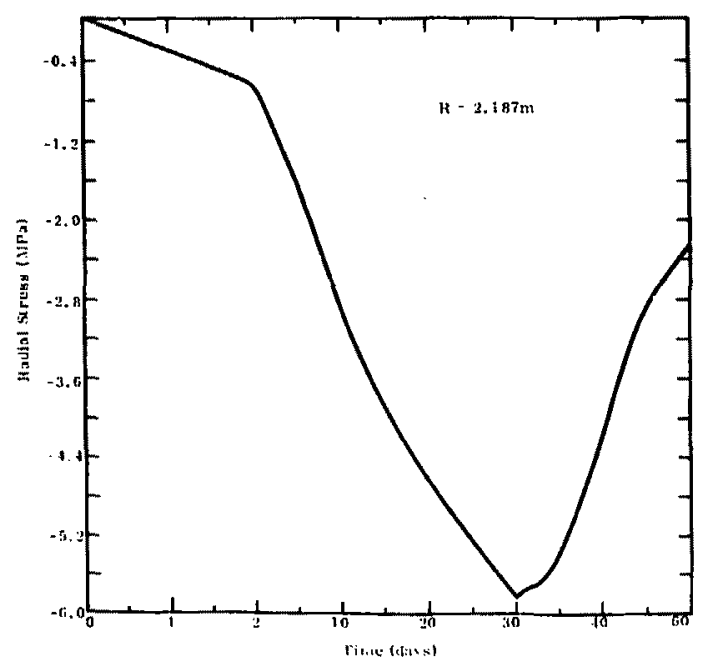

Figure DI-9. NTS Heater Simulation Case 2A

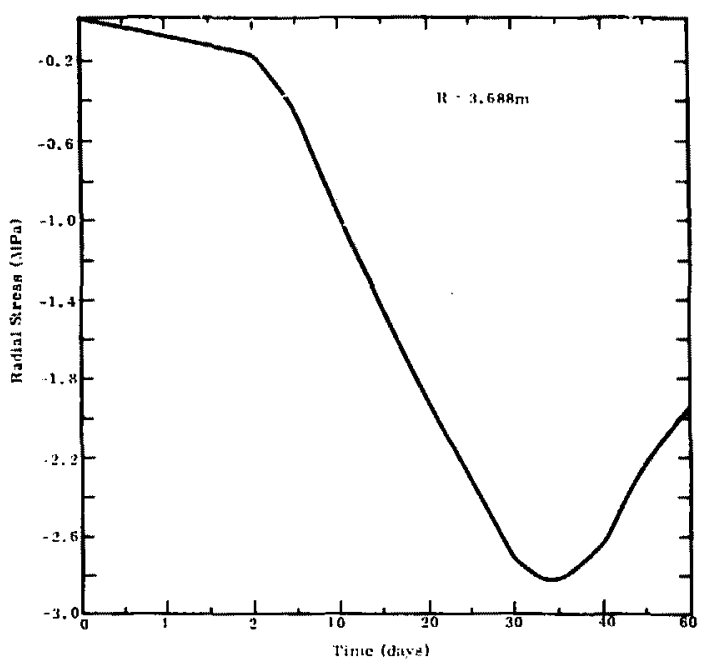

Figure DI-10. NTS Heater Simulation Case 2A 


$$
\text { DI] }
$$




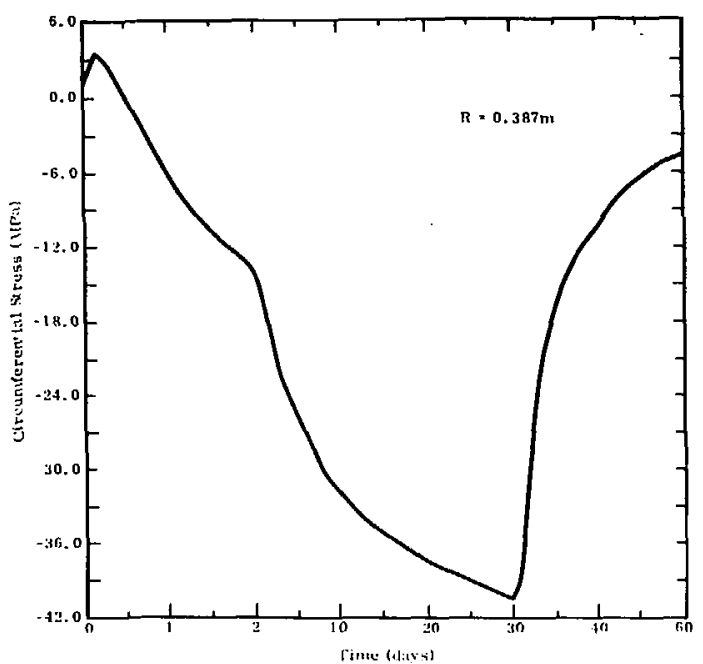

Figure DI-I3. NTS Heater Simulation Case ID

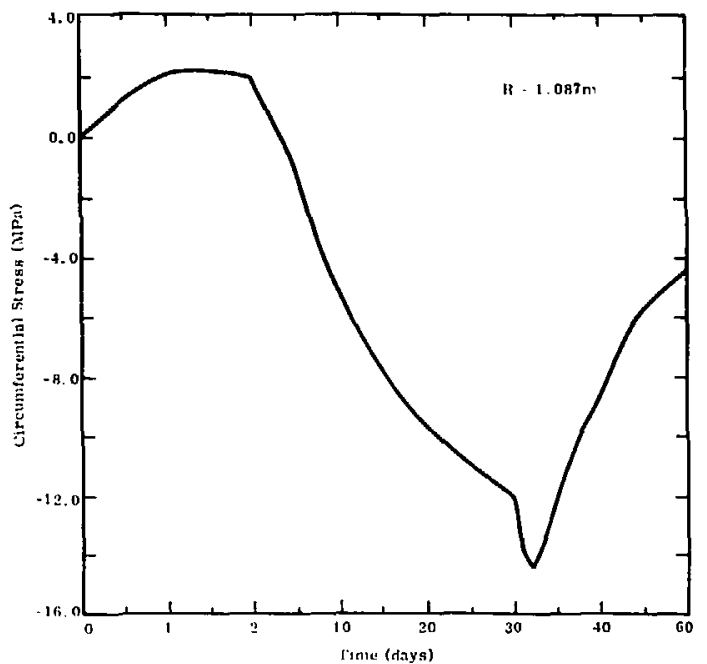

Figure DI-I/4. NTS Heater Simulation Case 1D 


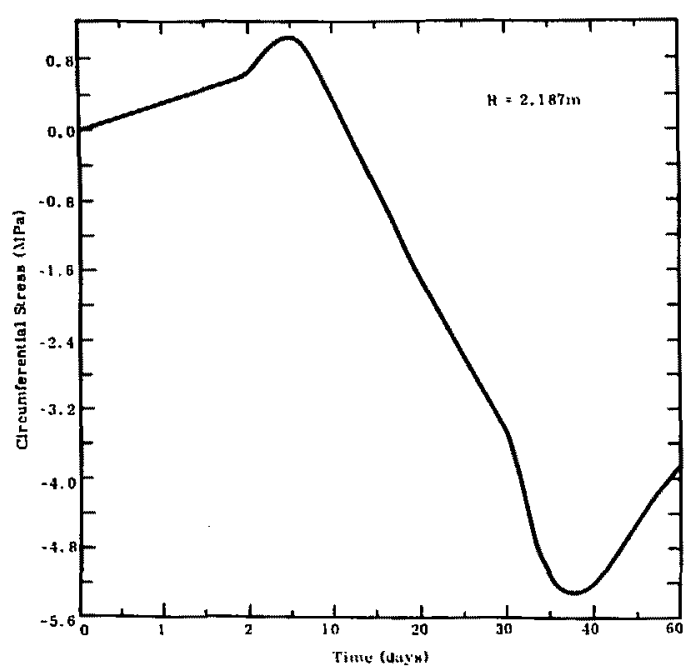

Figure DI-15. NTS Heater Simulation Case 1D

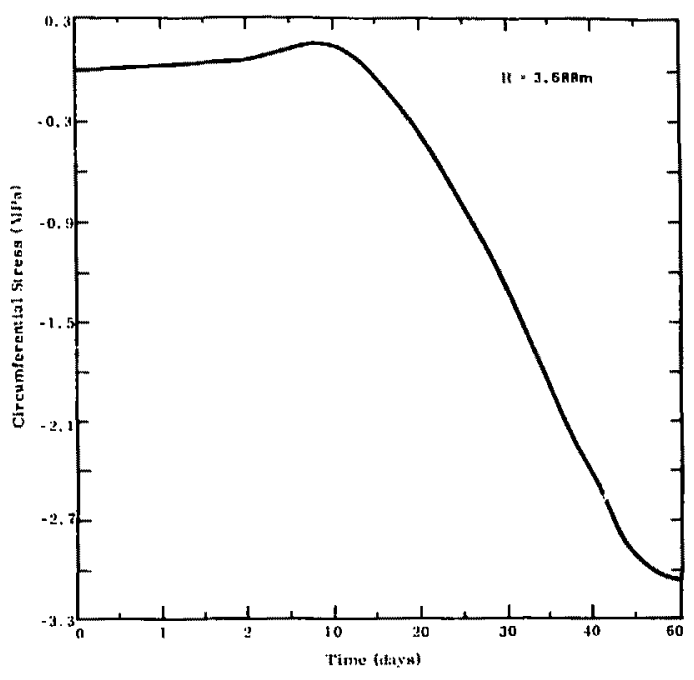

Figure DI-16. NTS Heater Simulatio: Cage 1D 


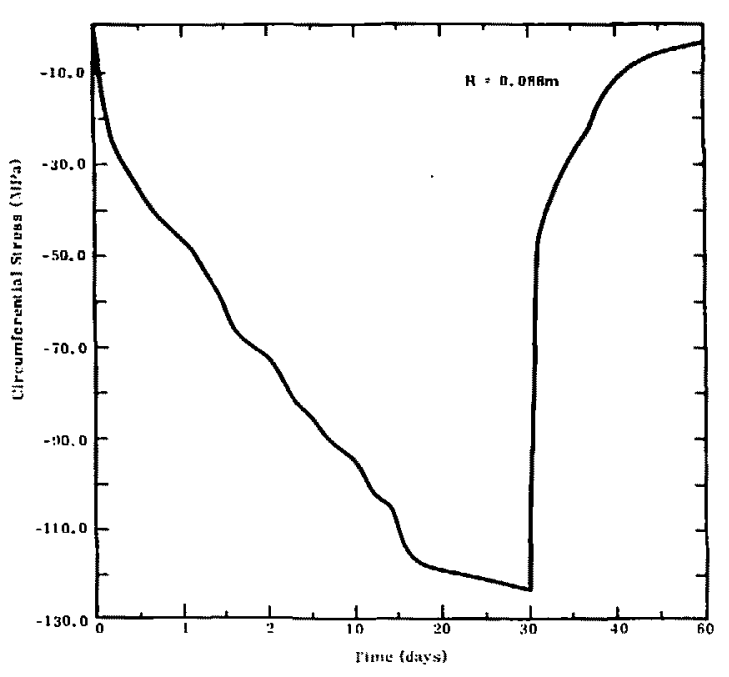

Figure DI-17. NTs Heater Simulation Case $2 \mathrm{~A}$

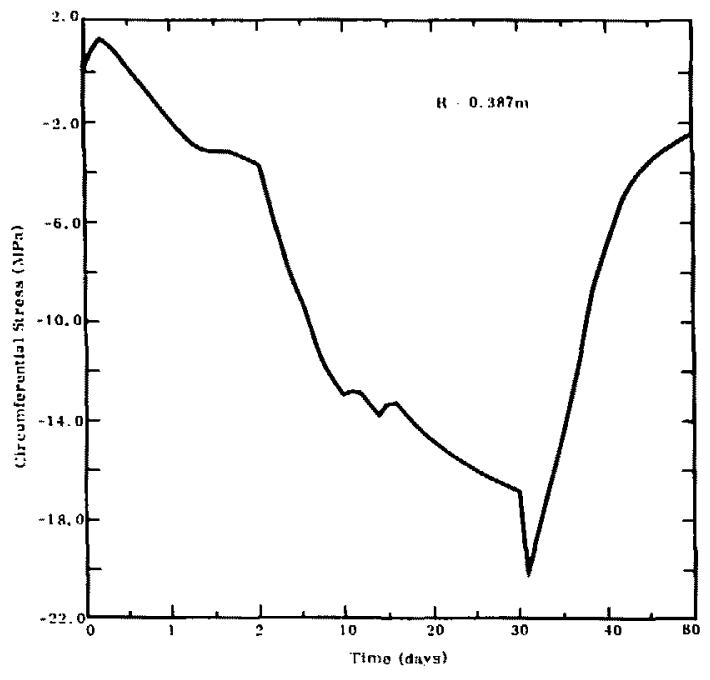

Figure DI-18. NTS Heater Simulation Case 2A 


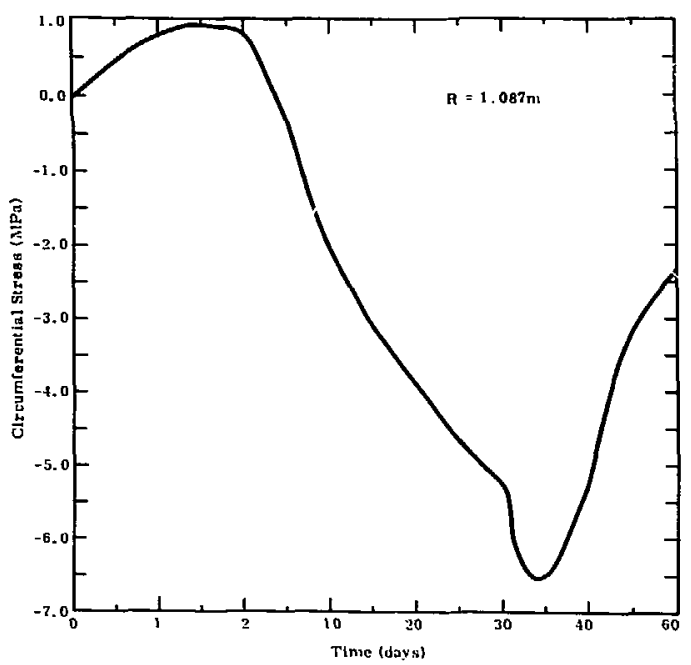

Figure RI-19. NTS Heater Simulation Case 2A

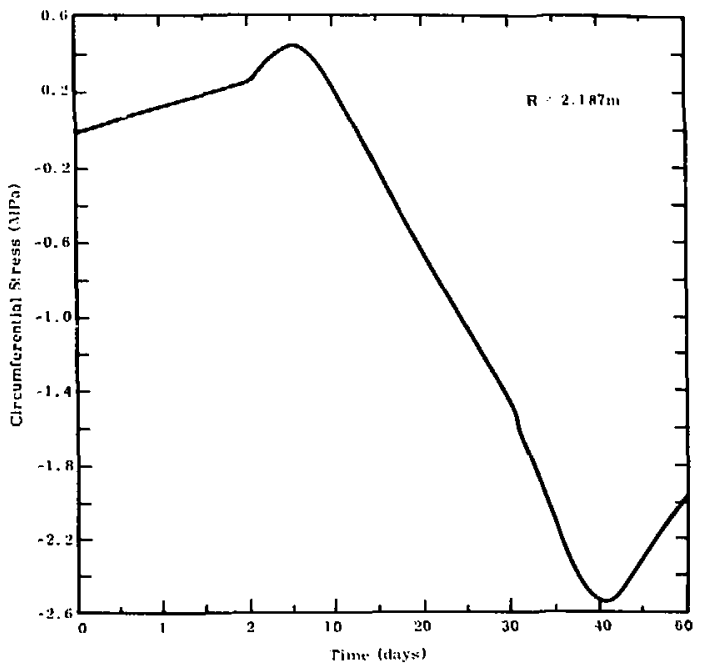

Figure DI-20. NTS Heater Simulation Case 2A 


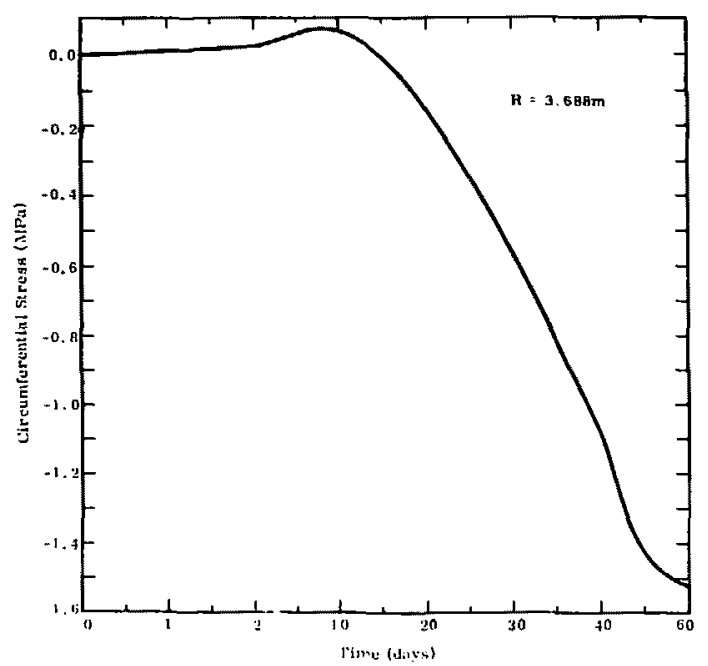

Fiqure CI-21. NTS Heater Simulation Case 2A

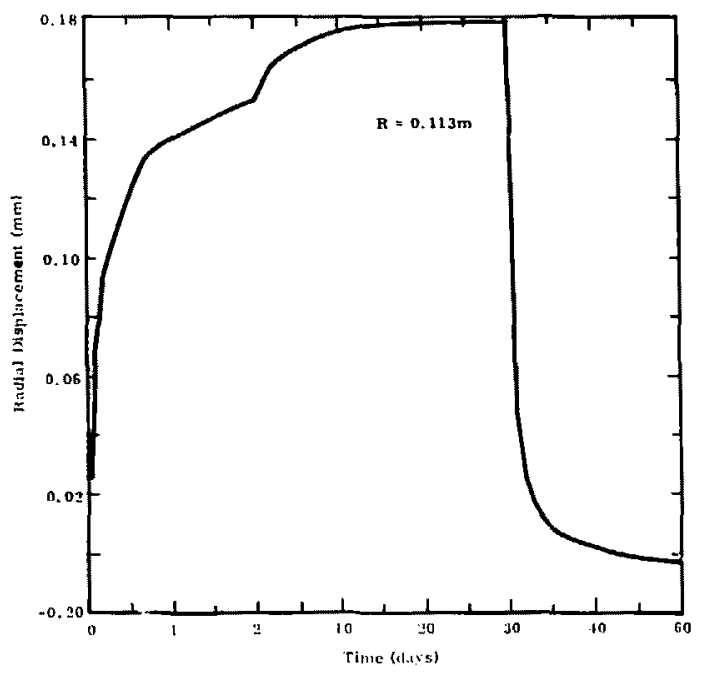

Figure DI-22. NTS Heater Simulation Cage 1D 


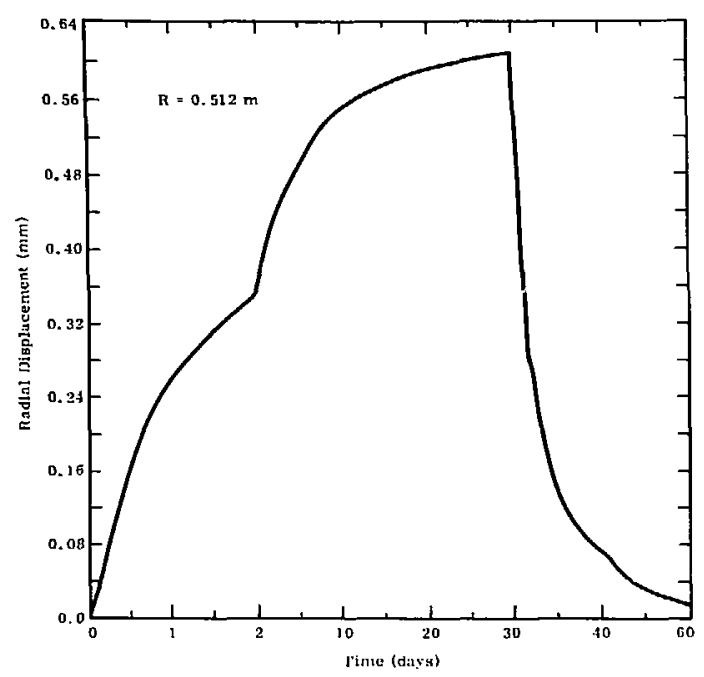

Figure DI-23. NTS Heater Simulation Case 1D

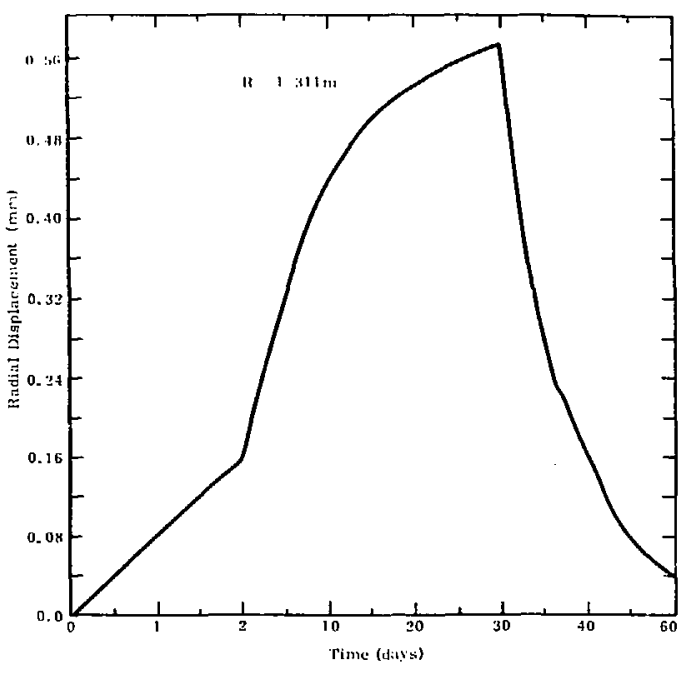

Figure DI-24. NTS Heater Simulation Case 10 


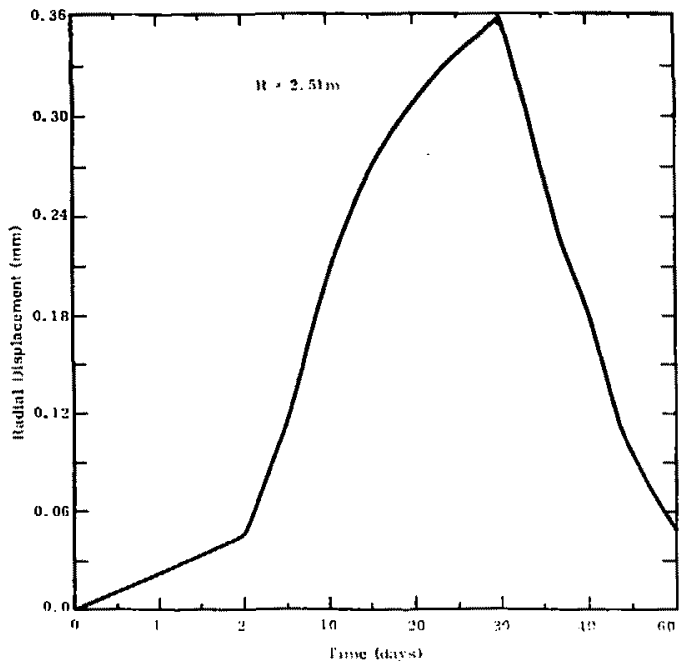

Figure DI-25. NTS Heater Simulation Case 1D

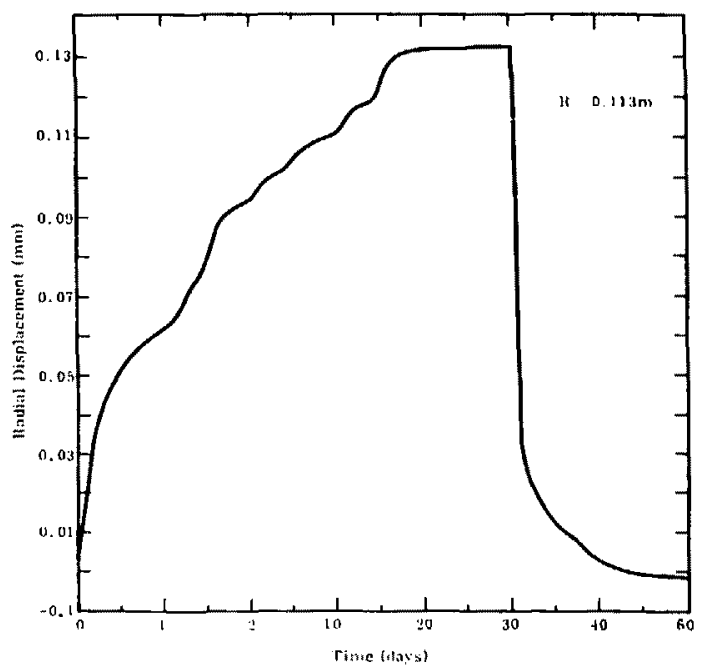

Figure DI-26. NTS Heater Simulation Case 2A 


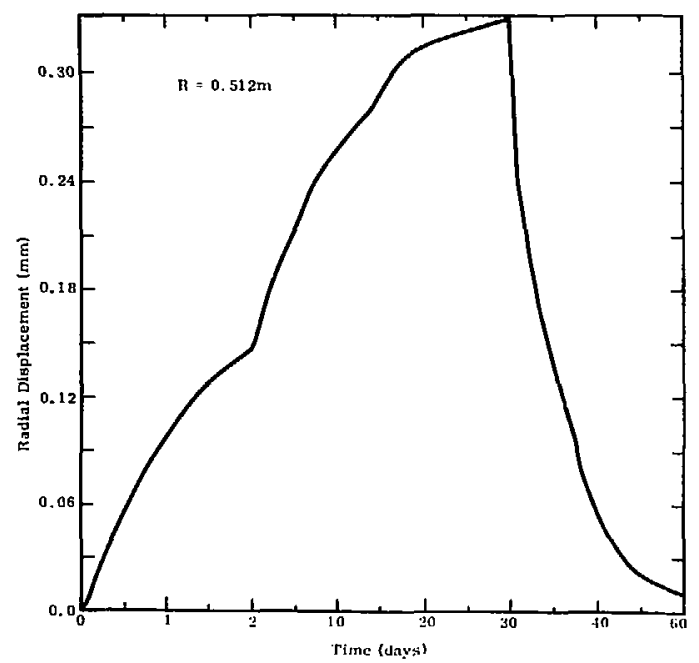

Figure DI-27. NTS Heater simulation Case 2A

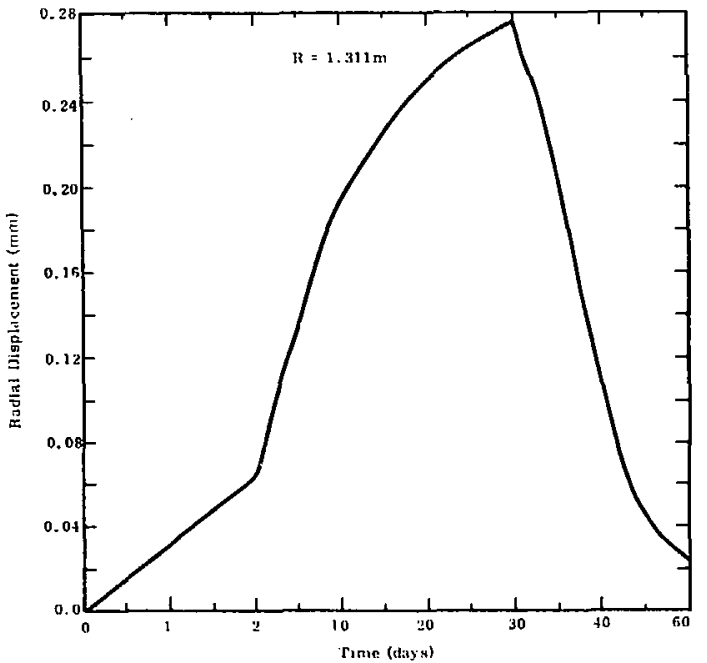

Figure DI-28, NTS Heater Simulation Case $2 A$ 


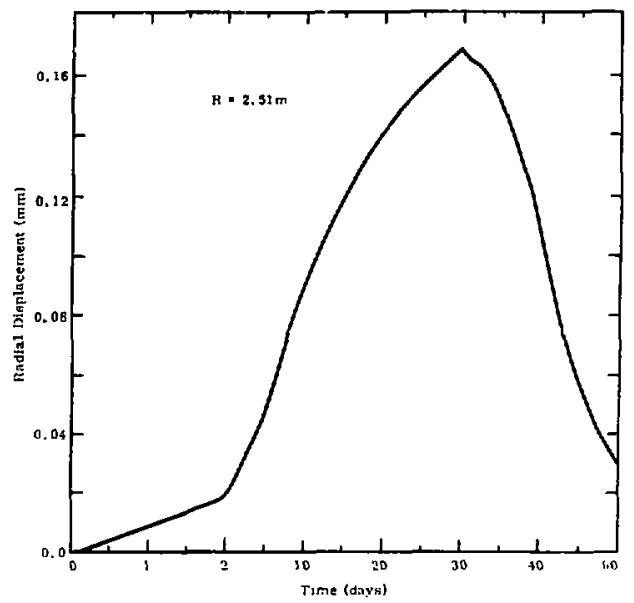

Figure DI-29. NTS Heater Simulation Case 2A

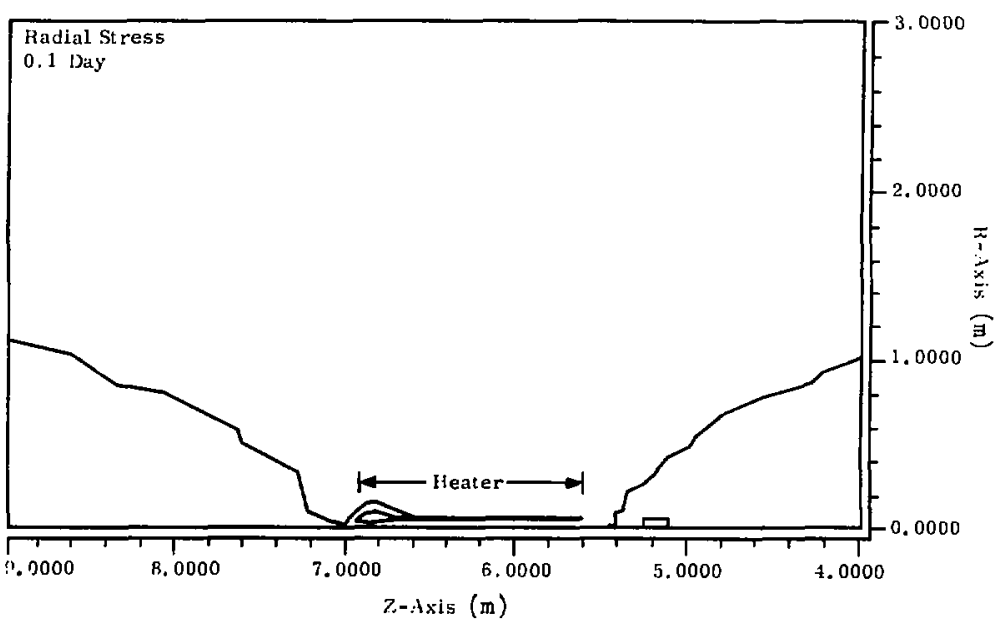

Figure DI-30. NTS Heater Simulation Case 1D 


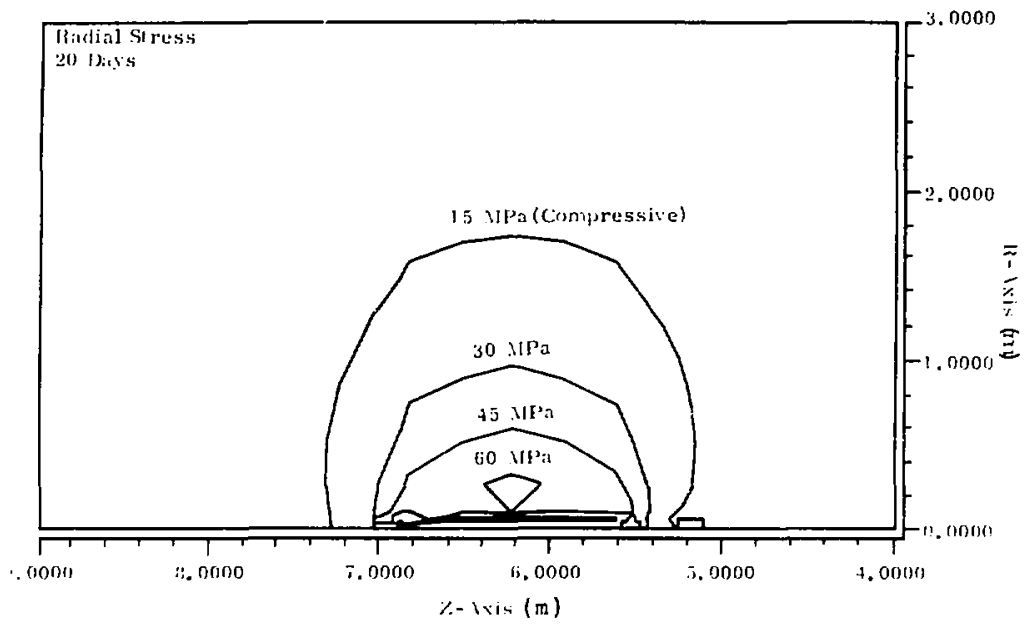

Figure DI-31. NTS Heater Simulation Case 1D

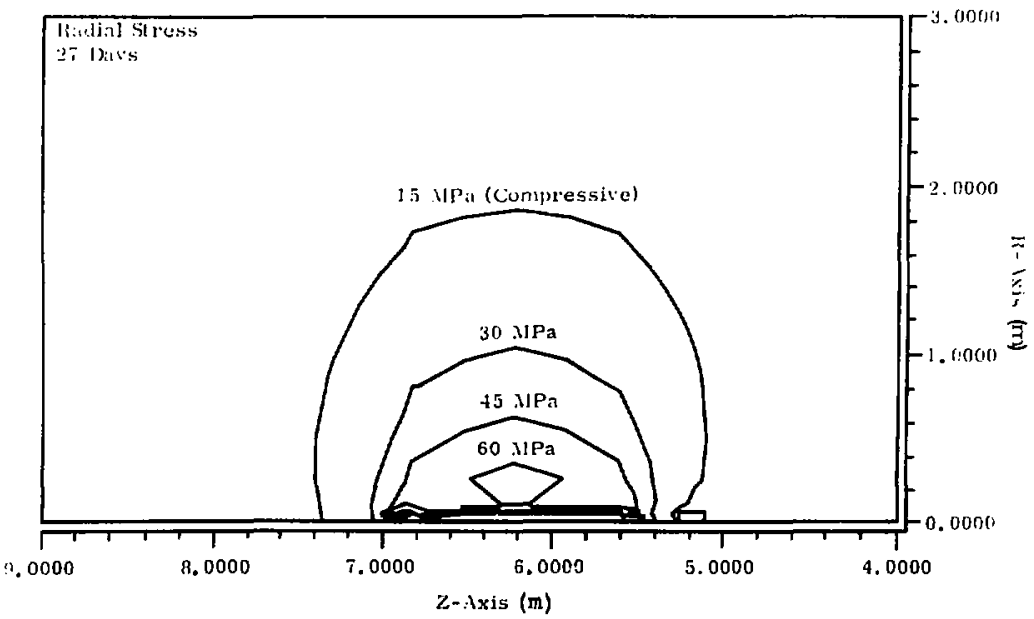

Figure DI-32. NTS Heater Simulation Caвe 1D 


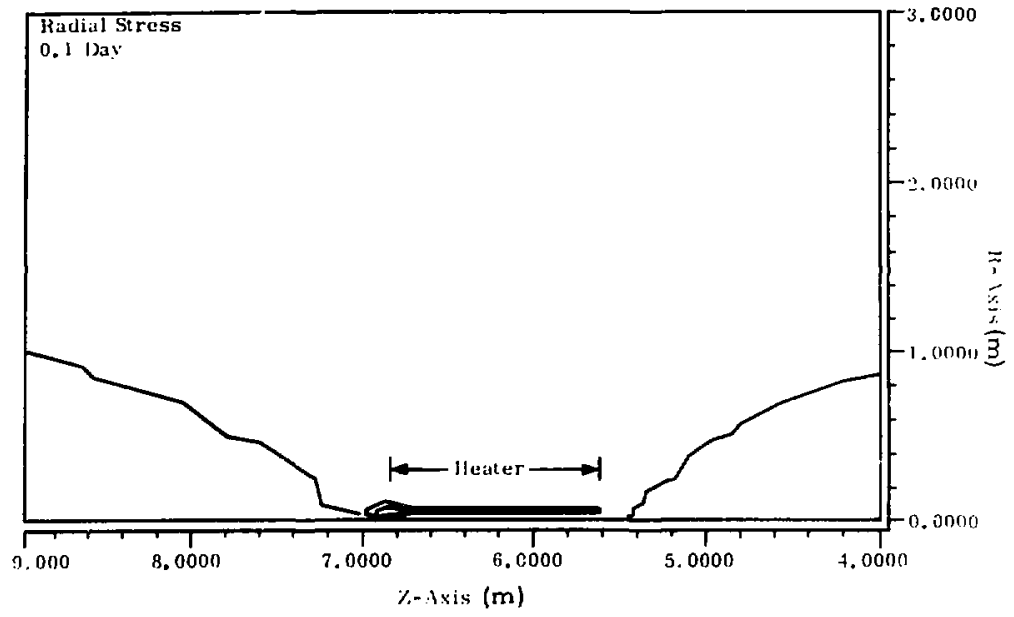

Figure DI-33. NTS Heater Simulation Case 2A

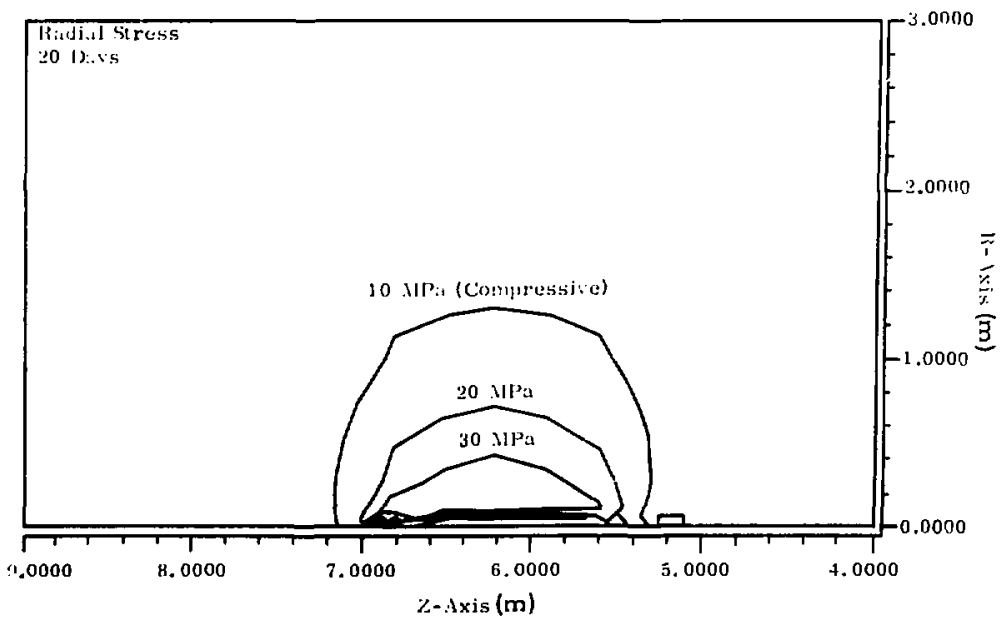

Figure DI-34. NTS Heater Simulation Case 2A 


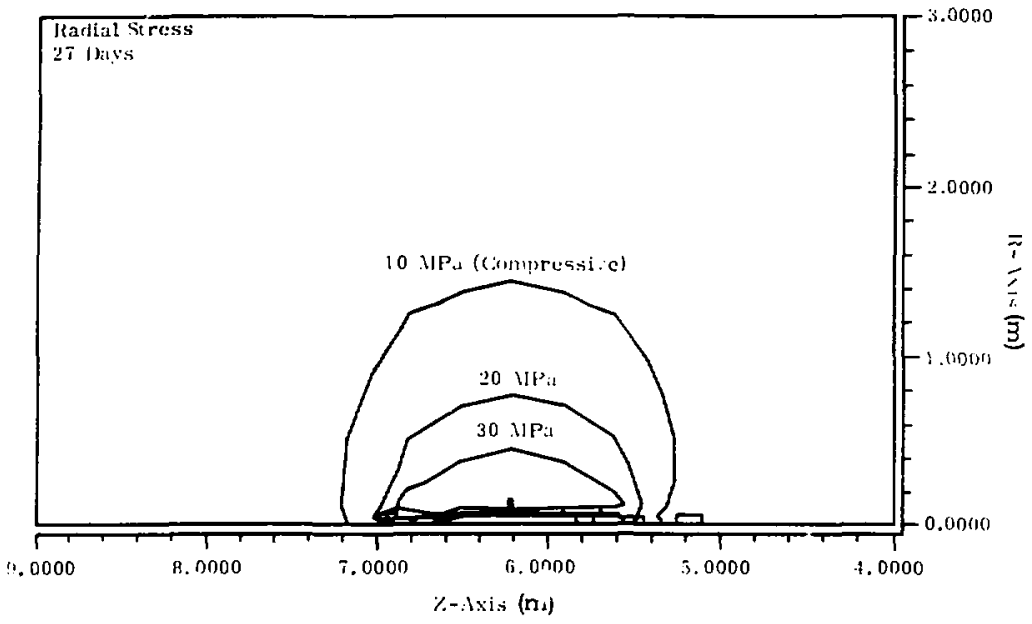

Figure DI-35. NTS Heater Simulation Case 2A

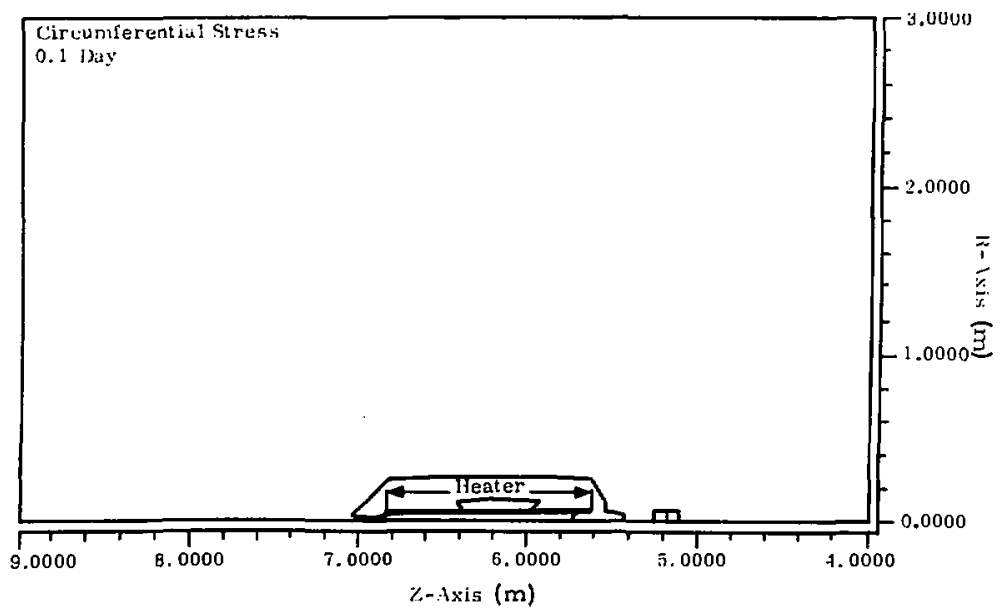

Figure DI-36. NTS Heater Simulation Cage 1D 


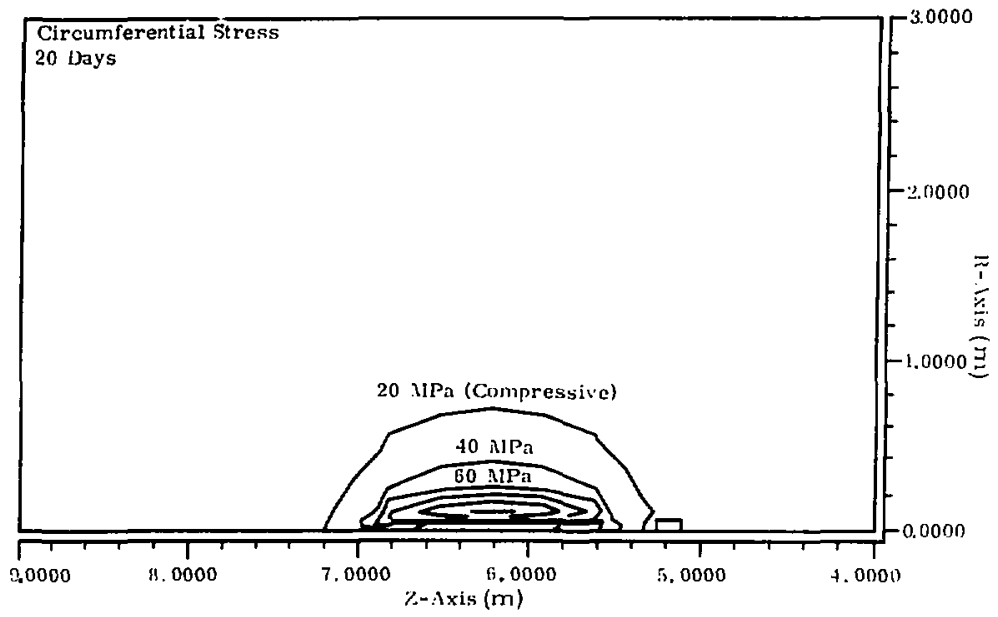

Figure DI-37. NTS Heater Simulation Case 1D

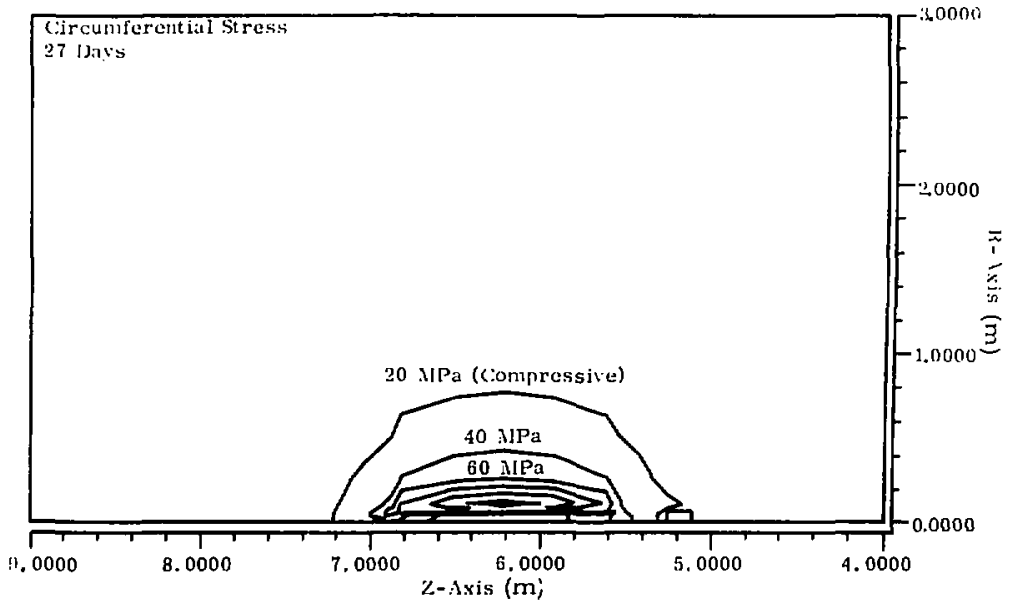

Figure DI-38. NTS Heater Simulation Case 1D 


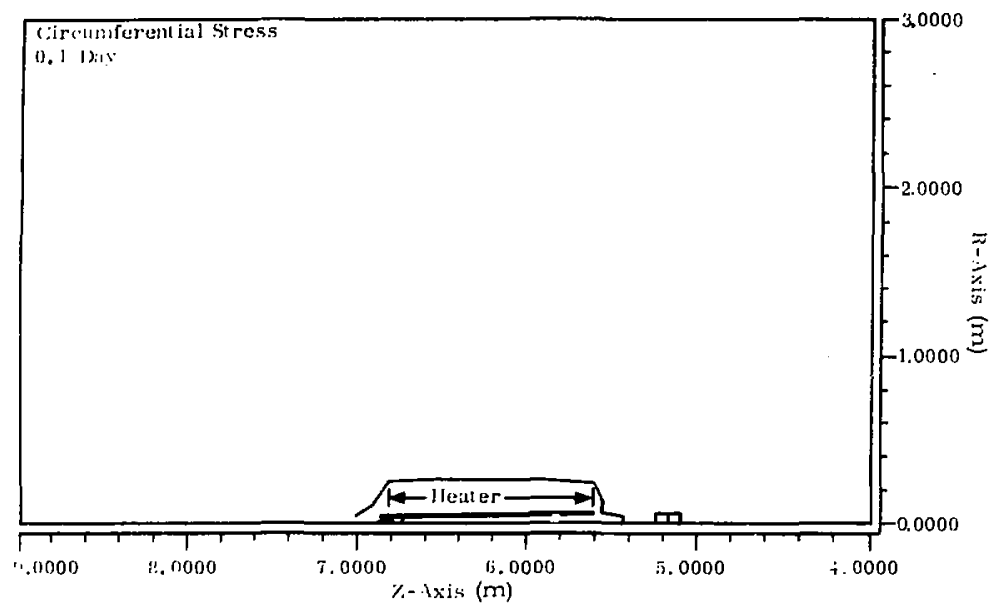

Figure DI-39. NTS Heater Simulation Case $2 \mathrm{~A}$

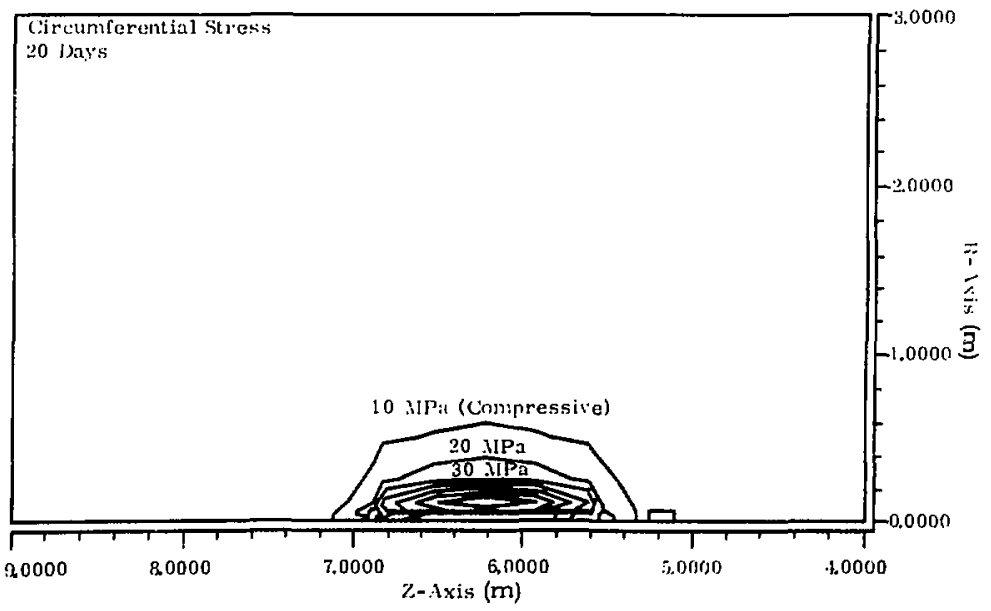

Figure DI-40. NTS Heater Simulation Case $2 \mathrm{~A}$ 


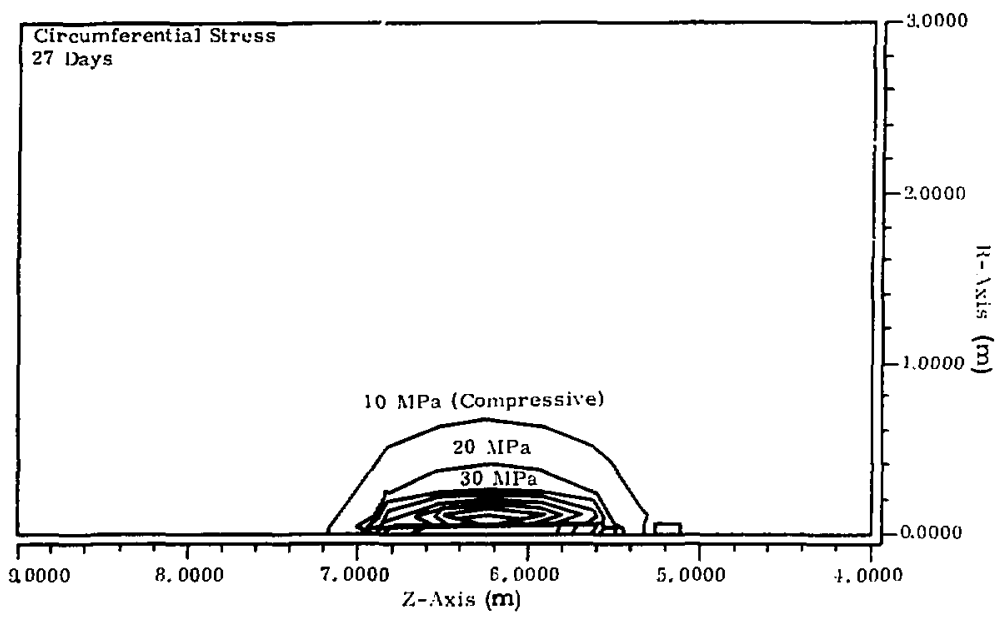

Figure DI-41. NTS Heater Simulation Case 2A

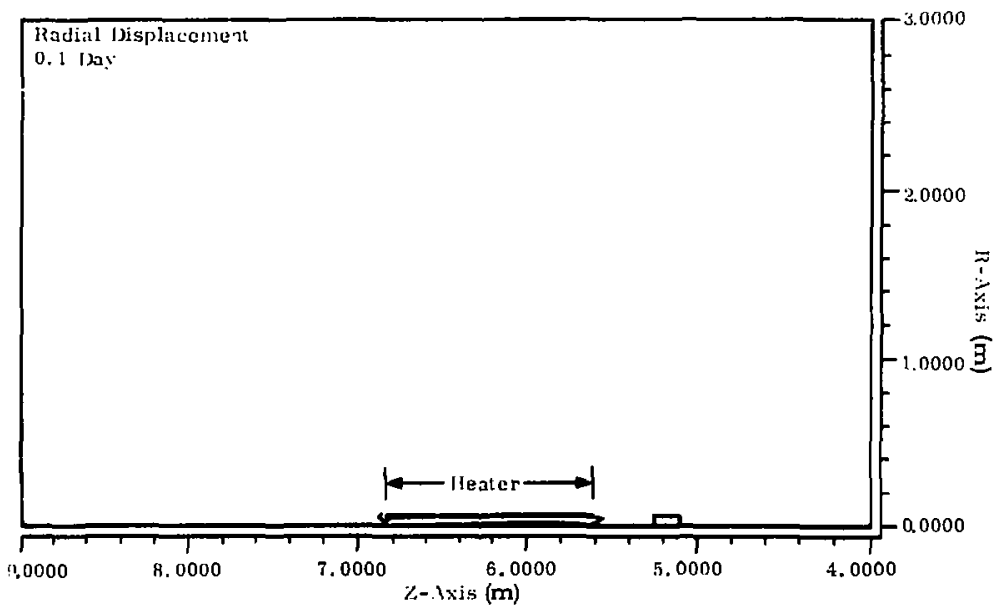

Figure DI-42. NTS Heater Simulation Case ID 


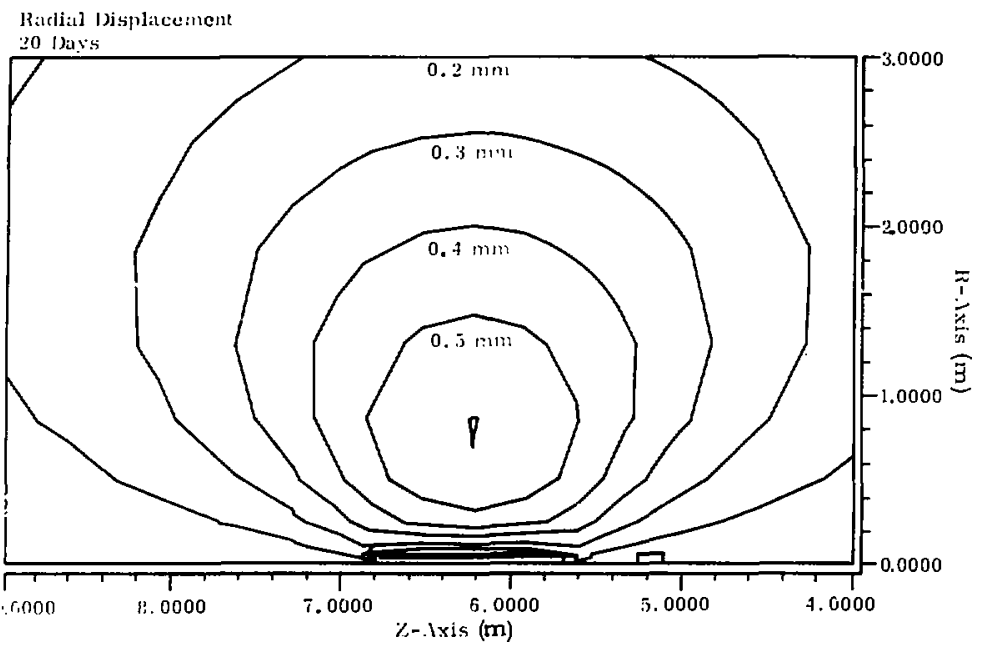

Figure DI-43. NTS Heater Simulation Case 1D

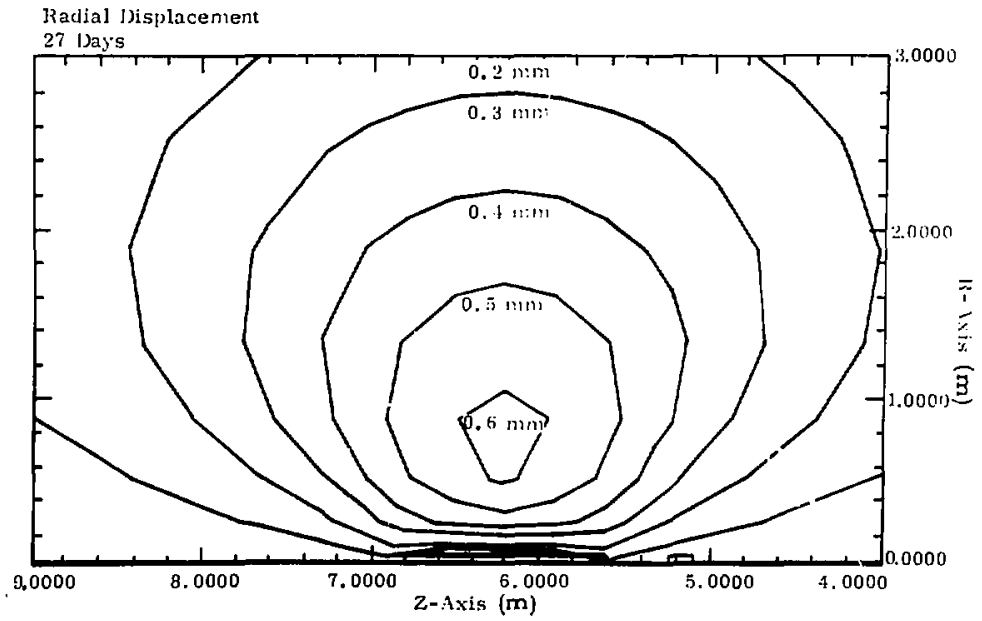

Figure DI-44. NTS Heater Simulation Case 1D 


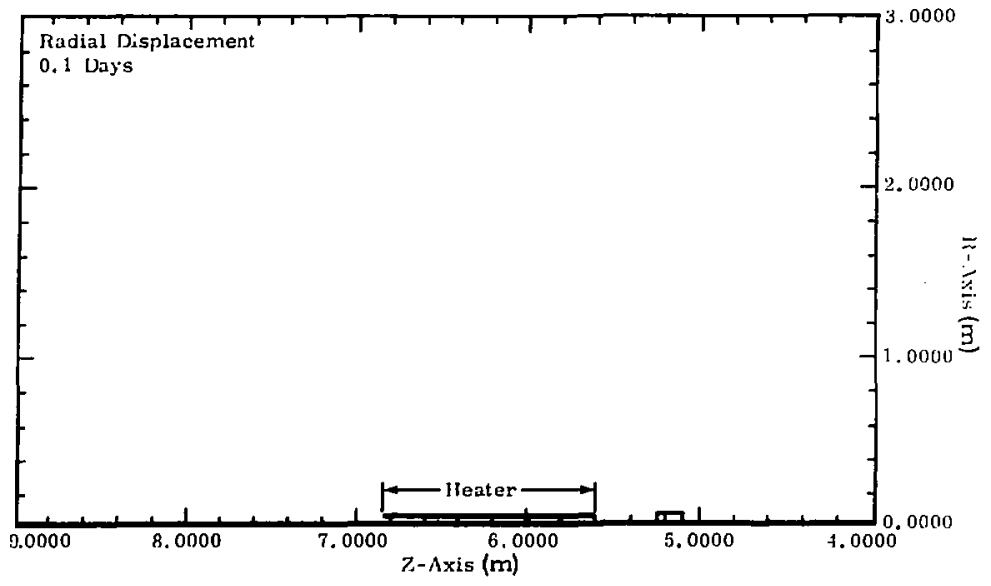

Figure DI-45. NTS Heater Simulation Case 2A

ladial IJisplacement

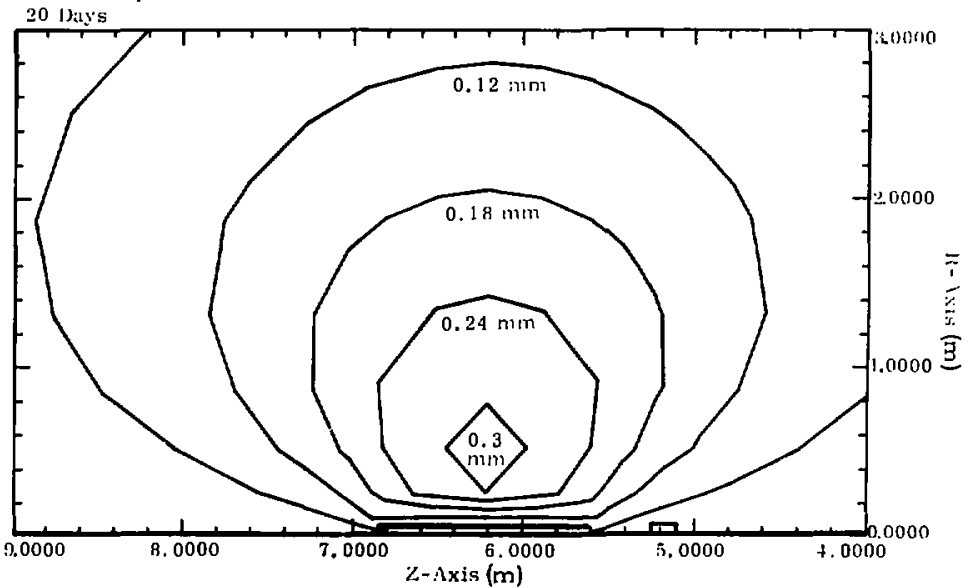

Figure DI-46. NTS Heater Simulation Case 2A 


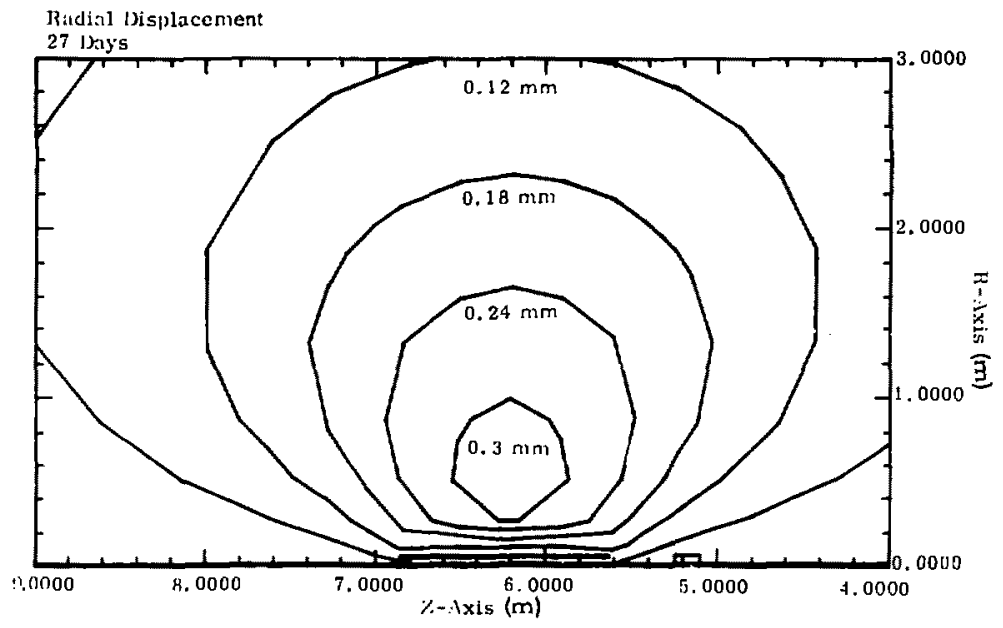

Figure DI-47. NTS Heater Simulation Case 2A 


\section{Sandia Laboratories}

date: August 28, 1979

to: J. K. Johnstone -4537
Albuquerque. New Mexico Livermore. Califo nia

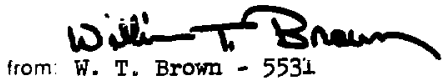

subjeci. Additional Thermomechanical Modeling of the Tuff In-situ Heater Experiment

Two additional calculationg have been run to model the planned heater experiment in weldec tuff at the Nevada Test Site. Results from earlier calculations (Reference 1) showed that for power levels of $1.25 \mathrm{~kW}$ and $2.5 \mathrm{~kW}$ the clrcumferential stresses near the heater hole would exceed the strength of the welded tuff. Those calculations were done primarily to determine locations for placement of stress and displacement instrumentation; however the calculated circumferential stresses are of concern because they indicate pol sible failure of the tuff which could prevent removal of the heater.

These current calculations were done in two-dimensional, axisymetric geometry whth the flinte-element code MARC. The model is 1dentical with that used for the previous calculations and is discussed in more detail in Reference 1 . The elastic properties used in the flrst set of calculations were obtained at a conflining stress of about $20 \mathrm{MPa}$ (Reference 3); however, sirice the major concern in these calculations is fallure near the surface of the heater hole, the unconflned strength of $137.7 \mathrm{MPa}$ (Reference 3) is used.

As with previous calculations, the results of the therwal modeling were supplied by Bruce Bulmer, 5623. The earlier calculations considered extremes of heater power levels as well as different thermal properties for the medium. Because results of both of those colculations indicated stresses that would exceed the unconflned strength, the current calculations considered lower power levels. Table 1, below, compares the properties used in the earlier celculations (cases $1 D$ and $2 A$ ) with those used in the latest calculations (ceses $2 \mathrm{~K}$ and $2 \mathrm{~L}$ ).

TABIE I. Thermal Properties of Tuff and Heater Power Levels.

\begin{tabular}{|c|c|c|c|c|}
\hline Case \# & $\begin{array}{l}\text { Water Bofling } \\
\text { Point, }{ }_{\mathrm{C}}\end{array}$ & $\begin{array}{c}\text { Rock } \\
\text { Ent ssivity }\end{array}$ & $\begin{array}{c}\text { Therngl } \\
\text { Conductivity }\end{array}$ & $\begin{array}{l}\text { Heater } \\
\text { Power, kW }\end{array}$ \\
\hline $\begin{array}{l}1 D \\
2 A \\
2 K \\
2 L\end{array}$ & $\begin{array}{l}235 \\
100 \\
100 \\
100\end{array}$ & $\begin{array}{l}0.6 \\
0.6 \\
0.6 \\
0.6\end{array}$ & $\begin{array}{l}\text { CONSTANT } \\
\text { VARTABLE } \\
\text { VARTABIE } \\
\text { VARIABLE }\end{array}$ & $\begin{array}{l}2.5 \\
1.25 \\
1.0 \\
0.5\end{array}$ \\
\hline
\end{tabular}


J. K. Johnstone - 4537

Results of these calculations are presented in Flgures 1 through 7 . Figures 1 and 2 show the varlation, near the surface of the heater hole, of the circumferential stress as a function of time for cases $2 K$ and $2 \mathrm{~L}$, respectively. Note that in each case the peak value of this component of stress does not exceed the ultimate strength. These locations are taken in the midplane of the heater.

In Figures 3 and 4, the radial component of stress is shown as a function of time at the same location for both case $2 \mathrm{~K}$ and $2 \mathrm{~L}$. D1screte fumpa can be seen in the plots in these four flgures. As in the earlier calculations, this behavior is due in part to the fact that the time axis is not unf form and in addition, there are discrete jumps in temperature caused by the varlable thermal conductivity. This latter effect occurs only for case $2 \mathrm{~K}$; in the results of case $2 L$ the temperature rise is not high enough for the variable coriductivity to influense the results.

The remaining figures show the spatial behavior of the radial and circumferential stress components and the displacement at 30 days, These values are also in the mid plane of the heater. In each case, the stresses are below the strength of $137.7 \mathrm{MPa}$ and thus no failure should occur. Note that the circumferential (hoop) stress falls off very rapidy wh distance from the surface of the hole. It is also clear that the peak value of the radiel stress does not occur at the surface of the hole, but after the occurrence of the peak this component also decays rapldiy. Unlike the earlier calculations, the inftial stresses due to overburden and gravlty loads have been included in these present results.

It was concluded from the Initial calculations (Reference 1) that the stresses and displacements could be messured within 1 meter of the heater centerline. However, these results show that the magnitudes of stresses and displacements are less than those that were initially calculated. Nevertheless, in each case, the stresses should still be measurable at 1 meter. In the worst case (2L) the radial stress Increases by about $5 \mathrm{MPa}$ above the inftial in-situ value and this should be within the resolution of the stress instrumentation. The displacements calculated for the $1 \mathrm{~kW}$ power level (case $2 \mathrm{~K}$ ) should be measurable by the displacement interferometer, but the displacements calculated for the $0.5 \mathrm{~kW}$ power level (case 2I) mey be marginal near a radius of 1 meter.

When all of the Information $1 \mathrm{~s}$ considered, the use of a $1 \mathrm{~kW}$ heater should eliminate the concerns regarding fallure of the welded tuff and should require no changes in the planned locations for instrumentation. 
J. K. Johnstone -4537

$-3-$

\section{References}

1. Memo, W. T. Brown, 5531, to J. K. Johnstone, 4537, dtd 6/4/79, Subject: Thermomechanlcal Analysis of Tuff In-S1tu Heater Experiment

2. Private Commanication, W. A. Olsson, 5532, to W. T. Brown, 5531, atd $3 / 7 / 79$

3. Memo, W. A. OIsson, 5532, to J. K. Johnstone, 4537, dtd 8/2/79, Subject: Mechanical Properties of Tuff from Nevada Test Site

WTB: $5531: 85$

Copy to:

4530 R. W. Lynch

4537 L. D. Tyler

4537 A. R. Lappin

4537 D. R. Waymire

5500 O. E. Jones

5510 D. B. Hayes

5511 D. F. McVey

5520 T. B. Lane

5530 W. Herrmenn

5531 L. D. Bertholf

5532 B. M. Butcher

5532 W. A. Olsson

5623 B. M. Bulmer 


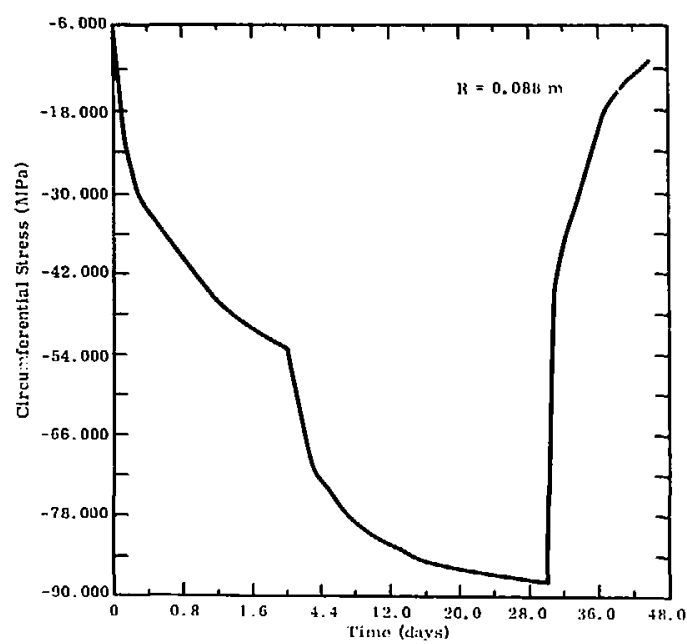

Figure DII-1. NTS Heater Simulation Case 2K

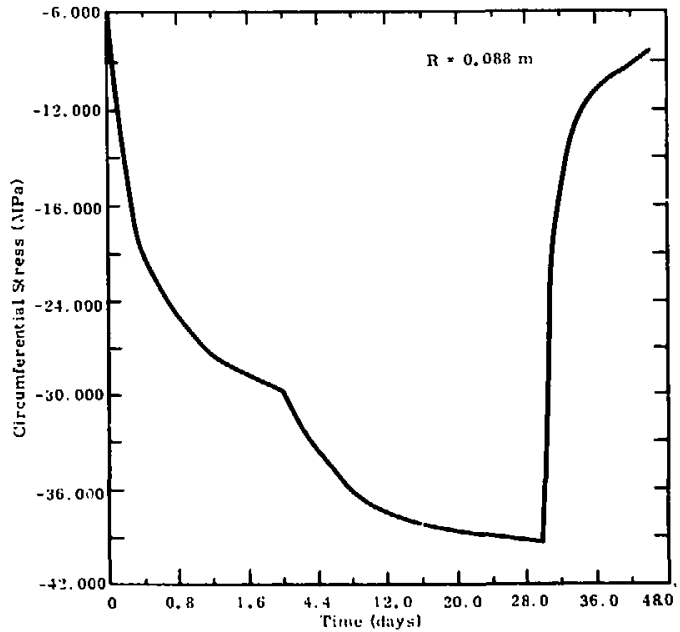

Figure DII-2, NTS Heater Simulation Case 2L 


$$
\text { 星了里了 }
$$



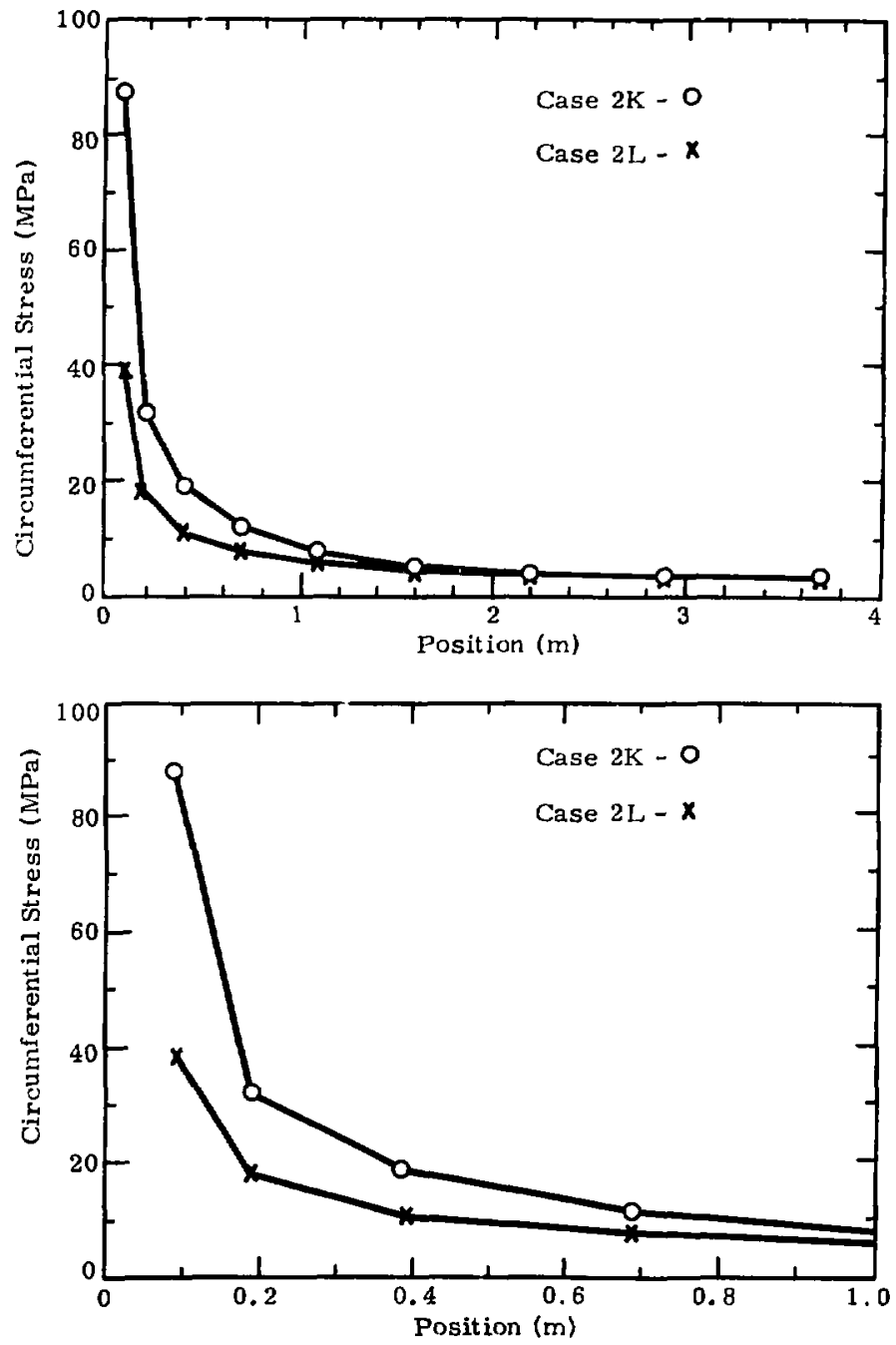

Heater Midplane $/ \mathrm{T}=30$ Days

Figure DII-5. Spatial Dependence of Circumferential Stresa, with Expanded Scale (Bottom) 

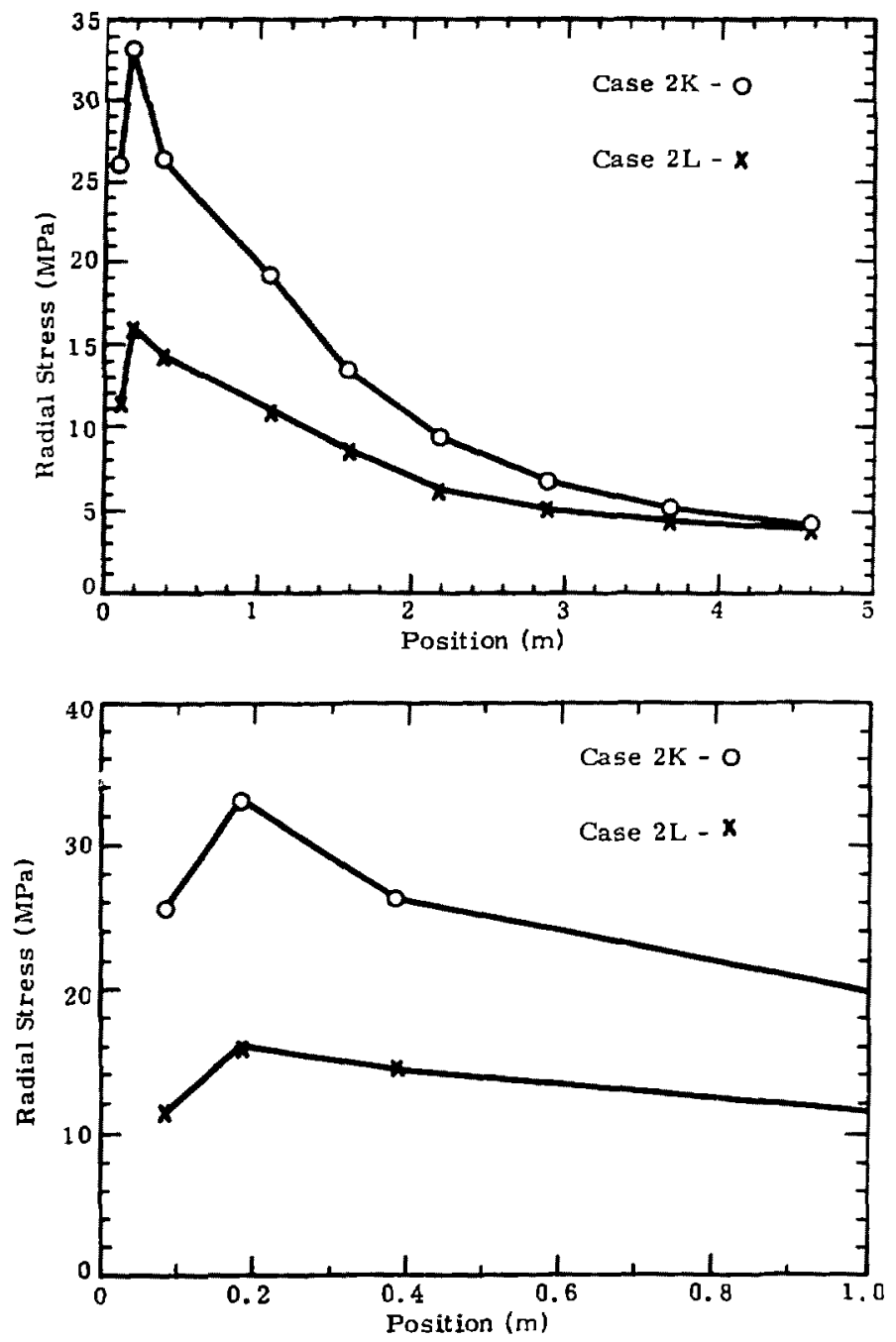

Heater Midplane $/ \mathrm{T}=30$ Days

Figure DII-6. SSatial Dependence of Radial Stress ith Expanded Scale (Bottom) 

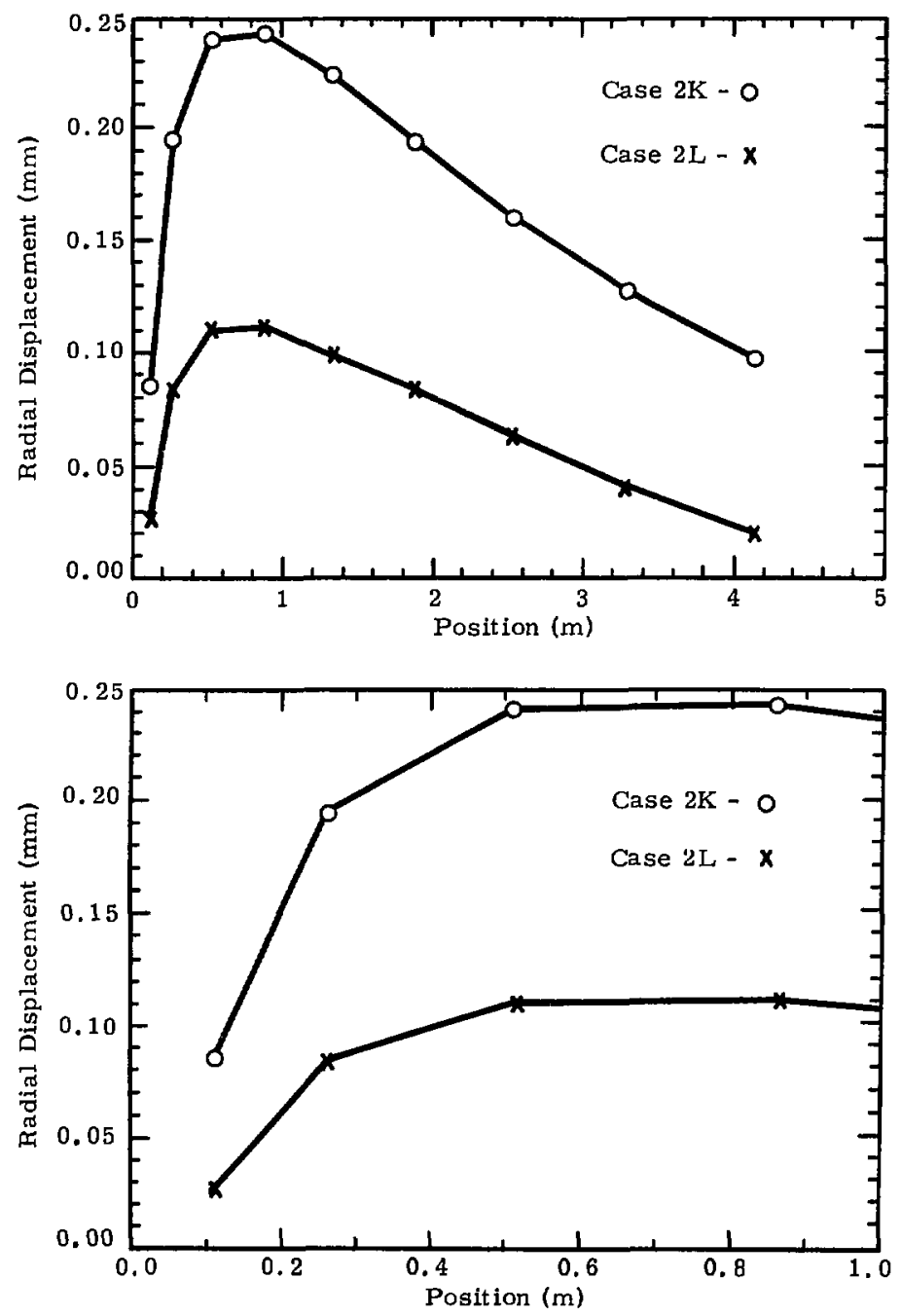

Heater Midplane $/ T=30$ Days

Figure DII-7. Spatial Dependence of Radial Displacement with Expanded Scale (Bottom) 


\section{Sandia Laboratories}

date: February 21, 1980

to: J. K. Johnstone -4537

\section{Willin: T:Prown \\ from: W. T. Brown - 5531}

Albuquerque. New Mexico L.tvermore. Caillornia

subject: In Situ Stresвes Near G-Tunnel Heater and Instrumentat1on Holes - Revision

Th1s memo reports the results of calculations that were done to estimate stress distributions in the vicinity of the heater hole and instrumentation holes in the G-tunnel water migration expirement. Because this experiment will measure water migration which can be driven, in part, by stress gradients, it is important to determine the extent to which the stresses encountered in the experimental altuation will approximate the actual at depth stress distribution.

Figure 1 represents a map view of the geometry near the instrumentation alcove in the experimental area of $G$-tunsel. The heater will be inserted Into a hole which is drilled into $a$ wall of the alcove at an angle of $20^{\circ}$ above horlzontal at approximately 3 meters above the floor. The hole has a length of about 20 meters and the heater is approximately 1.2 meters long. Figure 2 is a schematic representation of a cross section of the tunnel containing the heater. In addition to the heater hole there are various instrumentation holes paraliel to the axis of the heater. Previous calculations have been reported in which the changes in stress due to thermal effects were determined $[1,2]$. The purpose of the current calculations is to estimate changes in in situ stresses due to the presence of the vartous opentings.

The calculations heve been divided into two distinct parts. In the first set of calculations the presence of the heater hole and of the instrumentat1on holes 18 neglected. These calculations are done with a closed-form solution which epproximates the actuel situation. A second set of finiteelement calculations has been done to approximate the stress distribution in the vicinity of the heater hole due to the influence of instrumentation holes. Both of these are discussed below.

\section{Stress Distributione Near Tunnel}

To approximate the stress distributions in the vicinity of the tunnel opening, solutions heve been obteined for the cross section shown in Figure 2. The method used for these calculations is besed on a solution technique developed by Greenepan [3] for obtaining an exact soluvion for stresses in the vicinity of an opening whose boundary approximates the shape of the actual structure.

The basic techniques used in these calculations come from the mathematical theory of elasticity and were developed for problems other than those 
associated with stresses in rocks, but are widely used for such problems [4]. The rock near a tunnel is assumed to be in e homogeneous stress fleld which is a combination of vertical and horizontal stresses but no gravity field. The tunnel cross section is assumed to have a shape which can be represented in the parametric form

$$
\begin{aligned}
& x=p \cos \beta+r \cos 3 \beta \\
& y=q \sin \beta-r \sin 3 \theta .
\end{aligned}
$$

Additionally, the structure is also to be in a state of generalized plane stress witl stresses at large distances from the boundary given by the constant normal components $\sigma_{x}=S_{x}, \sigma_{y}=S_{y}$ and shear component $T_{x y}=T_{x y}{ }^{*}$

By a proper cholce of the parameters $p$, q and $r$ in $\mathrm{Eq}$. ( 1 ), an ovaloid which is a good approximation to the tunnel cross section can be obtained. By using a Cartesian coordinate system, in which the $x$-axis is parallel to the horizontal direction and the angle $\beta$ is measured counterclockwise from the $x$-axis, the tunnel width is $2(p+r)$ and the tunnel height is given by $2(q+r)$. The value for $r$ is obtained from the radius of curvature between the wall and celling. The particular values obtalned for the cross section in Figure 2 are

$$
\begin{aligned}
& p=6.546 \\
& q=2.431 \\
& r=-.601
\end{aligned}
$$

The oveloid defined by these velues is shown in Figure 3 and it comperes favorably with the actual cross section.

The method used to obtein stress values is falrly elaborate and is not given here in deteil. The essential features of the solution are outlined; details can be found in the paper by Greenspen [3].

Two sets of curves are defined by

$$
\begin{aligned}
& f_{1}(x, y)=\alpha, \\
& f_{2}(x, y)=\beta,
\end{aligned}
$$

and then palr of values $(\alpha, \beta)$ defines curvilinear coordinates in the $x, y$ plane which are intersections of these curves. A conformal transformation maps the boundary of the opening into the $\alpha, \beta$ plane and dertvatives of a stress function with respect to $\alpha$ and $\beta$ are used to calculate the stresses $\sigma_{\alpha}, \sigma_{\beta}$ and $\tau_{\alpha \beta}$. These stresses turn out to be rather complicated functions of $\alpha$ and $\beta$ and of the parameters $(p, q, r)$ describing the opening, but they do not depend on the material parameters. This plane stress solution corresponds to a thin plate with an opening, but the tunnel requires a 
plune strain solution in which the displacements parallel to the tunnel axis are zero. The corresponding out-of-plane stress can be obtatned from $\sigma_{z}=\nu\left(\sigma_{\alpha}+\sigma_{\beta}\right)$, where $\nu$ is Poisson's ratio. This out-of-plene stress is not given here but can be calculated easily.

Stress components $\sigma_{\alpha}, \sigma_{\beta}$ and $\tau_{\alpha}$ have been calculated for a region which extends about 60 meters vertically and horizontally from the boundary of the tunnel. Two different calculations have been done in which the vertical stress was fixed at

$$
\mathrm{s}_{\mathbf{y}}=8.274 \mathrm{MPa}
$$

and the horizontal stress was taken to be

$$
\mathrm{s}_{\mathbf{x}}=6.067 \mathrm{MPa} \text { and } \mathrm{s}_{\mathbf{x}}=2.955 \mathrm{MPa} \text {. }
$$

These values are meant to represent measured in situ stresses [5]. The variation of stress depends only on the tunnel shape and the ratio of vertical to horizontal initial stresses.

For display purposes, it 1s more useful to have stresses defined in the $x, y$ coordinate system. This can be done with the transformation

$$
\sigma_{i j}^{\prime}=\sigma_{\mu \nu} \frac{\partial x_{\mu}}{\partial x_{1}^{\prime}} \frac{\partial x_{\nu}}{\partial x_{j}^{\prime}}
$$

where $(1, f, f, v)=1,2$. The $\sigma^{\prime}$ terms are values in the $x, y$ system; for example, $\sigma_{11}^{\prime}=\sigma_{x}$, etc. In the $\alpha, \beta$ systen $\sigma_{11}=\sigma_{\alpha}$ and the $x^{\prime} s$ have similar Interpretations, $x_{1, e .,} x_{1}=\alpha, x_{1}^{\prime}=x$. The repeeted indices, of course, indicate summation. The Cartesian coordinetes $(x, y)$ are defined in terms of $(\alpha, \beta)$ according to

$$
\begin{aligned}
& x=\left(e^{\alpha}+a b e^{-\alpha}\right) \cos \beta+a c^{3} e^{-3 \alpha} \cos 3 \beta \\
& y=\left(e^{\alpha}-a b e^{-\alpha}\right) \sin \beta-a c^{3} e^{-3 \alpha} \sin 3 \beta
\end{aligned}
$$

where $a, b$, and $c$ are constants depending only on $p, q$, and $r$.

Contours of vertical $\left(\sigma_{y}\right)$ and horizontal stress $\left(\sigma_{x}\right)$ are displayed in Figures $4,5,6$, and 7 for the two different values of the horizontel stress. It is clear that in a distance of about two tunnel widths the stress are approximately equel to their applied values. Thus, at the location of the heater, perturbations due to the tunnel are negliglble. However, this does not account for atress variations due to the presence of the instrumentation holes. Th1s is addressed below.

There is a small region of tension, for each of these cases, near the corners. This is not shown on the plots. 
J. K. Johnstone - $4537 \quad$-4- February 21, 1980

The methods used for these calculations are useful because it requires very little time after the initial programing of the equations. It saves, for example, the time required to generate a new finite element mesh for each calculation. The usefulness 1s, of course, limited to fairly simple elastic problems in which the structure can be approximated by the simple curves represented by Eq. (1).

Strl $=3$ Distributions Near Heater and Instrumentation Holes

Figure 8 shows a cross section of a plane which is normal to the axis of the heater, where the heater has the orlentation shown in Figure 2. There are various instrumentation holes parallel to the heater axis, with an interferometer hole pleced normal to this direction. The major concern is the perturbation in stress at the position of a given hole due to the presence of other holes.

This problem is not reducible to a closed-form solution similer to the one just discussed. Therefore, a finite-element model has been developed to treat this problem in an approximate fashion. In Figure 9, a ochemetic representation of a finite-element computing region 1s shown in which only the heater hole and two of the holes at the smalleat radius are considered. An elastic solution was done to calculate stress distributions in this plane, but thermal effects were 1gnored.

The material parameters used were the same as those used in Reference 1. However, the stress veriation turns out to be simflar to the preceding problem in that these values depend on the shepes and very little on the material parameters. This is only approximately true because of the nature of the boundary conditions. Contours of vertical and horizontal stress are shown for this problem in Figures 10-13 in the same fashion as for the previous problem. There is little streas interaction between adjacent holes in either vertical or horizontal directians. The stresses used as boundary conditions are not the actual values that act on the cross section shown in FIgure 8 , but the relative magnitudes are approximately correct.

These problems have ignored the presence of a temperature fleld but this presents no major difficulty. At locations distant from the holes the thermel stress add to the purely elastic terms. Since the original thermal stress calculated $[1,2]$ did not include the presence of instrumentation holes, the stresses are not correct at those locations. However, the perturbations are fairly small because of the hole sizes.

\section{References}

1. Memo, W. T. Brown, 553I, to J. K. Johnstone, 4537, dtd 6/4/79, subject: Thermomechenical Analysis of Tuff In-Situ Heater Experiment.

2. Memo, W. T. Brown, 5531, to J. K. Johnstone, 4537 , dtd $8 / 28 / 79$, subject: Additional Thermomechanical Modeling of the Tuff In-Situ Heater Exper1ment. 
J. K. Johnstone - $4537 \quad-5-\quad$ February 21, 1980

3. Greenspan, Martin, "Effect of a Small Hole on the Stresses in a Uniformly Loeded Plate," Querterly Appl. Math., 2, pp. 60-71 (1974).

4. Terzaghi, Karl and Richart, F. F., "Stresses in Rock Cavities," Geotechnique--The International Journal of Soil Mechanics, III. No. 2, pp. 57-90 (1952).

5. J. K. Johnstone, personal communication.

WTB : 5531: $1 \mathrm{~s}$

Distribution:

4530 R. H. Lynch

4537 L. D. Tyler

4537 A. R. Leppin

4537 D. R. Waymire

5500 O. E. Jones

5510 D. B. Hayes

5511 D. F. McVey

5520 T. B. Iane

5530 W. Herrmann

5531 L. D. Bertholf

5532 B. M. Butcher

5532 W. A. Olsson

5533 A. J. Chabai

5534 J. R. Asay

5531 W. T. Brown 


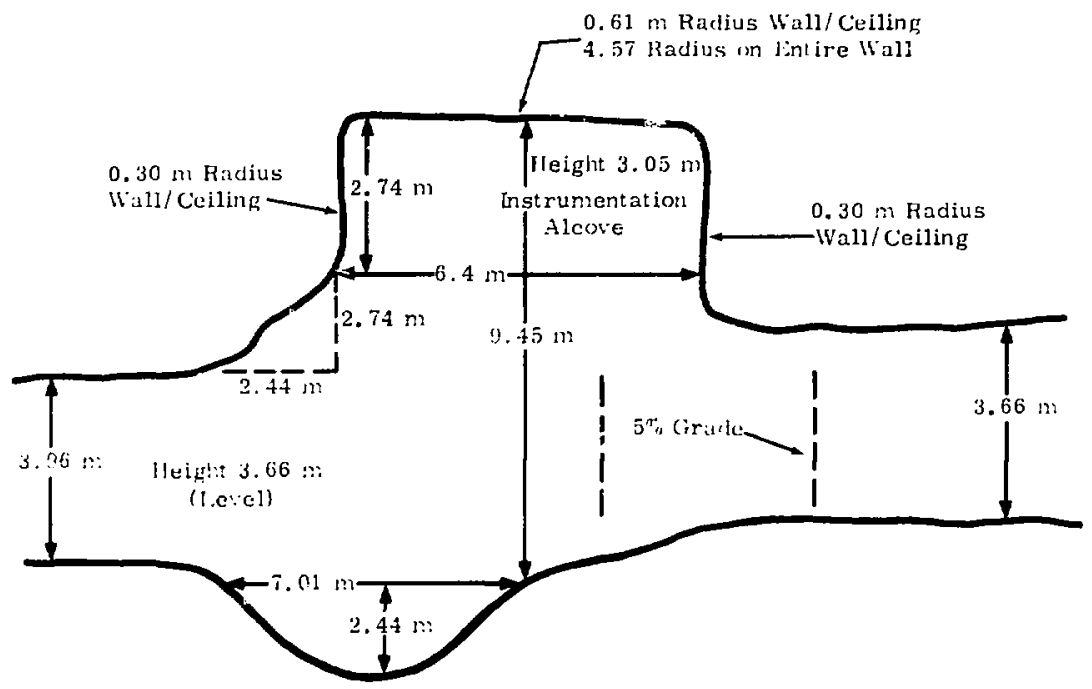

Figure DI:I-1. Map View of G-Tunnel Test Area (Not to Scale)

Nint to Scinle

Heater

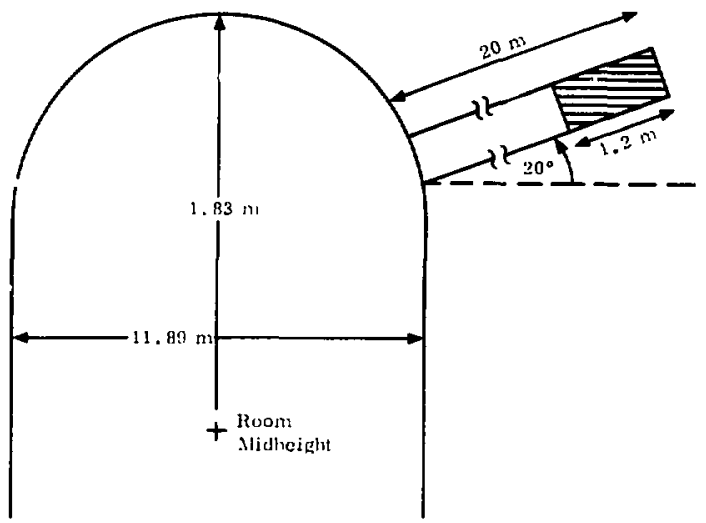

Figure DIII-2. Schematic Representation of Tunnel Cross Section Near heater Location Parameters Used Represent Dimension at Widest Location (Tunnel + Alcove) 


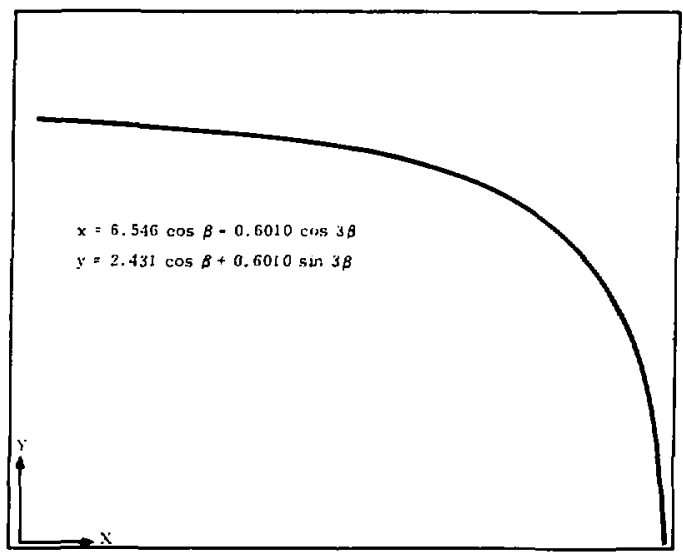

Figure DIII-3. Ovaloid Approximating Tunnel Cross Section, Shape is Symmetry about $x$-axis and $y$-axis

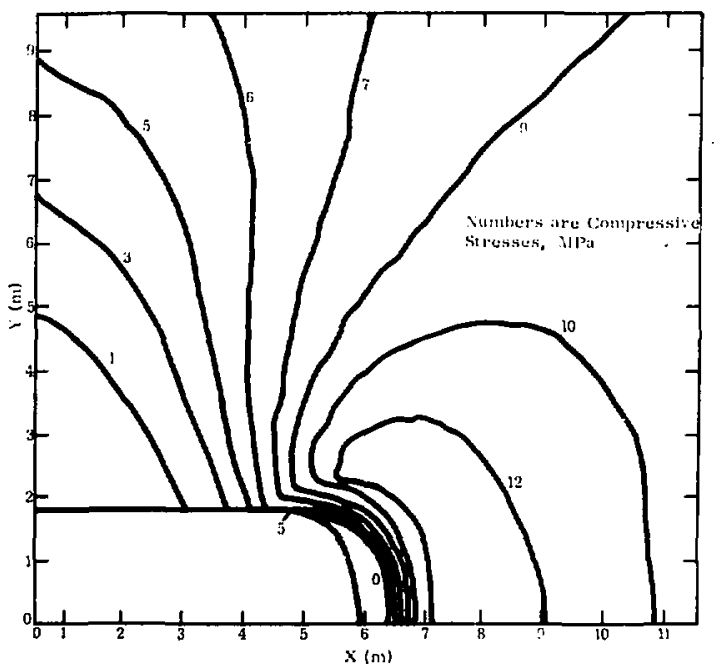

Figure DIII-4. Vertical Stress Contours Near Tunnel, Stress Distributisn $\vdots$ s Symetric about $x$-axis and $y$-axis. $S_{x}=6.067 \mathrm{MPs}, s_{y}=$ 


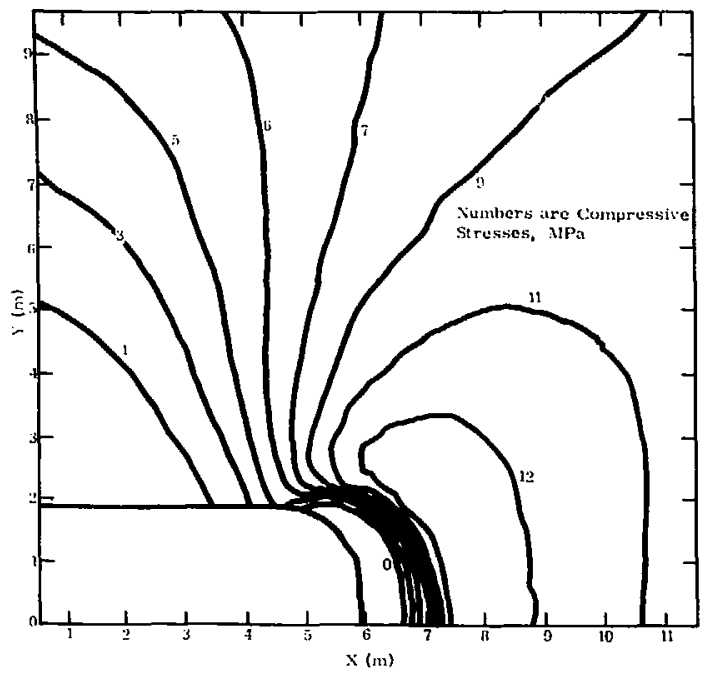

Figure DIII-5, Horizuntal Stress Contours Near Tunnel. Stress Distribution is Symetric about $x$-axis and $y$-axis. $S_{x}=6.067 \mathrm{MPa}$, $s_{y}=8.274 \mathrm{MPa}$

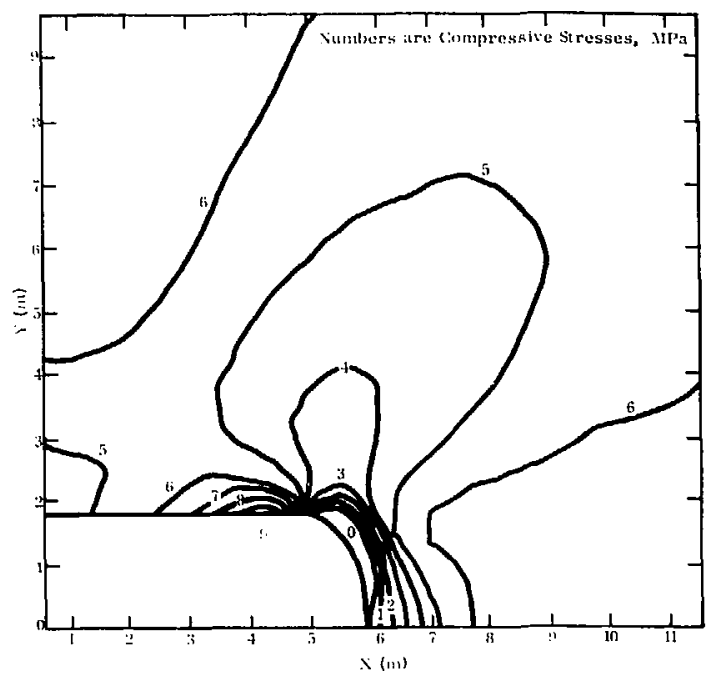

Figure DIII-6. Vertical Stress Contours Near Tunnel. Stress Distribution is Symmetric about $x$-axis and $y$-axis. $S_{x}=2.955 \mathrm{MPa}$, $\mathrm{S}_{\mathrm{y}}=8.274 \mathrm{MPa}$ 


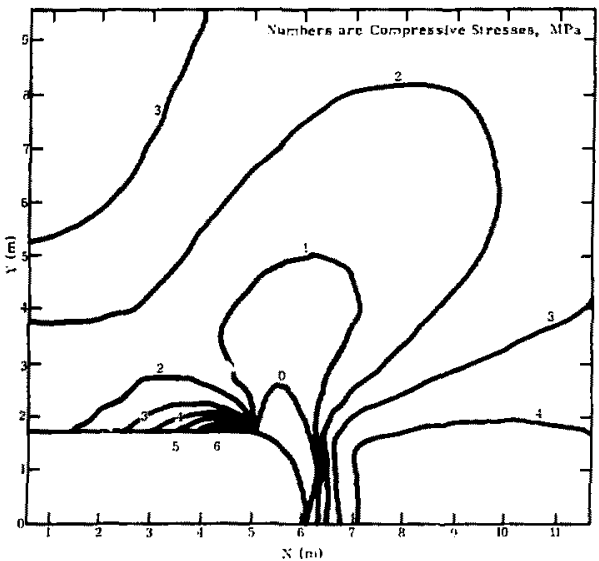

Figure DIII-7. Horizontal stress Cantours Nea" Tunnel. Stress Disiribution is Symmetric aivut $x$-axis and $y$-axis. $S_{x}=2.955 \mathrm{MPa}$, $s_{y}=8.274 \mathrm{MPa}$

(†)

A Heater hola

13 Water illigration Jloles

C. Thernocouple lloles

1) St ress Measurement Hole

I: lager Interfornneter llole

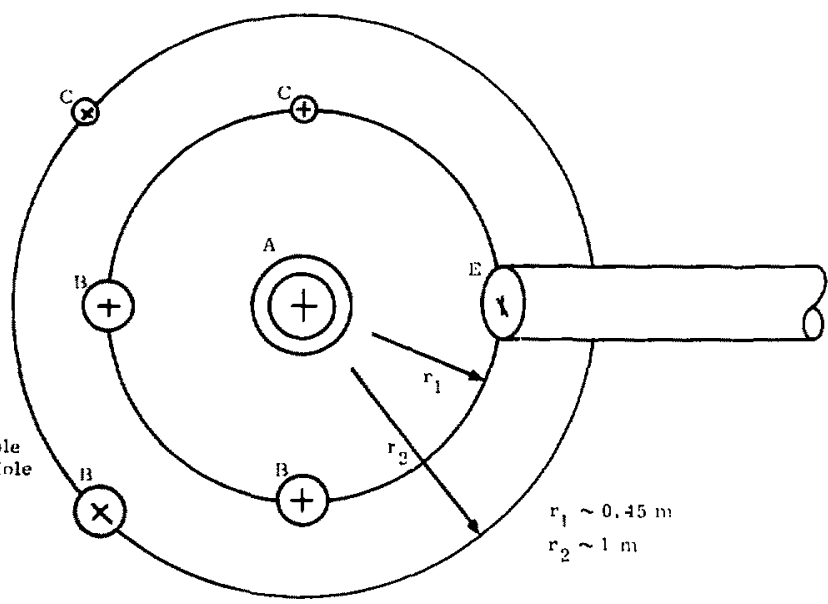

Figure DIII-B. Conceptual Experimental Array for Tuff Water Migration/Heater Experiment 


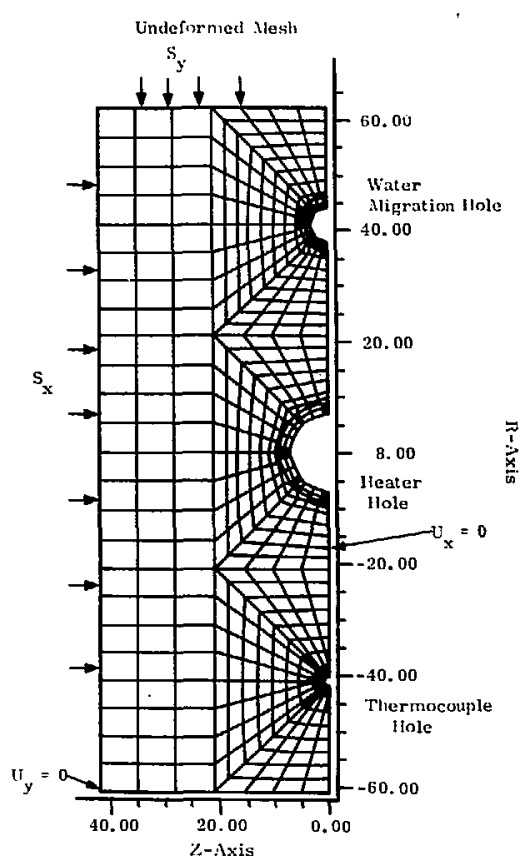

Figure DIII-9. Finite-Element Mesh for Representation of Heater and Instrumentation Holes

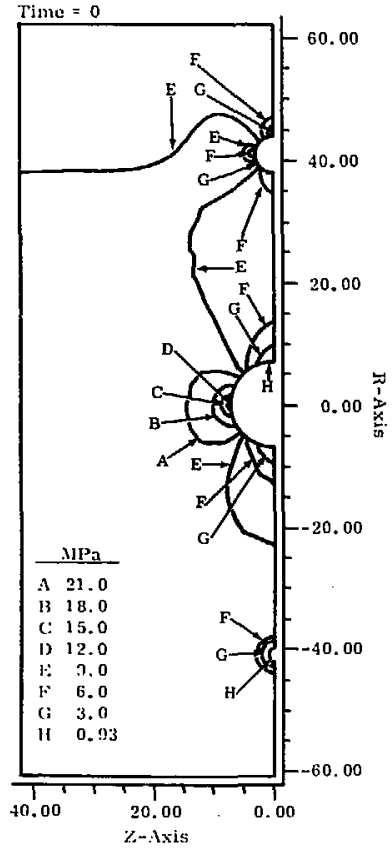

Figure DIII-10. Vertical Stress Near Holes. $\mathrm{s}_{y}=8.274 \mathrm{MPa}, \mathrm{s}_{\mathrm{x}}=6.067 \mathrm{MPa}$ 


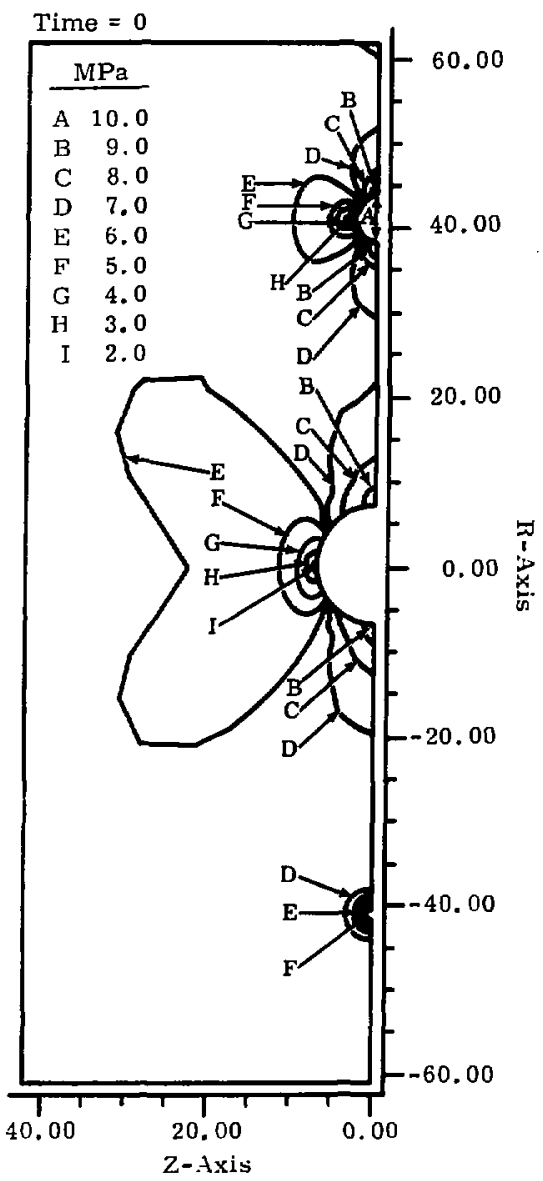

Flgure DIII-11. Horlzontal Stress Near Holes. $S_{y}=8.274 \mathrm{MPa}$, $\mathrm{s}_{\mathrm{x}}=6.067 \mathrm{MPa}$.

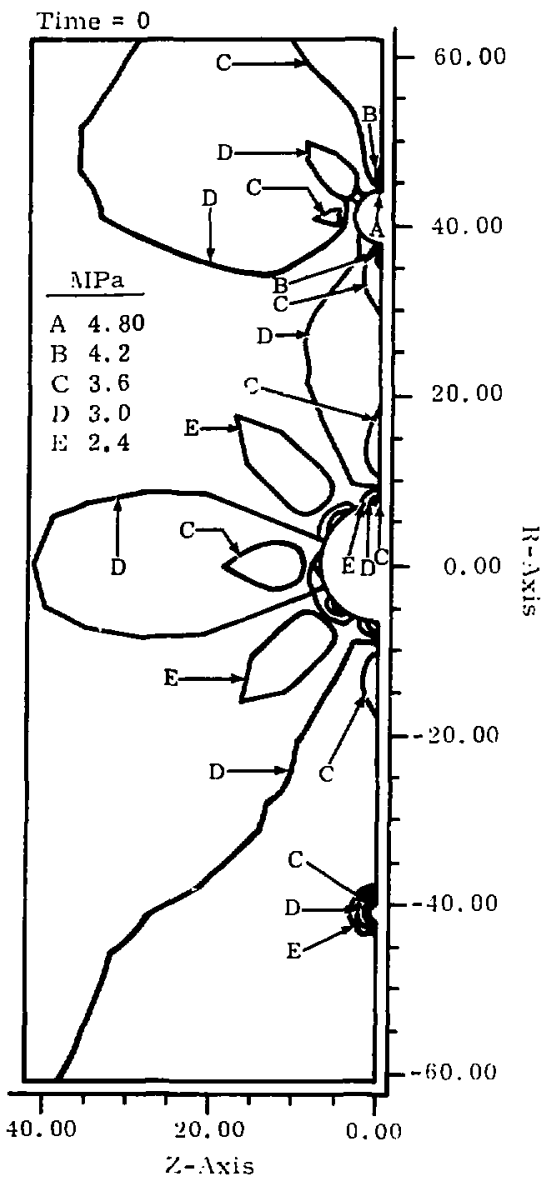

Figure DII $1-12$. Horizontal Stress Neal Holes. $s_{y}=8.274 \mathrm{MPa}$, $\mathrm{S}_{\mathrm{x}}=2.964 \mathrm{MPa}$ 


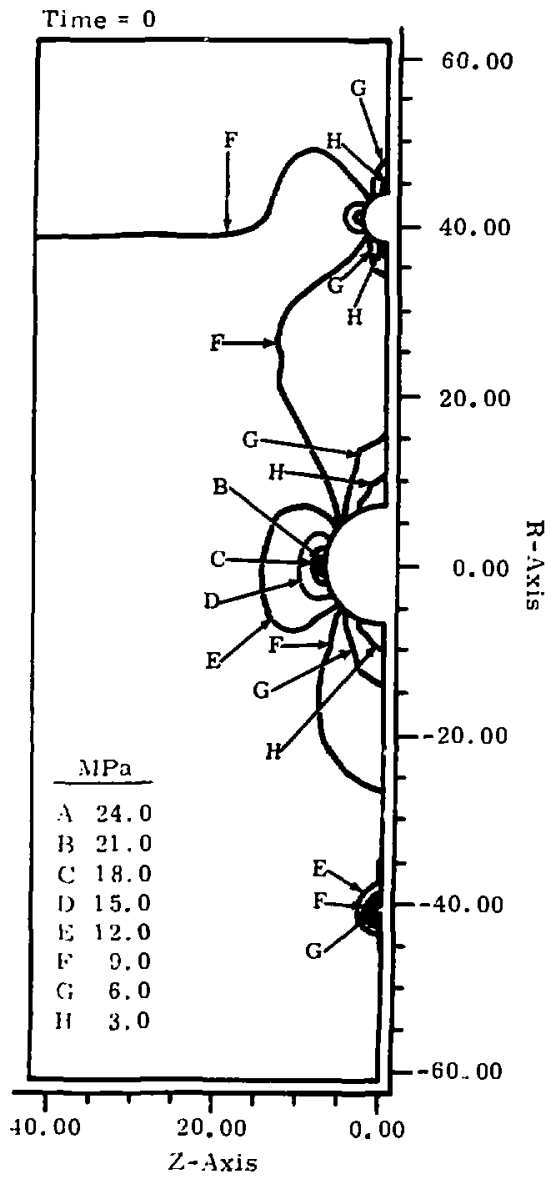

Figure DIII-13. Vertical Stress Near Holes.

$\mathrm{s}_{y}=8.274 \mathrm{MPa}, \mathrm{s}_{x}=2.964 \mathrm{MPa}$ 
US Department of Energy

Asst Secretary for Def. Programs Mail Stop 5F-066

Washington, DC 20545

Attn: D. C. Sewel1 (DP-1)

US Department of Energy

Asst Sec. for Nuclear Energy

Mail Stop 6E-095

Washington, DC 20545

Attn: G. W. Cunningham (NE-1)

US Department of Energy (7)

Office of Nucl Waste Management

Mail Stop B-107

Washington, DC 20545

Attn: S, Meyers, NE-30

R. G. Romatowski, NE-30

C. A. Heath, NE-30

D. L, vieth, NE- 30

R. Stein, OW, NE-30

C. R, Cooley, NE-30

M. W. Frei, NE-30

US Department of Energy (2)

Richland Operations office

PO Bax 550

Richland, WA 99352

Attn: F. Standerfer

D. J, Squires

US Department of Energy

Albuquerque Operations office PO Box 5400

Albuquerque, NM 87185

Attn: D. T. Schueler, Jr.

US Department of Energy

San Francisco Operations office

1333 Broadway, Wells Fargo Bldg

Oakland, CA 94612

Attn: L. Lanni

Rockwel1 International (2)

Atomics International Division

Rockwe 11 Han ford Operations

Richland, WA 99352

Attn: R. Deju

B. Dietz
US Department of Energy (24)

Nevada Operations office PO Box 14100

Las Vegas, NV 89114

Attn: M. E. Gates

R. W. Taft

R. W. Newman

J. B. Cotter

M. P. Kunich

H. L. Melancon

A. J. Roberts

R. M. Nelson

D. G. Jackson

P. J. Mudra

R. H, Marks, CP-1

S. R. Elliott

B. W. Church

T. H, Blankensh ip

R. R. Loux (10)

US Department of Energy

NTS Support office

$P C$ Box 435

Mercury, NV 89023

Attn: J, H, Dryden

F. Huckabee

L. P, Skousen

DOE Region 9

Dirctor of External Affairs

111 Pine Street, 3rd Floor

San Francisco, CA 94111

Aten: D, J, Cook

US Department of Energy

Columbus Program

Richland Operations Office

$505 \mathrm{King}$ Avenue

Columbus, OH 43201

Attn: J. 0 . Neff

Nuclear Regulatory Commission (2)

Washington, DC 20555

Attn: J. C. Malaro, M/S SS674

R. Boyle, M/S P -522

Holmes \& Narver, Inc.

PO Box 14340

Las Vegas, NV 89114

Attn: A. E, Gurrola 
DISTRIBUTION (cont):

University of California

Lawrence Livermore National Laboratory (7) PO Box 808

Livermore, CA 94550

Attn: L, D. Ramppott, L-204

A. Holzer, 1-209

L. B. Ballou, L-204

J. S. Kahn, L-49

K. Street, L-209

R. C. Carlson, L-204

A. B. Miller, L-204

Los Alamos National Scientific Laboratory (6) PO Box 1663

Los Alamos, NM 87545

At $n$ : K. Wolfsberg (2)

L. S, Germain, M/S 570

L. Lanham, M/S 755

B. R. Crowe, $M / S 978$

J. R. Smych, M/S 978

West inghouse (7)

PO Box 708

Mercury, niv 99023

Attn: D. C. Durrill

Westinghouse - AESD (1)

PO Box 10864

Pittsburgh, PA 15236

Attn: J. B. Wright (6)

W. R. Morris

T. E. Cross

R. J. Batorich

C. R. Bolmgren

W. A. Henninger

University of Arizona

Nuclear Fuel Cycle Research

Tucson, $A Z 85721$

Aten: J. G. MeCray

US Genlcric Survey ( 3 )

Natioral Center

Reston, VA 22092

Aten: C. D. DeBuchananne, M/S 410

P. R. Steven $\mathrm{s}, M / \mathrm{S} 410$

D. B. Stewart, M/5 959
US Geologic Survey (2)

PO Box 25046

Federal Center

Denver, CO 80225

Aten: G. 3. Dixon, M/S 954

W. S. Twenhofel, M/S 954

Geologic Soniety of America

3300 Penrose Place

Boulder, CO 80302

Attn: J. C. Frye

University of Kansas

Kansas Geological Survey

Lawrence, KS 66044

Aten: W. W. Hanbleton

Battelle Memorial Institute (10)

Office of Nucl Waste Isolation

$505 \mathrm{King}$ Avenue

Columbus, $\mathrm{OH} 43201$

Attn: N. E. Carter

S. Basham

J. Carr

ONHI Liorary (5)

R. A. Robinson

W. Carbiener

State of Nevada

Governor's office of Planning Coordination

Capitol Complex

Carson City, NV 89710

Aten: R. Hill, State

Planning Coordinator

Fenix \& Scisson, Inc.

PO Box 498

Mercury, NV B9203

Attn: F. D. Waltman

State of Nevada

Capitol Complex

Carson Cicy, NV 89710

Attn: N. Clark

Dept of Energy

Woodward-Clyde Consultants

Wegtern Region library

No. 3 Embarcardero Center

San Francisco, CA 94111 
DISTRIBUTION (cont):

Computer Sciences Corp. 6565 Arlington Blyd

Falls Church, VA 22046

Attn: J. Lahoud

John A. Blume Engineers

Sheraton Palace Hotel

1340 Jessie Street

San Francisco, CA 94105

Attn: 1 . Yanev

Harvard University (2)

Dept of Earth Sciences

Cambridge, MA 02138

At tn: R. Siever

Dartmouth College

Dept of Earth Sciences

Hanover, NH 03755

Attn: J. Lyons

Internat 1 Atomic Energy Agency

Div of Nucl Power \& Reactors

Karntner Ring 11

PO Box 590, A-1011

Vienna, Austria

Aten: J. P. Colton

Fenix \& Scisson, Inc.

PO Box 15408

Las Vegas, NV 89114

Attn: G. Pinder

California Energy Resources

Conservation \& Devel Ccm

1111 Howe Avenue

Sacramento, CA 95825

Attn: A, Soinski

Univeraity of california

Lawrence Berkeley Laboratory

Energy \& Environment Division

Berkeley, CA 94270

Attn: P. Witherspoon

Hanford Eng Development Lab

PO Box 1970

Richland, WA 99352

Attn: D. Cantley
Arthur D. Little, Inc.

Acorn Park

Cambridge, MA 02140

Attn: C. R. Hadlock

Brown University

Dept of Geological Sciences

Providence, RI 02912

Attn: B. Giletti

Texas A\&M University

Center for Tectonophysics

College Station, TX 77840

Attn: J. Handin

Law Engineering Testing Co

2749 Delk Road, SE

Marietta, GA 30067

Attn: B. Woodward

Holmes \& Narver, Inc.

PO Box 1

Mercury, NV 89023

Attn: G. E. Christensen

Subcommittee on Energy

Research \& Production

Room B-374

Rayburn House Office Bldg

Washington, DC 20575

At $t n: S$. Lanes, Staff Dir.

Dept of Health and Environment

Bureau of Radiation Control

Forbes Field

Topeka, KS 66620

Attn: G. W. Allen, Director

State of Connecticut

Energy Research and Policy

80 Washington Street

Hartford, CT 06115

Attn: F. N. Brenneman

Executive office

Lansing, MI 48909

Attn: W, C. Taylor

Science Advisot

Dir for Policy and Planning

325 West Adams St - Room 300

Springfield, IL 62706

Attn: A. Liberatore 
DISTRIBUTION (cont):

Nuclear Energy Division Nuc 1 Projects Coordinator PO Box 14690

Baton Rouge, LA 70808

Attn: L. H. Bohlinger

Oregon Dept of Energy

Labor \& Industries Bldg

Room 111

Salem, OR 97310

Attn: D. W. Godard

Radiation Protection Div 1000 Northeast loth Street PO Box 53551

Oklahoma City, OK 73152

Attn: R. L. Craig, Dir

Reynolds Elect \& Eng Co., Inc. (6) PO Box 14400

Las Vegas, NV 89114

Attn: H. D. Cunningham

W. G. Flangas

G. W. Adair

V. M. Milligan

C. W. Dunnam

E. J, Beecher

Radiation Health Info Project

Environmental Policy Inst

317 Pennsylvania Ave, SE

Washington, DC 20003

Attn: E. Walters

State of South Caralina

Div of Energy Resources

Edgar A. Brown Bldg

1205 Pendleton Street

Columbia, SC 29201

Aten: L. E, Priester, Jr.

Federal Agency Relations 105017 th St, NW

Washington, DC 20036

Attr: O. H. Davis, Dir

Environmental Program Supvr

903 Ninth Street office Bldg

Richmond, VA 23219

Aten: K. J. Buttleman

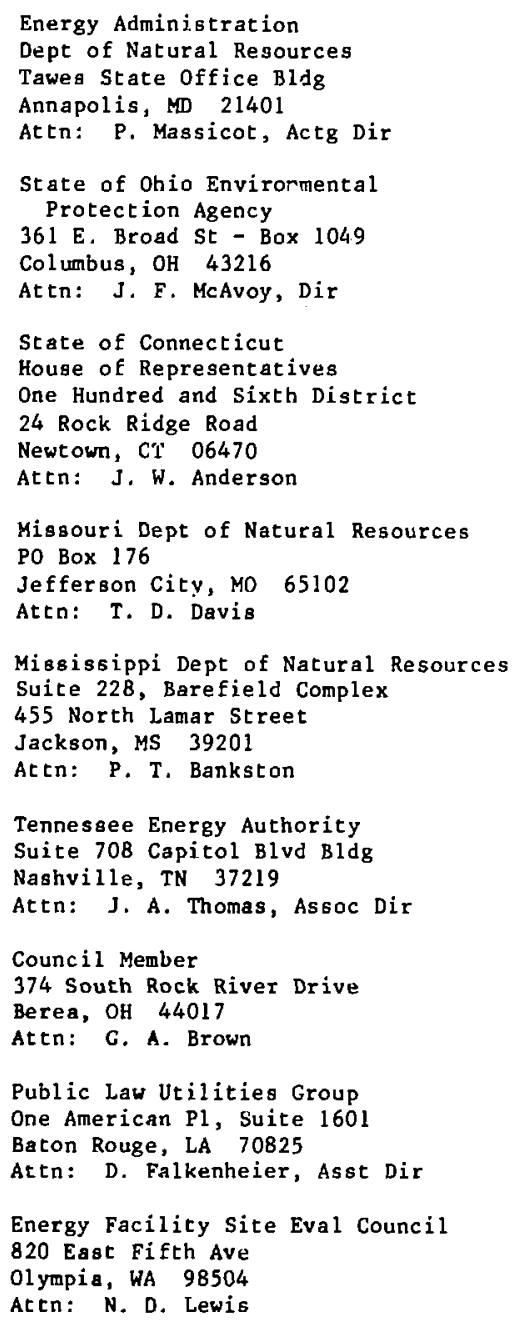




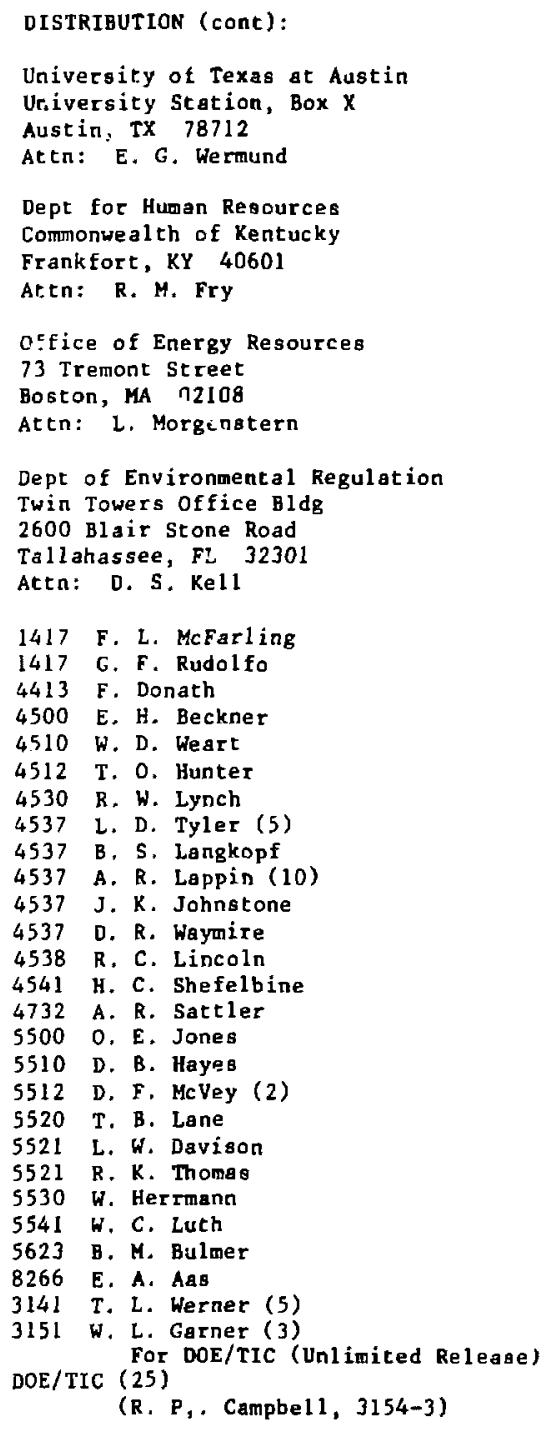




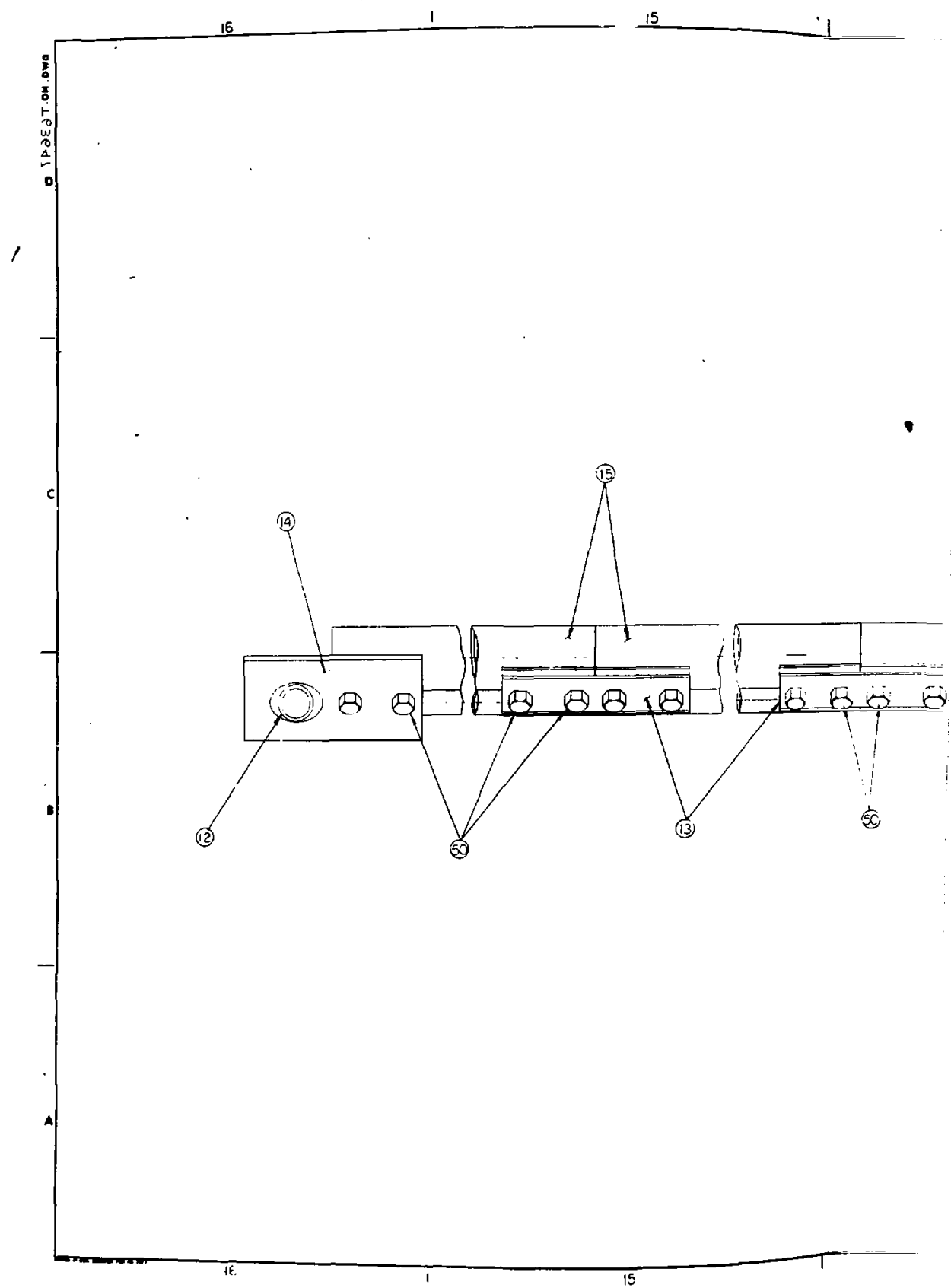



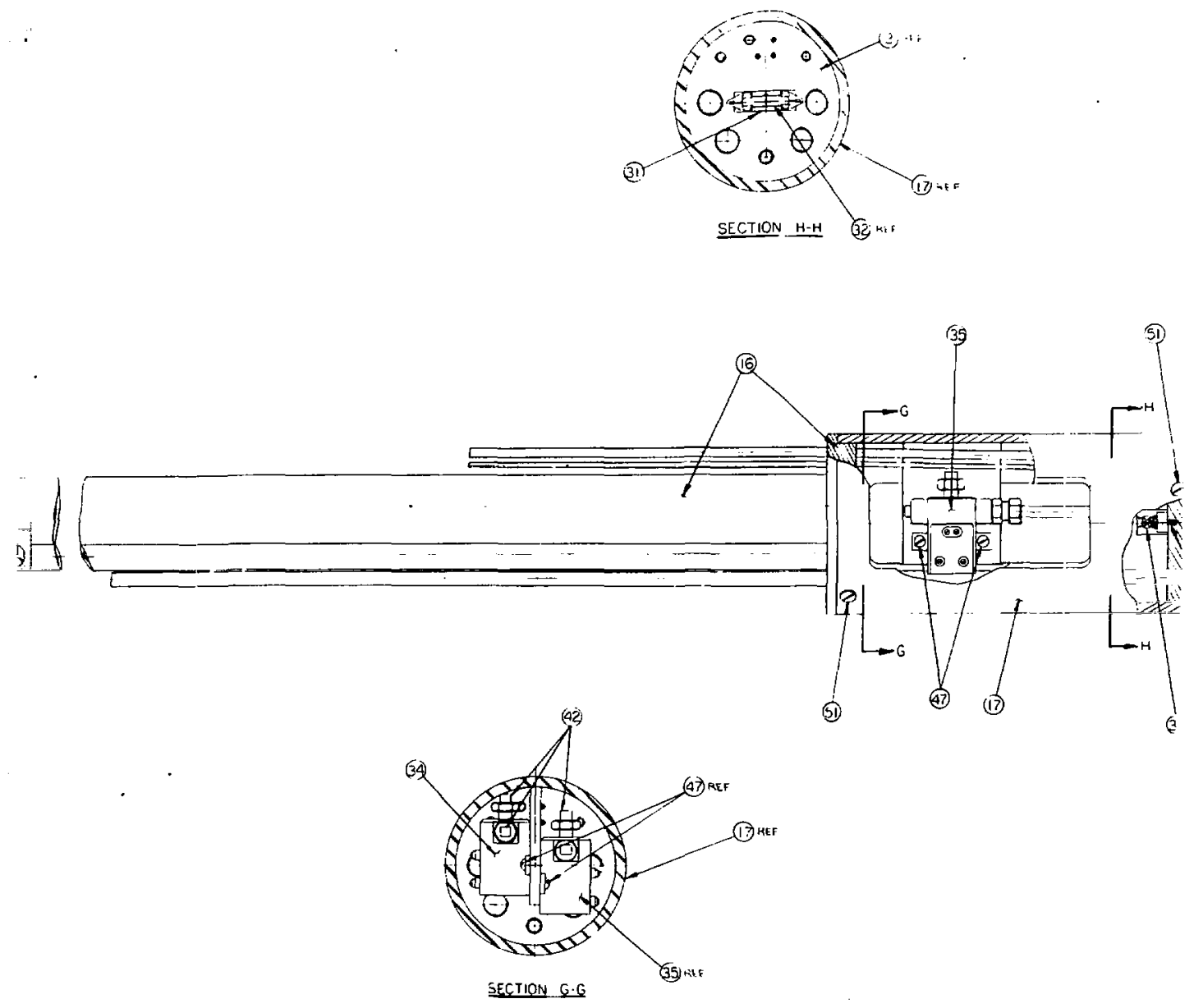

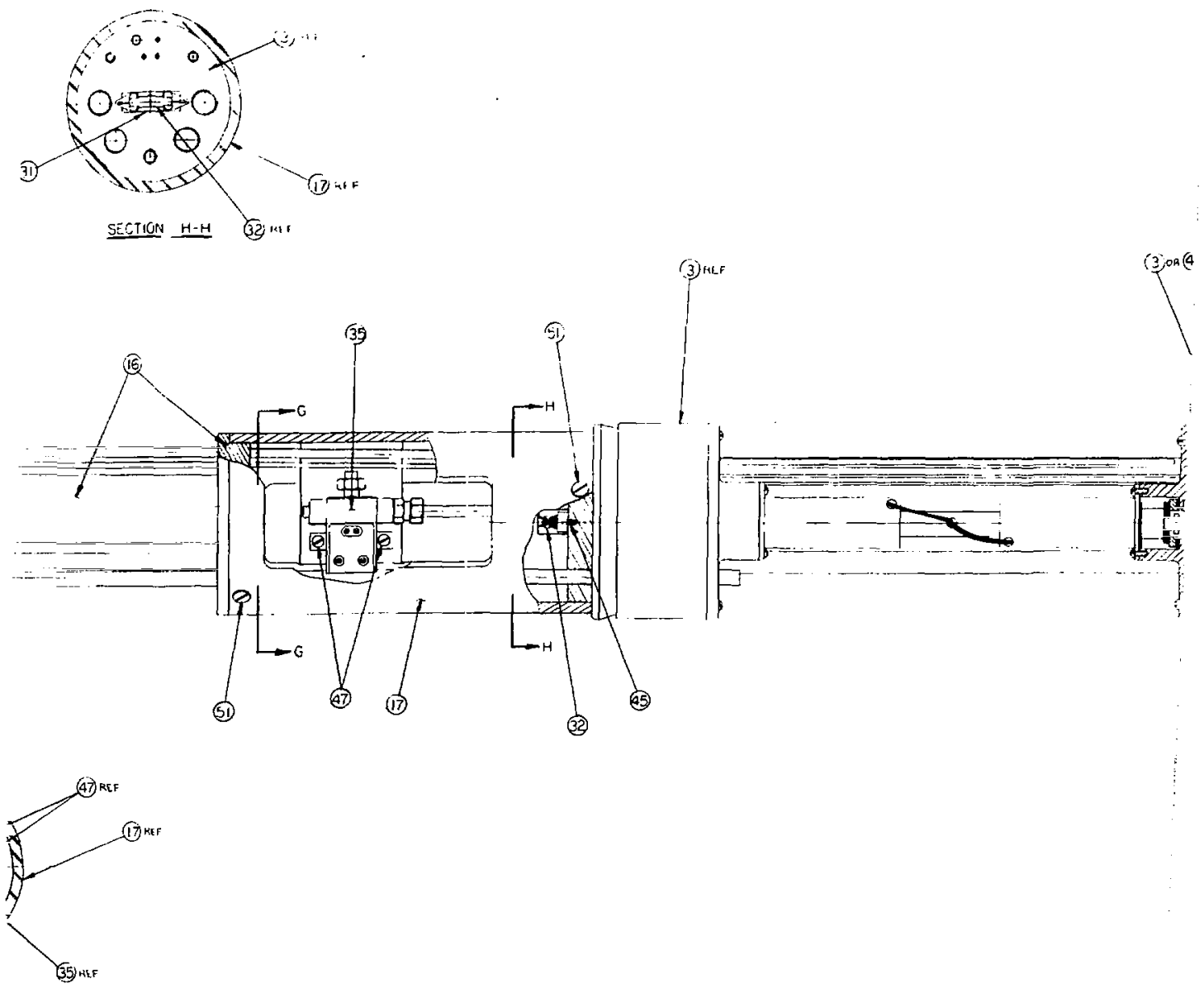

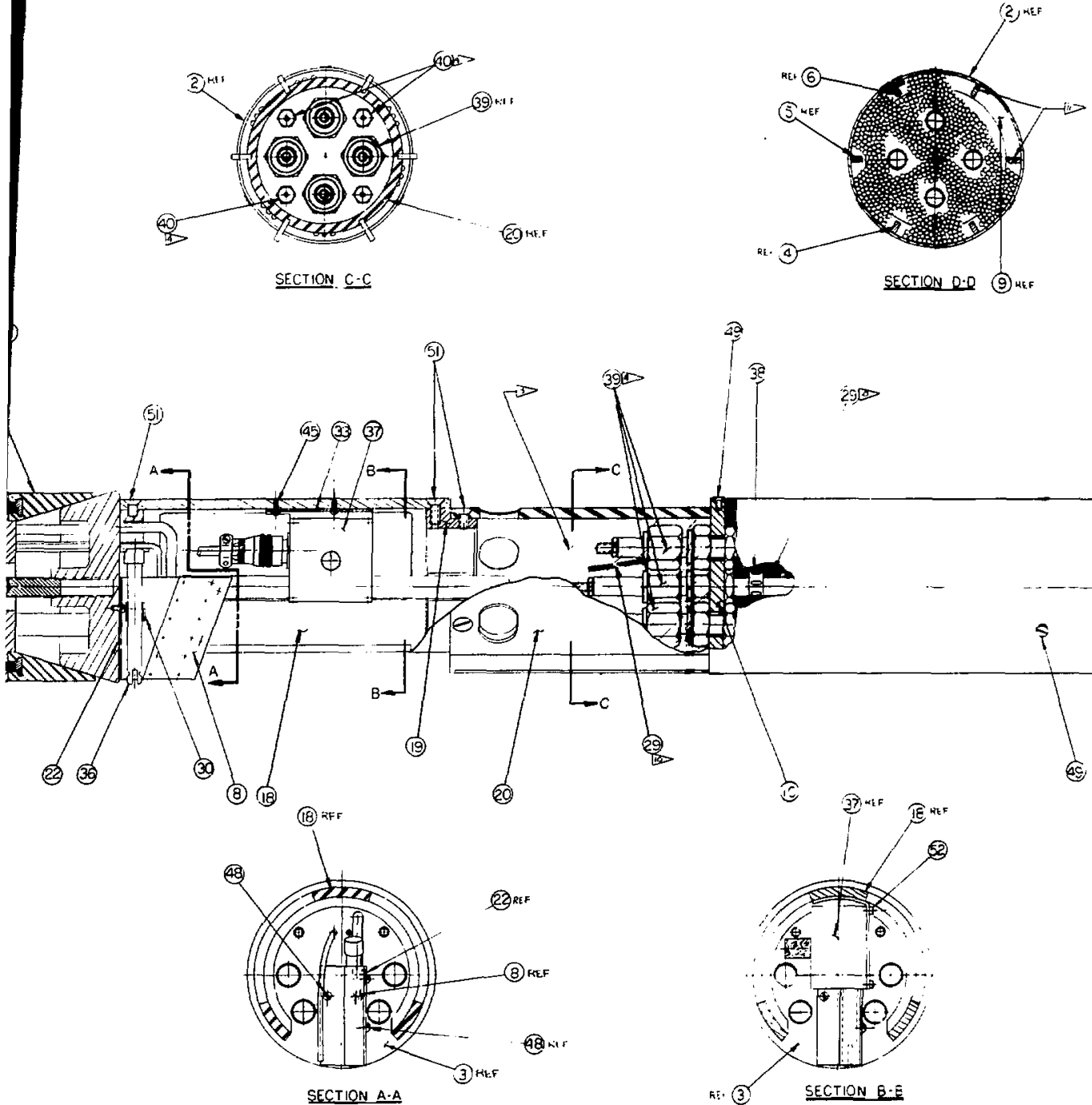


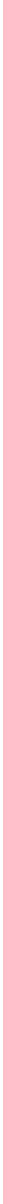


7. MaY gE OATAINEO FROM:

sensantx

WIIT DOLSA MYYE."

c. MaY ot obsalwe tron.

THUW OER SCIEHIIFIC CORP.

AL GuQuERouE, H.M.

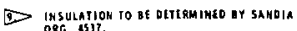
ORC. 1s37.

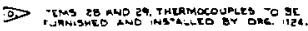

WL-AGK nELO AT Jiscretion $=F$

iNG.NLER.

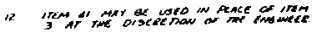

\section{MOTES:}

1. FOR ELMERAL RGOUI REMENI

2. WELO E INSPECT PER MULI E30E ELECTRDOES PER ATS

Perrimc

$[7$ POITIMC MATtRIAL T

4. CONHECTORS TO EL SUPPLI ORt, 1123.

3. MAY AE OBTAINEO IROM, HAMLIN INC.

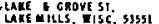
MAY GE OATAIMED FROM:

CULJOH INDUSTRITS COSTA MLSA, CAL. " 9Z62?
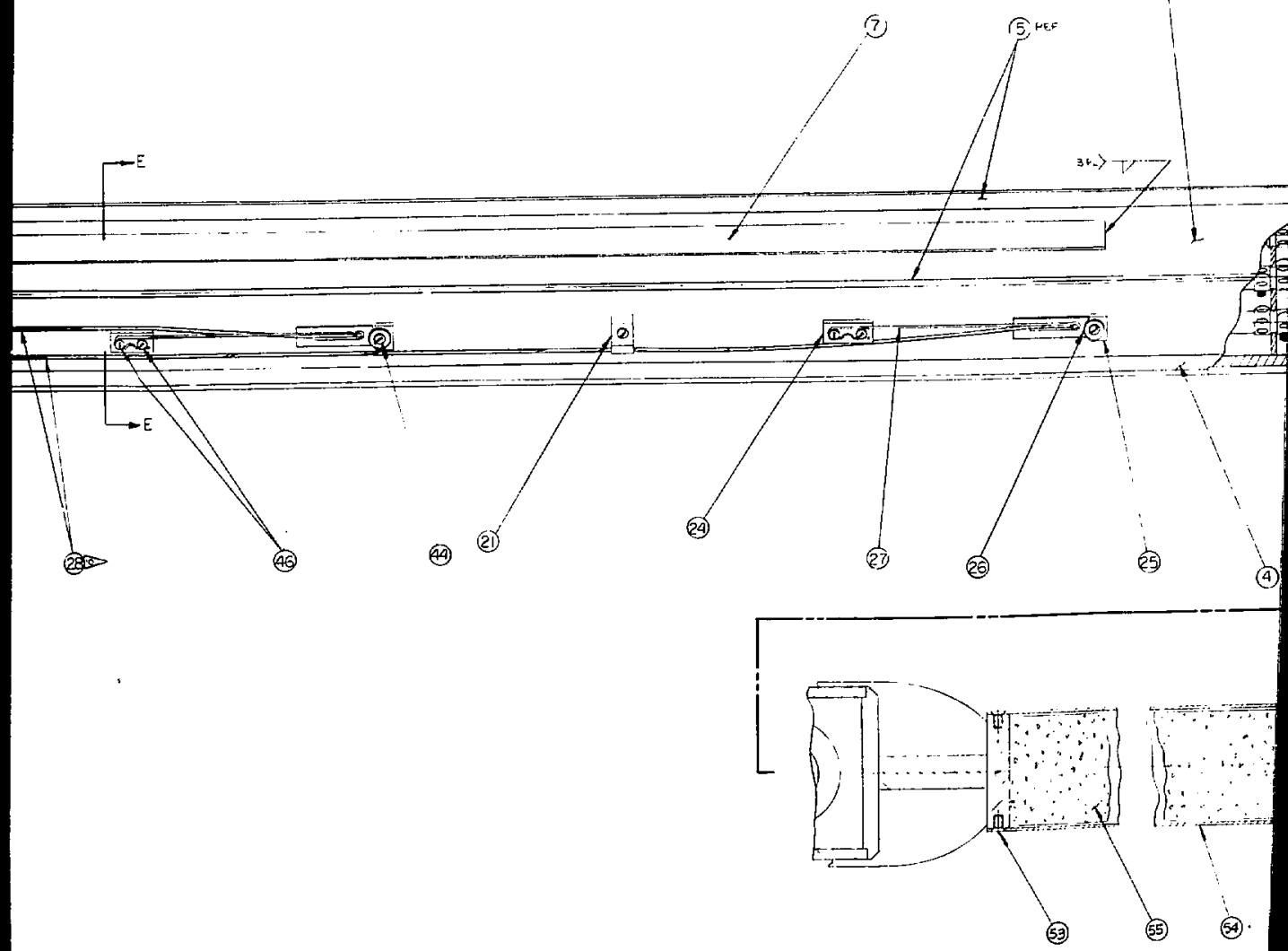
